\title{
The Impact of Liquid-Liquid-Vapour Phase Behaviour on Coke Formation from Model Coke Precursors
}

\author{
by
}

Daniele Minicucci

A thesis submitted in conformity with the requirements for the degree of Master of Applied Science, Graduate Department of Chemical Engineering and Applied Chemistry, University of Toronto

C Copyright by Daniele Minicucci 2000 
National Library

Acquisitions and Bibliographic Services

395 Wellington Street Ottawa ON K1A ON4 Canada
Bibliothèque nationale du Canada

Acquisitions et services bibliographiques

395, ne Wellington Otlawa ON K1A ON4 Canada
The author has granted a nonexclusive licence allowing the National Library of Canada to reproduce, loan, distribute or sell copies of this thesis in microform, paper or electronic formats.
L'auteur a accordé une licence non exclusive permettant à la Bibliothèque nationale du Canada de reproduire, prêter, distribuer ou vendre des copies de cette thèse sous la forme de microfiche/film, de reproduction sur papier ou sur format électronique.

L'auteur conserve la propriété du droit d'auteur qui protège cette thèse. $\mathrm{Ni}$ la thèse ni des extraits substantiels de celle-ci ne doivent être imprimés ou autrement reproduits sans son autorisation. 


\section{Abstract}

Catalysts used in the hydrogenation processes of heavy feedstocks deactivate due to coke deposition. Although the mechanism for coke formation is not fully understood, condensation reactions of polycyclic aromatic compounds present in the feeds are a key aspect. The effect of coke deposition on catalyst performance is typically modelled using accelerated aging agents comprising model coke precursors. Mixtures employed in such studies include polycyclic aromatic compounds such as anthracene as a coke precursor, and long chain alkanes such as hexadecane as a diluent. It is shown in this thesis that binary and pseudo binary mixtures of polynuclear aromatic compounds and n-alkanes present TYPE II, TYPE IV, or TYPE III phase behaviour according to the van Konynenburg and Scott (1980) phase projection classification. Incubation periods and the apparent autocatalytic effects associated with batch coke deposition experiments in such systems are explained through a combination of high temperature phase equilibrium experiments and computations with the model systems anthracene + n-alkane + hydrogen, pyrene + n-alkane + hydrogen, and hexaphene $+n$-alkane. 


\section{Acknowledgments}

I wish to thank Professor John Shaw for helping me break through the many roadblocks encountered in this thesis. I enjoy working with you. Thank-you for providing me with this valuable experience. I also greatly appreciate your financial support.

I wish also to acknowledge the financial support from NSERC.

For his help in the lab, I wish to thank Dr. Haiyong Cai.

I will always remember the friends I have made at the University of Toronto, especially through the Chemical Engineering Graduate Students' Association. A special thanks goes to Rami and Pratima for their friendship and advice. Rami, I enjoy our Tawlet matches.

To my family, [ extend my love and express thanks for your strong values and patience.

Finally, I would like to thank Jennifer for her love and patience. I love you. 


\section{Table of Contents}

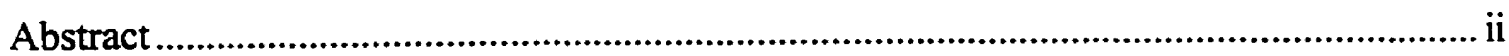

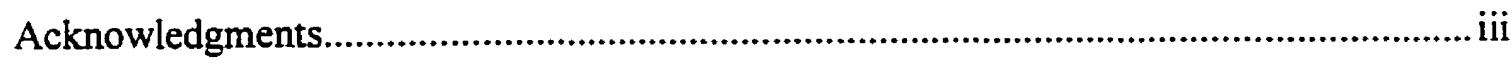

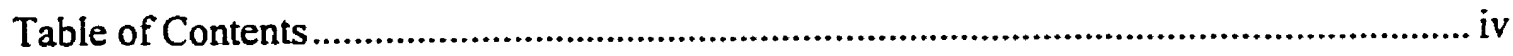

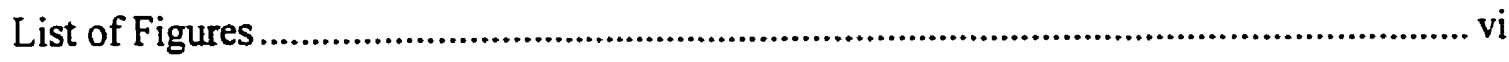

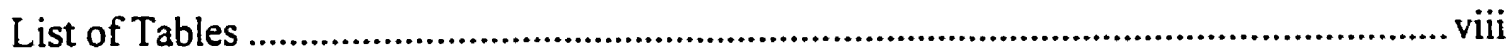

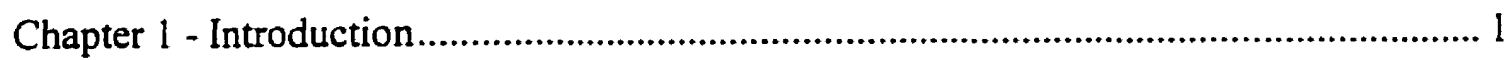

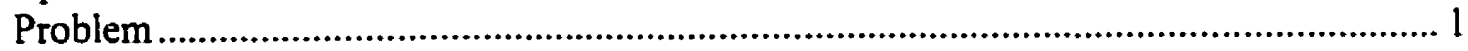

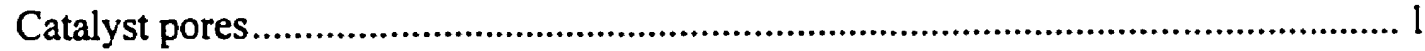

Induction Period........................................................................................... I

A Link Between Kinetics and Phase Behaviour ..................................................... 2

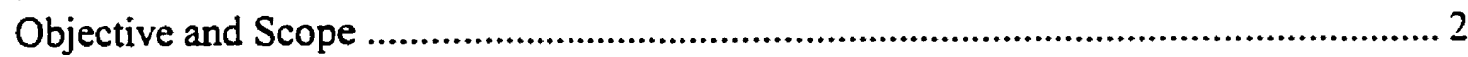

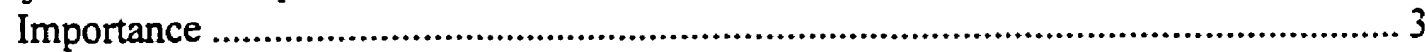

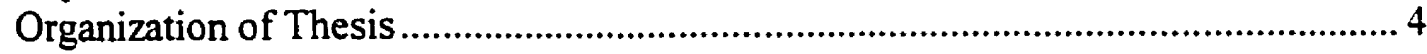

Chapter 2 - Literature Review and Background.......................................................5

Coking Kinetics .............................................................................................. 5

Two Models of Coke Deposition on Hydrogenation Processing Catalysts ................ 5

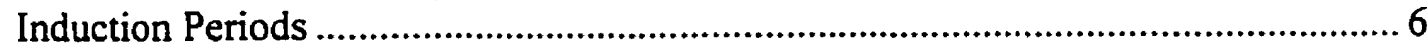

Anthracene as a Model Precursor for Coke Formation ....................................... 6

Phase Equilibrium and Modelling ................................................................ 7

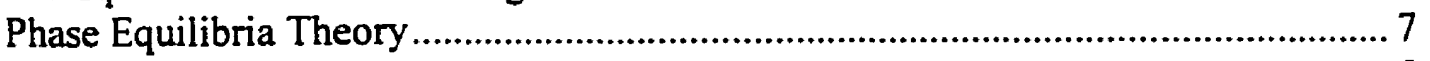

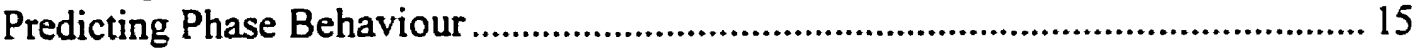

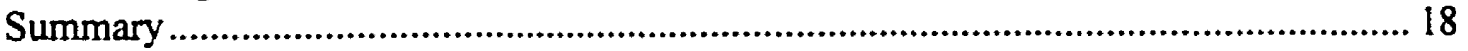

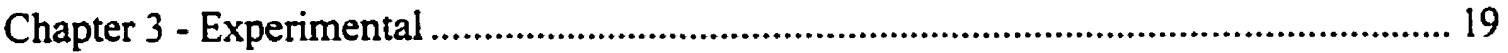

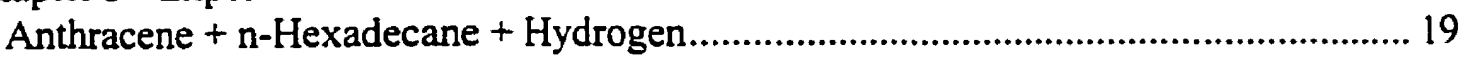

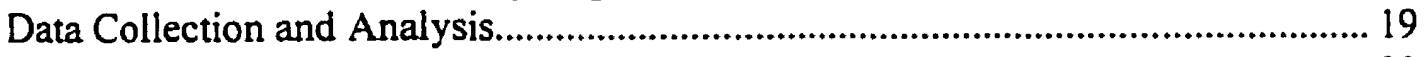

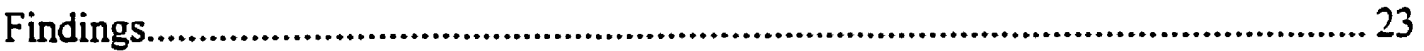

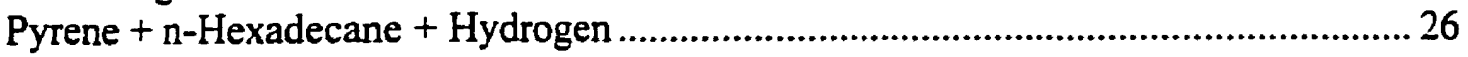

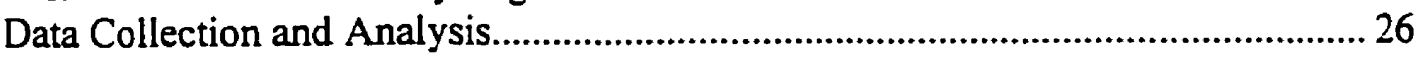

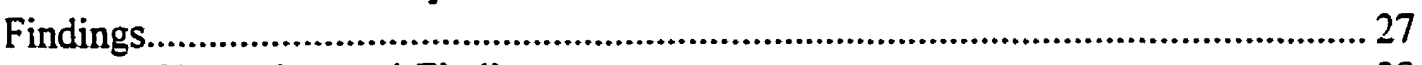

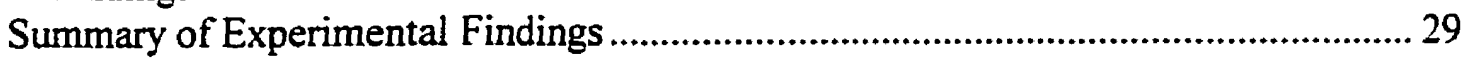


Chapter 4 - Phase Equilibria Models of PAH's with n-Alkanes ...................................... 30

CMG Software and Modelling Parameters..................................................................... 30

Binary Interaction Parameters for PAH's + n-Alkanes ............................................... 31

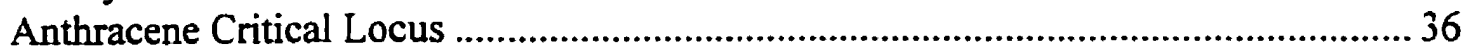

Effect of Hydrogen on Critical Loci ....................................................................... 38

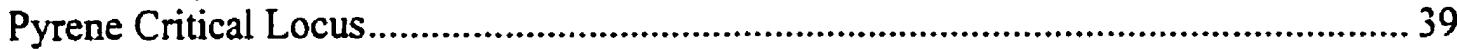

Reaction Products of Anthracene.................................................................................... 40

Summary of Chapter Findings .................................................................................... 45

Chapter 5 - Impact of Multiphase Behaviour on Coking Kinetics................................... 47

Chapter 6 - Summary and Conclusions.......................................................................... 50

Chapter 7 - Recommendations for Further Work........................................................... 52

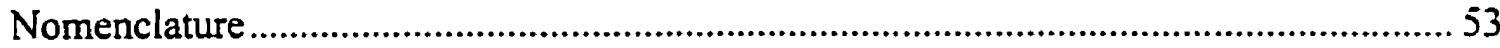

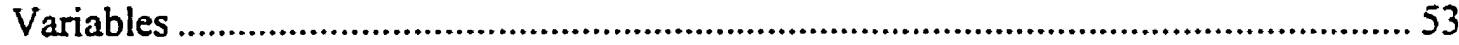

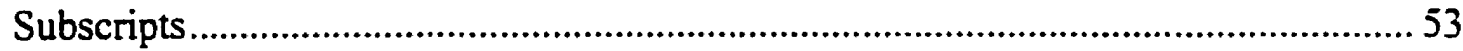

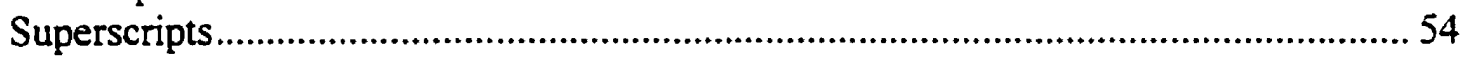

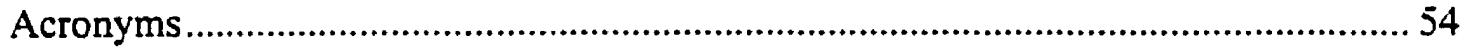

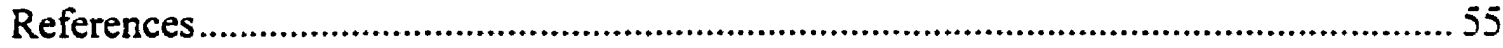

Appendix A - View Cell Calibration...................................................................................

Appendix B - Liquid Density Estimation....................................................................... B1

Appendix C - P-R EOS Binary Interaction Parameters Fit to

Solid-Fluid Solubility Data. 


\section{List of Figures}

Figure l - Appearance of irreversible asphaltene precipitation with $\mathrm{ABVB}+$ dodecane + hydrogen feed.

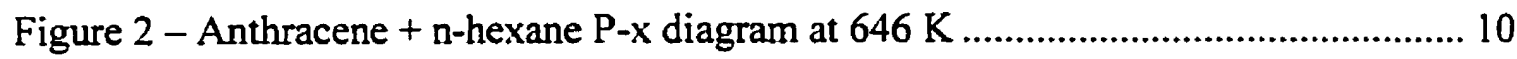

Figure 3 - P-T binary phase projections....................................................................... 12

Figure 4 - Type IV binary phase projection with solidification of the heavier component.

Figure 5- Schematic representation of the view cell, imaging equipment and auxiliary equipment.

Figure 6 - Sample image of view cell contents (oriented on its side with the bottom of the cell towards the left side of the image)

Figure 7 - Location in composition space (mole fraction) of experiments with anthracene. (• used for density measurements; ${ }^{\circ}$ qualitative experiments.) ..... 23

Figure 8 - Density measurements for anthracene + hexadecane + hydrogen at $646 \mathrm{~K}$ and $5 \mathrm{MPa}$

Figure 9 - Hypothetical case showing three distinct density zones if LLV phase behaviour is present.

Figure 10 - Intensity data showing changes in the relative density of the contents of the view cell for pyrene + hexadecane at $120^{\circ} \mathrm{C}$ and 4.9 psia.

Figure 11 - Location of liquid-vapour and solid-liquid boundaries as a function of temperature for pyrene + hexadecane

Figure 12 - Calculated solubiltiy model for anthracene + propane mixture at $420 \mathrm{~K}$ superimposed on available data.

Figure 13 - P-R binary interaction parameter correlation for anthracene + n-alkanes and PAH's + n-alkane families.

Figure 14 - Binary interaction parameters for anthracene + pseudo n-alkanes. ................. 36

Figure 15 - Critical temperature loci for anthracene + n-alkane mixtures ......................... 37

Figure 16 - Critical pressure loci for anthracene + n-alkane mixtures .............................. 37

Figure 17 - $\mathrm{P}-\mathrm{T}$ diagram for anthracene + pseudo $\mathrm{n}$-alkane $(\mathrm{CN}=5.6)$ showing the effect of hydrogen on $\mathrm{L}_{1} \mathrm{~L}_{2} \mathrm{~V}$ phase boundary and location of $\mathrm{K}$ - and $\mathrm{L}$-points....... 38 
Figure 18 - Pyrene + pseudo n-alkane critical temperature loci ........................................ 40

Figure 19 - Possible initial reaction products of anthracene (Lewis, 1980) .................... 42

Figure 20 - Predicted phase behaviour of hexaphene and anthracene + pseudo n-alkanes

Figure 21 - $P$-x diagram for hexaphene $+50: 50 n$-pentadecane:n-hexadecane at $646 \mathrm{~K}$. and expanded log-scale view of the low composition range........................... 44

Figure $22-\mathrm{P}-\mathrm{x}$ diagram for anthracenc $+25: 75 \mathrm{n}$-pentane:n-hexane at $448 \mathrm{~K}$............... 45

Figure 23 - Location of phase behaviour cases that impact coking kinetics. .................... 47 


\section{List of Tables}

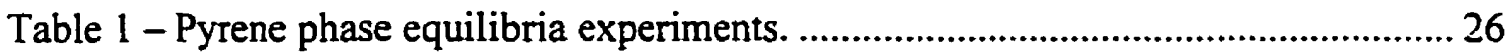

Table 2 - Critical properties, acentric factors, specific gravities, and normal boiling points used for computer simulations................................................ 31

Table 3 - Binary interaction parameters for PAH + n-alkane pairs. ............................... 33 


\section{Chapter 1 - Introduction}

\section{Problem}

Catalytic hydrogenation processing is an attractive technology for upgrading heavy oil and bitumen, since it offers higher liquid product yields than other competing processes. However, a major drawback is the high cost associated with replenishing deactivated catalyst. Traditional hydrogenation processing catalysts deactivate due to the formation of "coke" and metal sulphide deposits on the catalyst (Thakur and Thomas, 1985). "Coke" is a non-volatile, carbonaceous deposit that arises primarily from dehydrogenation-condensation reactions of polycyclic aromatics in the feed (Absi-Halabi and Stanislaus, 1991). As of yet. the scientific community has not agreed on the mechanism of coke formation and deposition. Proposed kinetic models to date are unable to encompass the variety of physical phenomena observed when working with hydrogenation processing catalysts and feeds.

\section{Catalyst pores}

All coke deposition mechanisms are based on one of two simplified models: pore-mouth plugging or uniform surface deposition. Generally, pore-mouth plugging models attribute loss of catalytic activity to small amounts of coke that preferentially deposit in a multilayer fashion at pore-mouths thereby rendering the pore inaccessible to reactants. Uniform surface deposition models attribute the loss in catalytic activity to the decrease in catalytic surface area that results as coke collects in a single layer on catalyst surfaces. Both models are supported by experimental findings; however, there are no theories explaining why coke can deposit on the same catalyst in two fundamentally different modes.

\section{Induction Period}

In many hydrogenation processes coke is formed from the onset. In other instances, very little or no coke is observed initially; but after an induction period, massive coking and the resulting loss in productivity are observed. Sasaki et al. (1993) observe induction periods of 1 to $51 / 2$ hours with anthracene and $1 / 2$ to 3 hours with phenanthrene during batch experiments. Clearly, something must happen to the feed materials before 
significant coking can occur. Sasaki's findings also suggest a progressive increase in the molecular size of the early carbonization products. Possibly, as enough carbonization products are produced to sufficiently change the physics of the system, coke formation becomes favourable.

\section{A Link Between Kinetics and Phase Behaviour}

Abedi et al. (1998) observe a link between coke formation and multiphase behaviour. When working with hydrogenation processing feeds, such as Athabasca Bitumen Vacuum Bottoms (ABVB), operating conditions play a major role on the extent of coke formation. In some instances no coke forms. but with a slight change in operating conditions, coke forms rapidly. As summarized in Figure 1, Abedi observed that coke did not form at temperatures in excess of $700 \mathrm{~K}$, in the $L_{1} V$ zone, where the pressure was such that multiphase behaviour was avoided for a mixture of ABVB (2 mol\%)+ dodecane $(47 \mathrm{~mol} \%)+$ hydrogen $(51 \mathrm{~mol} \%)$. In this case the coke precursors were dispersed at low concentration in the $\mathrm{L}_{1}$ phase. Rapid coking did however arise at $655 \mathrm{~K}$, where the pressure allowed for $L_{1} L_{2} V$ phase behaviour. Since, in published coking reaction models, the initial rate of coke formation is proportional to coke precursor concentration raised to some power, the rate of coke formation increases dramatically with the appearance of the second liquid phase $\left(L_{2}\right)$, rich in coke precursors, even though the operating temperature is lower than in the case where no coke is formed. This is a dramatic though anecdotal example which illustrates that simple kinetic models alone cannot explain the contrary phenomena observed when studying coke formation in heavy oil systems, (i.e. the rate of coke formation can be altered radically at fixed temperature and composition through slight changes in operating pressure).

\section{Objective and Scope}

The objective of this thesis is to investigate the possible connection between kinetics and phase behaviour as it applies to catalyst deactivation by coke formation in hydrogenation processes. Of particular importance is the system anthracene + hexadecane + hydrogen at temperatures near $646 \mathrm{~K}$, since these conditions simulate industrial hydrogenation operations. Anthracene is a typical model-coke precursor used in many laboratory 
simulations to study the long-term effects of coke formation on catalyst activity. It is expected that this work will be the basis for a detailed and quantitative study.

\section{Importance}

Understanding the link between kinetics and phase behaviour is invaluable when developing kinetic models for coke formation, developing mechanisms for coke deposition, and designing or optimizing hydrogenation processes. Phase behaviour can change dramatically giving rise to very different phenomena with seemingly very little difference in operating conditions. Knowledge of the location of "danger zones" and operating away from them can dramatically increase the productivity and life of expensive hydrogenation catalysts.

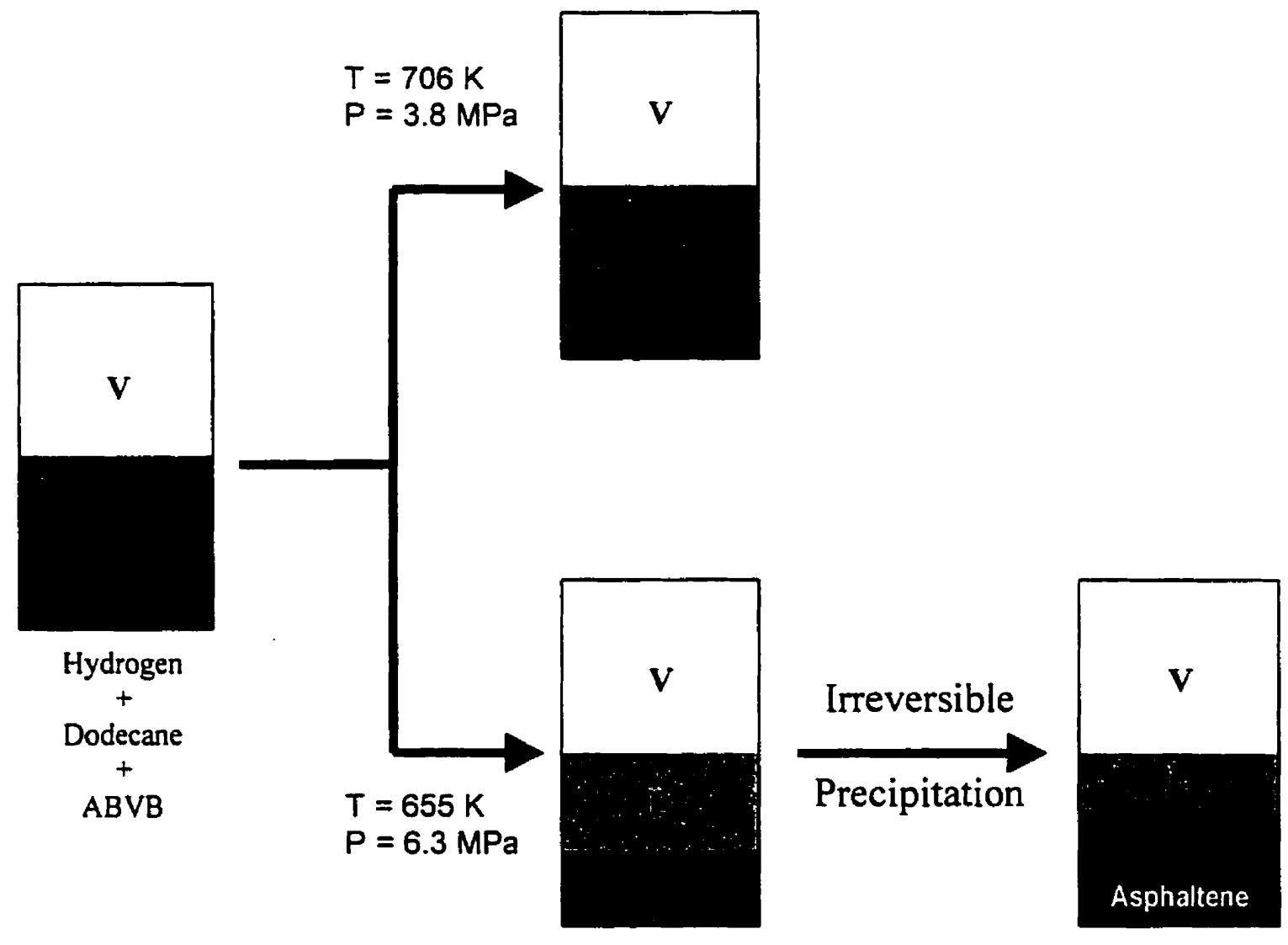

Figure 1 - Appearance of irreversible asphaltene precipitation with ABVB + dodecane + hydrogen feed. 


\section{Organization of Thesis}

Background material on coke deposition mechanisms and induction periods are presented in Chapter 2. A brief description of relevant phase equilibrium theory is also presented. Experimental phase equilibria and liquid density measurements of the anthracene + hexadecane + hydrogen system at $646 \mathrm{~K}$ were performed, as well as, qualitative phase equilibria experiments for the pyrene + hexadecane + hydrogen system. All experimental procedures and results are described in Chapter 3. Computer simulations of the critical phenomena of anthracene with normal alkanes were also obtained. This proved to be a difficult task because published interaction parameters for equations of state did not describe the phase behaviour of the mixtures. These simulation results are discussed in Chapter 4. Since anthracene is highly reactive in the presence of a catalyst at typical hydrogenation processing temperatures, as time proceeds during coking experiments larger molecular products will form thus giving rise to mixtures quite different from the initial feed. The phase behaviour of typical reaction products and intermediates is also simulated. These results are also presented in Chapter 4 The impact of the predicted and experimentally observed phase behaviour on published models for coke formation and deposition on hydrogenation catalysts is discussed in Chapter 5. Finally. conclusions and recommendations are found in chapters 6 and 7 respectively. 


\section{Chapter 2 - Literature Review and Background}

\section{Coking Kinetics}

\section{Two Models of Coke Deposition on Hydrogenation Processing Catalysts}

Uniform surface deposition (Richardson et al. 1996) and pore-mouth plugging (Muegge and Massoth, 1991) are two observed models for coke deposition within catalyst pellets. Richardson et al. suggest that coke deposits uniformly on the catalyst surface with monolayer coverage, thus affecting the smallest pores (with highest surface area to volume ratios) before affecting larger pores. Others link this type of coverage to the catalyst acidity (Gray et al., 1992; Absi-Halabi and Starislaus, 1991). Generally speaking, larger molecular species in the oil, which contain the majority of metals. are attracted to the acidic sites of the catalyst structure, where they absorb and begin to coke. Therefore, the driving force for absorption is the attraction to the acidic catalyst sites found in the $\gamma-\mathrm{Al}_{2} \mathrm{O}_{3}$ support. Typical experimental findings that suggest uniform surface deposition show a loss of pore volume for only the smallest pores (Absi-Halabi and Stanislaus 1991), a gradual decreases in catalyst surface area, and a gradual decreases in pore volume as overall coke content increases. Deposition beyond a molecular monolayer is not accounted for in this modelling approach.

Muegge and Massoth (1991) studied the effect of coke produced from a model-coke precursor, anthracene, on the physical properties and intrinsic activity of a $\mathrm{Ni}-\mathrm{Mo}$ catalyst. Their findings include carbon uniformly distributed throughout the particle, significant loss of pore volume with increasing coke, little loss of catalyst surface area with increasing coke, and no preference for coke to close off either smaller or larger pores. These observations suggest that coke forms preferentially at internal pore-mouths. "[Ideally], at low coke, there is significant penetration of coke into the pore, with little constriction of the pore-mouth. As coke content increases, the coke preferentially deposits nearer the pore-mouth, with only small additional penetration into the pore." Typical experimental findings that suggest pore-mouth plugging show no preferential blocking of smaller pores, and a significant lowering of diffusivity as overall coke content increases. This model, based on experiments, is consistent with localized multilayer deposition and is inconsistent with the purely catalytic reactions based 
deposition model above. Since neither of the conflicting models has been substantially proven or disproven, it is clear that more study is required to shed light on the mechanisms of coke deposition on hydrogenation catalysts.

\section{Induction Periods}

Most batch kinetic studies on the carbonization of anthracene report the existence of an induction period prior the appearance of the solvent insoluble products (Sasaki et al, 1993; Peters et al, 1991; Scaroni et al., 1991). Sasaki observed induction periods with anthracene in pyridine, toluene, and heptane solvents at temperature of 713,733 , and $753 \mathrm{~K}$. The induction periods increase with increasing solubility parameter of the solvents and decrease sharply with temperature. Assuming apparent first-order kinetics for reactions taking place during the induction period, they are able to calculate apparent activation energies of 45,45 and $46 \mathrm{kcal} / \mathrm{mol}$ for the chemical change that occurs prior to the appearance of solvent-insolubles in heptane, toluene, and pyridine respectively. Despite the different induction periods observed for the appearance of different solventinsolubles, similar apparent activation energies for their initial formation were calculated. This suggests "a progressive increase in the molecular size of the early carbonization products which is governed by similar reaction mechanisms." Once the induction period is completed, there is a drastic increase in the coke yield. This raises the question as to what criterion marks the completion of the induction period and the initiation of rapid coking.

\section{Anthracene as a Model Precursor for Coke Formation}

Many investigations of hydrogenation catalyst deactivation use highly reactive compounds, such as polycyclic aromatic hydrocarbons (PAH's), as model-coke precursors. Anthracene is a typical model coke precursor used in many laboratory and computer simulations. As mentioned, Muegge and Massoth (1991) use anthracene dissolved in hexadecane to study the effect of coke on the physical properties and intrinsic activity of hydrogenation catalyst. Although model-coke precursors can provide valuable insights into the chemical behaviour of the more complex materials, the coke formed certainly differs from coke formed from heavy oil or residue feeds found in industrial applications. 
The phase behaviour of systems of polycyclic aromatic hydrocarbons mixed with normal alkanes has been studied previously. Peters et al. (1989) reported that phenanthrene + propane exhibits liquid-liquid-vapour (LLV) phase behaviour over a wide compositional range. Shaw et al. (1993) observed LLV behaviour for an aromatic with alkane mixture, (n-decylbenzene + ethane). It seems reasonable to suppose that anthracene or its coking reaction products + n-alkanes mixtures may exhibit complex phase behaviour as well, although, this is unproven.

\section{Phase Equilibrium and Modelling}

In order to appreciate the phase diagram transitions presented in this thesis, it is necessary to explain some general concepts pertaining to the phase behaviour theory of asymmetric mixtures. The discussion that follows provides a concise presentation of these necessary concepts, and is divided into two main sections. The first section includes the application of the Gibbs phase rule, the classification scheme of van Konynenburg and Scott (1980), the effect of the asymmetry of a mixture, and the implications of the presence of a solid phase. Emphasis is placed on systems with three components or less. The second section discusses methods of predicting phase behaviour, in particular the use of the PengRobinson equation of state (Peng and Robinson, 1976); special emphasis is placed on finding binary interaction parameters for hydrocarbon-hydrocarbon systems.

\section{Phase Equilibria Theory}

\section{Multicomponent-Multiphase Behaviour of Organic Fluids}

According to the second law of thermodynamics, the total Gibbs energy, $G^{t}$, for a closed system at constant temperature and pressure is minimized at equilibrium, thus

$$
d G_{P . T}^{\prime}=0
$$

For an open system with $N$ components, the change in Gibbs energy for a change between equilibrium states is

$$
d G^{\prime}=-S^{\prime} d T+V^{\prime} d P+\sum_{i=1}^{N} \mu_{i} d n_{i}
$$

where $\mu_{i}$ is the chemical potential of the $i^{\text {th }}$ component. The chemical potential is, by definition, the change in the total Gibbs energy as the result of adding $d n_{i}$ moles of 
component $i$ at constant temperature and pressure, holding the moles of the other components constant:

$$
\mu_{i} \equiv\left(\frac{\partial G^{t}}{\partial n_{i}}\right)_{P . T \mu_{i, n}}
$$

For a system with $\pi$ phases, the necessary condition for equilibrium is

$$
\mu_{i}^{\alpha}=\mu_{i}^{\beta}=\cdots=\mu_{i}^{\pi} \quad \text { for } i=1,2, \ldots N
$$

Substituting Equation 3 into Equation 4 yields $N(\pi-1)$ equations. From the detinition of chemical potential and the additional criterion $\Sigma x_{i}=1, \mu_{i}$ is a function of pressure, temperature, and $(N-1)$ independent mole fractions. Equation 3 then represents $2+\pi(N-1)$ variables, and the number of degrees of freedom $(F)$ is

$$
F=\{2+\pi(N-1)\}-\{N(\pi-1)\}=2-\pi+N
$$

Equation 5 is the well-known Gibbs phase rule. If one allows for critical phenomena, i.e. two or more phases with identical properties, the Gibbs phase rule becomes

$$
F=2-\pi+N-C
$$

where $\mathrm{C}=1$ if two phases are critical, and $\mathrm{C}=2$ it three phases are critical.

The application of the Gibbs phase rule has many implications. For instance, in a onecomponent system $(N=1)$ the maximum number of degrees of freedom is two; therefore, the phase equilibria for a one-component system are represented by two variables, $P$ and $T$. A line represents two-phase equilibrium (choosing $P$ or $T$ fixes the other variable), and a point represents three-phase equilibrium.

When these concepts are extended to two-component systems, interesting phenomena are observed. The maximum degree of freedom is three; therefore, for a planer representation one variable must be fixed. Fixing composition results in a pressuretemperature (P-T) diagram; fixing pressure results in a temperature-composition ( $\mathrm{T}-\mathrm{x})$ diagram; and fixing temperature results in a pressure-composition ( $\mathrm{P}-\mathrm{x})$ diagram. For two-phase equilibria $(\pi=2)$ the degree of freedom is two. Fixing $P$ and $T$, such that liquid-vapour behaviour is stable, fixes the composition of the two phases. Figure 2, a computer simulated $\mathrm{P}-\mathrm{x}$ diagram for anthracene $+\mathrm{n}$-hexane at $646 \mathrm{~K}$, illustrates this point. Choosing a pressure that intersects the liquid-vapour region, say $4 \mathrm{MPa}$, allows for 
liquid-vapour phase behaviour for feed compositions $\left(x^{9}\right)$ between $x^{\prime}$ and $y^{\prime}$. The resulting homogenous liquid phase will have an anthracene compositions of $x^{\prime}$, and the resulting homogenous vapour phase will have an anthracene compositions of $y^{\prime}$. However, it is possible that the mixture will not split, hence, resulting in a metastable phase. The feed composition in the two-phase region represents the total composition of anthracene in the heterogeneous mixture. Feed compositions less than $x^{\prime}$ results in a single homogeneous vapour phase with an anthracene composition of $x^{\circ}$, and feed compositions greater than $y^{\prime}$ results in a single homogeneous liquid phase also with an anthracene composition of $x^{\circ}$. The vapour-liquid ratio on a molar basis in the two-phase region follows from an application of the Lever rule. If $n^{v}$ is the number of moles in the vapour phase and $n^{l}$ is the number of moles in the liquid phase, then the vapour-liquid mole ratio is

$$
\frac{n^{\prime}}{n^{\prime}}=\frac{x^{\prime}-x^{\circ}}{x^{\circ}-y^{\prime}}
$$

For three-component systems similar behaviours are observed, and ternary systems are considered prototypes for multicomponent mixtures. The maximum number of degrees of freedom is four; therefore, to represent all possible phase behaviour types on a twodimensional diagram two variables must be fixed. In ternary systems it is common to fix pressure and temperature; the remaining compositions are represented by equilateral triangles. A point within the triangle represents a ternary mixture, on the side represents a binary mixture, and at a vertex a pure component. In such a representation single-phase behaviour results in two degrees of freedom, and two compositions must be specified. Two phases results in one degree of freedom. Consequently, fixing one composition fixes the other; thus, all the compositions of the second phase are fixed as well. The relative amount of each phase is determined by the application of the Lever rule along the equilibrium tie lines connecting the compositions of the two phases. Three phases imparts zero degrees of freedom at fixed temperature and pressure; the compositions of the three coexisting phases are fixed. The three compositions plotted on a ternary diagram fix the vertices of a triangle; points within the triangle represent compositions of the heterogeneous mixtures of three phases. The ratio of the amounts of each phase is determined by the Lever rule. 


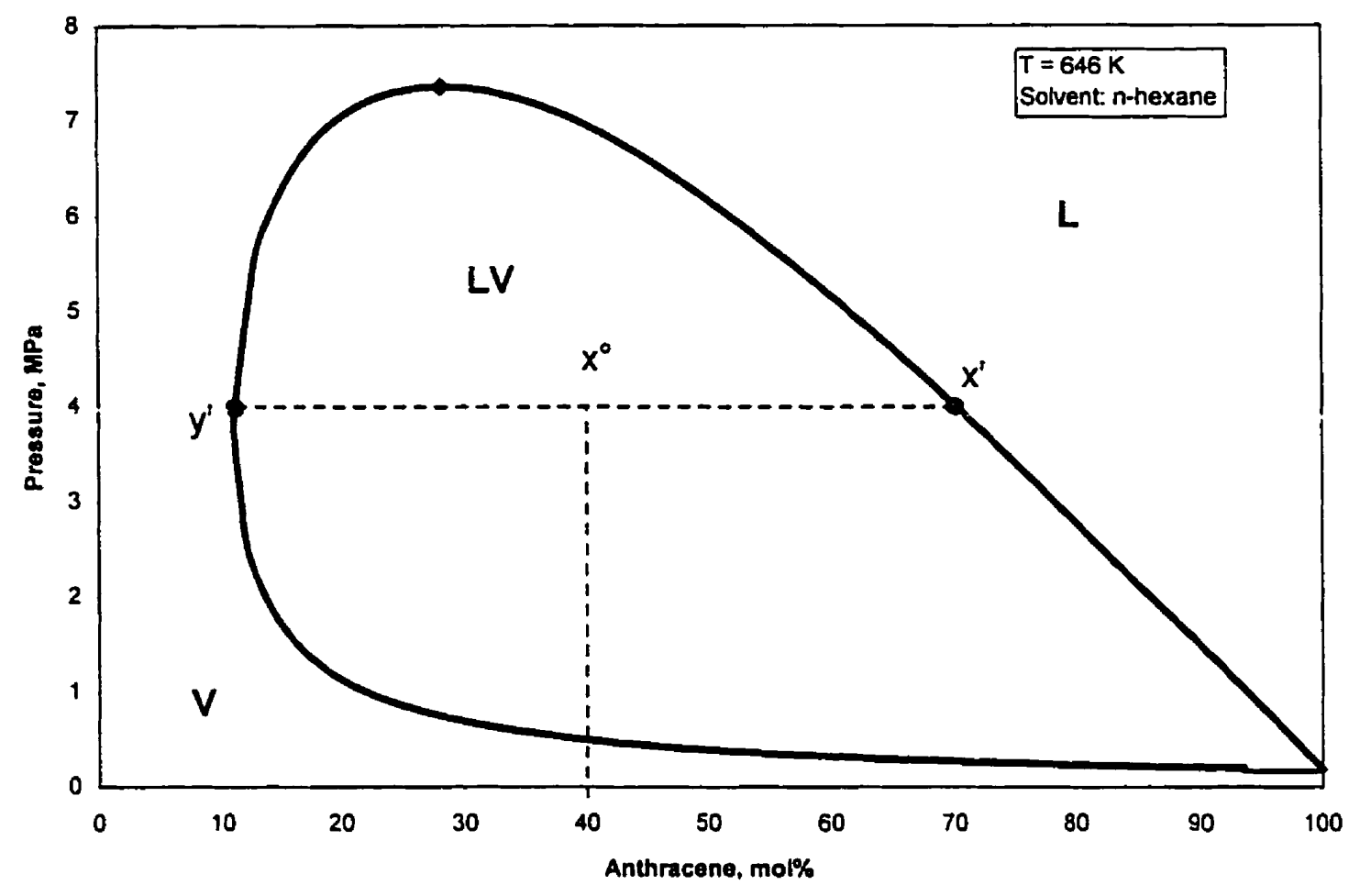

Figure 2 - Anthracene + n-hexane P-x diagram at $646 \mathrm{~K}$

Of particular importance for this thesis is when the ratio of the amounts of two adjacent members of a homologous series is fixed. In a ternary system this results in a pseudo binary mixture. For three phase equilibria $(\pi=3)$, the pseudo binary mixture $(N=2)$ imparts one degree of freedom. Fixing temperature fixes the overall composition of the pseudo component and the other component in the liquid-liquid-vapour region. Since the ratio of the components that make-up the pseudo component is known, all the compositions are specified. This common strategy of creating pseudo components allows one to observe transitions in phase behaviour more readily and more completely than would be the case with binary mixtures (without introducing the complexity normally associated with three component systems). Examples are shown in Chapter 4.

\section{Classification of Fluid Phase Equilibria}

The van der Waals equation of state was used by van Konynenburg and Scott (1980) to create a general classification scheme for organic fluid phase equilibria. They predicted five general classes of phase behaviour by varying combinations of parameters for the 
equation of state. The classification scheme is based on binary mixtures; nevertheless, the concepts are easily extended to multicomponent systems. A sixth class of phase behaviour (Type VI) cannot be calculated from the van der Waals equation of state but has been found experimentally (Schneider, 1991). Type VI phase behaviour is very rare and is not discussed here.

Figure $3 \mathrm{a}$ is a P-T projection of Type I phase behaviour. A continuous $\mathrm{L}=\mathrm{V}$ critical locus joins the vapour pressure lines of each pure component; moreover, as the temperature increases, the location of the critical point in composition space moves towards higher compositions of the heavier component. The critical locus goes through a maximum; thus, vapour can exist at higher pressures for the mixtures than for either of the pure components at the same temperature. Only $\mathrm{L}, \mathrm{V}$, and $\mathrm{L}+\mathrm{V}$ phase equilibria are possible.

Type II. presented in Figure $3 \mathrm{~b}$, is similar to Type I except for a region of liquid-liquid immiscibility at low temperatures (below the critical temperature of the light component). The $L_{1}=L_{2}$ critical locus begins at the upper critical endpoint (UCEP) of the three phase equilibrium curve $\left(L_{1} L_{2} V\right)$ and extends to very high pressures. The UCEP in this case is a liquid-liquid critical point in the presence of a vapour $\left(L_{2}=L_{1}+V\right)$. This type of critical point is commonly referred to as an L-point. The liquid-liquid immiscibility of Type II phase behaviour typically occurs at intermediate compositions. 


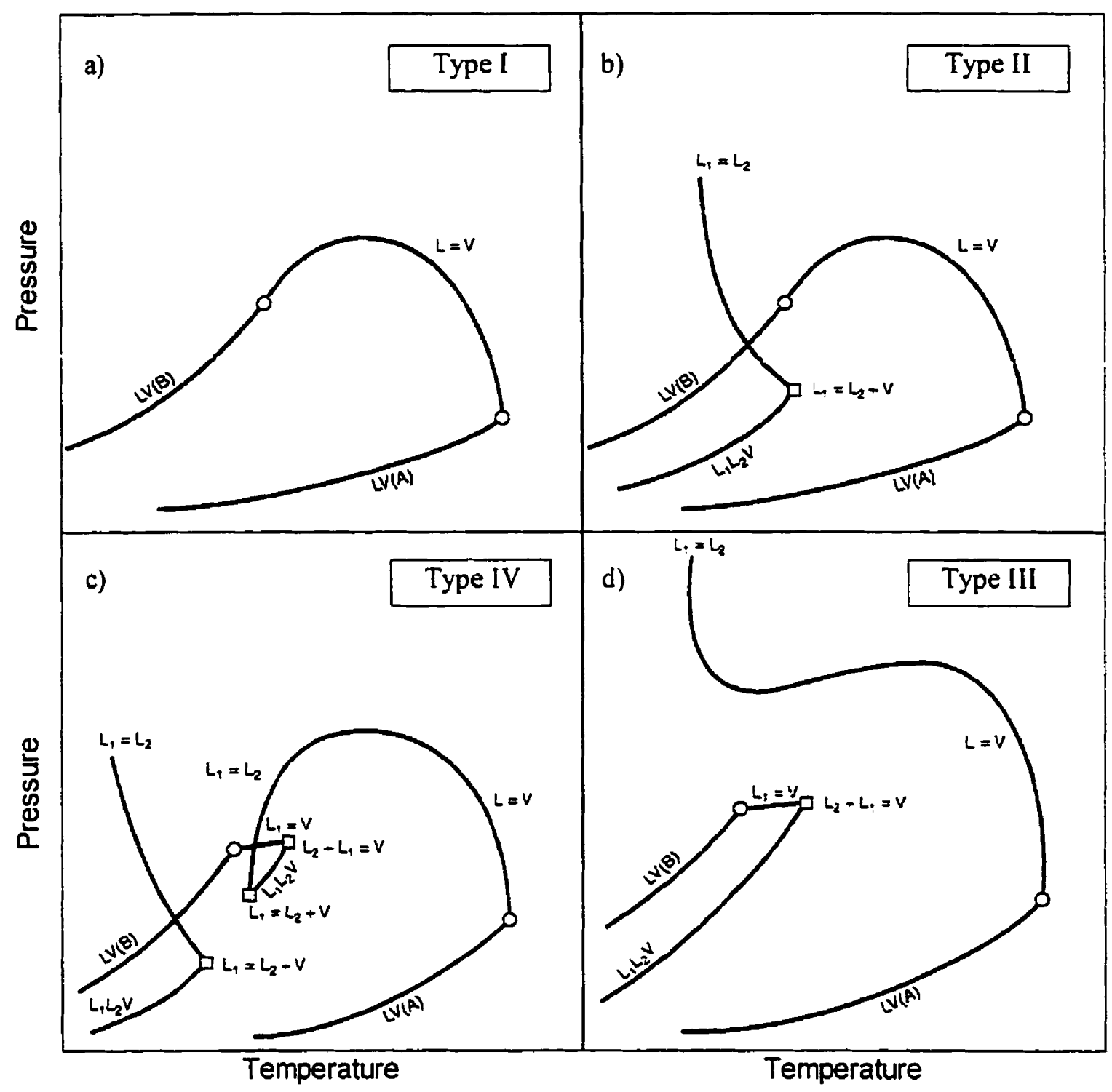

Figure 3 - P-T binary phase projections

It is more sensible to skip over Type III to Type IV since Type IV is a more natural progression from Type II. The significance of this progression is discussed below on asymmetric fluids. As seen in Figure 3c, Type IV phase behaviour retains the low temperature region of liquid-liquid immiscibility found in Type II; while, the $\mathrm{L}=\mathrm{V}$ critical locus becomes discontinuous. Starting at the critical point of the light component vapour pressure curve, the $L_{1}=V$ critical curve extends similar to Type I or Type II; however, it now ends at the UCEP of a second (high pressure, high temperature) $L_{1} L_{2} V$ equilibrium curve. This UCEP is a liquid-vapour critical point in the presence of a 
second heavier liquid $\left(\mathrm{L}_{1}=\mathrm{V}+\mathrm{L}_{2}\right)$ and is commonly referred to as a $\mathrm{K}$-point. From the lower critical endpoint (LCEP) of this second $L_{1} L_{2} V$ curve, which is also an $L$-point, the critical curve continues as a $\mathrm{L}_{1}=\mathrm{L}_{2}$ critical locus and will transform into $\mathrm{L}_{2}=\mathrm{V}$ critical locus at temperatures above the $\mathrm{K}$-point. The $\mathrm{L}_{2}=\mathrm{V}$ critical locus continues, joining the heavy component vapour pressure curve at its pure component critical point. While low temperature liquid-liquid immiscibility typically occurs at intermediate compositions, high temperature liquid-liquid immiscibility tends to appear at lower compositions of the heavier component. Many suggest that Type $\mathrm{V}$ phase behaviour is not really a separate classification from that of Type IV, and merely is Type IV where the low temperature $L_{1} L_{2} V$ equilibrium curve is obscured by solidification of the heavier component. The same argument applies to Type I and Type II. More discussion on the role of solidification follows.

Returning to Type III phase behaviour. Figure $3 \mathrm{~d}$ shows a P-T projection unlike any seen previously. Simply, Type III phase behaviour arises when the low temperature and high temperature $L_{1} L_{2} \mathrm{~V}$ equilibrium curves meet. This meeting implies that as the components change. a smooth transition in the type of phase behaviour can occur. Examples of carbon dioxide with n-alkanes show a continuous and consistent transition from Type II, through Type IV, to Type III as the carbon number of the n-alkane increases (Schneider, 1991). Increasing the carbon number increases the relative size of the n-alkane to carbon dioxide; this is a related to the asymmetry of the mixture.

\section{Asymmetric Mixtures}

Reservoir fluids, heavy oils, or bitumen + light hydrocarbon mixtures possess heavy and light fractions. Typically the heavy fractions, which contain asphaltenes, are present at significant mass fractions; but the light fractions dominate on a mole basis. Such fluids are referred to as asymmetric mixtures. There is a growing body of experimental and theoretical work concerning the phase behaviour of well-defined asymmetric hydrocarbon fluids. In a recent paper, Raeissi, Gauter and Peters (1998) highlight the role of the degree of asymmetry on the nature of the phase behaviour exhibited by quasi binary mixtures of light gases (e.g., carbon dioxide, methane, propane) + members of various homologous series (alkyl-benzenes, n-alkanes, $n$-alcohols). Light gases tend to 
be completely miscible (Type I phase behaviour) with the smallest members of homologous series. As the degree of asymmetry increases, the mixtures become only partially miscible at low temperatures but remain miscible at elevated temperatures; this occurrence is classified as Type II phase behaviour. As the degree of asymmetry is increased further, a second miscibility gap appears in the near critical region of the light component and one finds $L_{1} L_{2} V$ phase behaviour at both low and high temperatures (Type IV phase behaviour). The mixtures remain miscible at intermediate temperatures. If the degree of asymmetry is increased still further, the miscibility gaps at high and low temperatures connect (Type III) resulting in a single $\mathrm{L}_{1} \mathrm{~L}_{2} \mathrm{~V}$ curve stretching from low to high temperatures.

As mentioned previously when two liquids are critical in the presence of a vapour, the phenomenon is referred to as an L-point. When a liquid and a vapour are critical in the presence of a second heavier liquid, the phenomenon is referred to as a $\mathrm{K}$-point. By tracking the presence of these phenomena the phase behaviour class of a binary mixture is readily determined. As the asymmetry increases, transition from Type II to Type IV occurs at a tricritical point (TCP). The TCP arises at the onset of high temperature $\mathrm{L}_{1} \mathrm{~L}_{2} \mathrm{~V}$ equilibrium, where the L-point and the $\mathrm{K}$-point coincide. If the asymmetry increases further. the high temperature $L_{1} L_{2} V$ equilibrium curve lengthens spanning a larger temperature and pressure range and the low temperature $L_{1} L_{2} V$ equilibrium curve extends to higher temperatures and pressures. At some point the L-points of the two $L_{1} L_{2} V$ equilibrium curves will join. This union occurs at a double critical endpoint, DCEP, and marks the Type IV/Type III transition. Examples of these transitions are observed in computer simulations of anthracene + pseudo n-alkane mixtures and are presented in a following chapter on phase equilibria models for model-coke precursors.

\section{Solid Interference}

If temperatures below the melting temperature of one or both of the components are considered, one must allow for the appearance of solid in the P-T projections noted above, since up to four phases may be present at equilibrium in binary mixtures as predicted by the phase rule, Equation 5 . The resulting P-T projections shown in Figure 4 $a, b, c$, and $d$ are illustrative and concern the solidification of the heavier component in a 
Type IV binary mixture. If the melting temperature of the heavier component is relatively low, the $\mathrm{SL}_{2} \mathrm{~V}$ curve stemming from the triple point of the heavier component intersects the lower $\mathrm{L}_{1} \mathrm{~L}_{2} \mathrm{~V}$ curve to form a $\mathrm{SL}_{1} \mathrm{~L}_{2} \mathrm{~V}$ four-phase point or Q-point - Figure $4 \mathrm{a}$. If the melting point of the heavier component is somewhat higher, the $\mathrm{SL}_{2} \mathrm{~V}$ curve stemming from the triple point of the heavier component passes in between the lower and upper $L_{1} L_{2} V$ curves - Figure $4 b$. In this case, the lower $L_{1} L_{2} V$ behaviour is not observed; and as the SLV curve does not intersect the upper $\mathrm{L}_{1} \mathrm{~L}_{2} \mathrm{~V}$ curve, a $\mathrm{Q}$-point is not present in the $\mathrm{P}-\mathrm{T}$ projection. If the melting temperature of the heavier component is higher still, the $\mathrm{SL}_{2} \mathrm{~V}$ curve intersects the upper $\mathrm{L}_{1} \mathrm{~L}_{2} \mathrm{~V}$ curve and a $\mathrm{Q}$-point is again observed. The resulting P-T projection, Figure $4 c$, is identical to the $\mathrm{P}-\mathrm{T}$ projection arising in a Type III + solid heavy component binary. If the SLV curve stemming from the triple point of the heavier component passes above the upper extremum of the $L_{1} L_{2} V$ curve, a case treated in detail elsewhere (Wisniak et al., 1998), $\mathrm{SL}_{1} \mathrm{~L}_{2} \mathrm{~V}$ phase behaviour is again suppressed and the P-T projection shown in Figure $4 \mathrm{~d}$ results.

\section{Predicting Phase Behaviour}

Modelling Phase Behaviour with an Equation of State

In order to model the phase behaviour of fluids the pressure-volume-temperature (PVT) relationship of the fluid must be known. This relationship is determined using analytical equations of state. One of the most widely use non-ideal equation of state (EOS) is the Peng-Robinson (P-R) EOS. For a pure fluid, the P-R EOS is expressed as

$$
\begin{aligned}
& P=\frac{R T}{v-b}-\frac{a \alpha}{v(v+b)+b(v-b)}, \text { where } \\
& a=\frac{27}{64} \frac{R^{2} T_{c}^{2}}{P_{c}}, \\
& b=\frac{R T_{c}}{8 P_{c}} \text {, and } \\
& \alpha=\left[1+\left(0.37464+1.5422 \omega-0.26992 \omega^{2}\right) \times\left(1-T_{r}^{0.5}\right)\right]^{2}
\end{aligned}
$$

Over the years many temperature dependent $\alpha$-functions have been proposed. The critical pressure, critical temperature and acentric factor $(\omega)$ of the pure fluid are all that 
are required as inputs. When the P-R EOS is extended to mixtures more information is required.

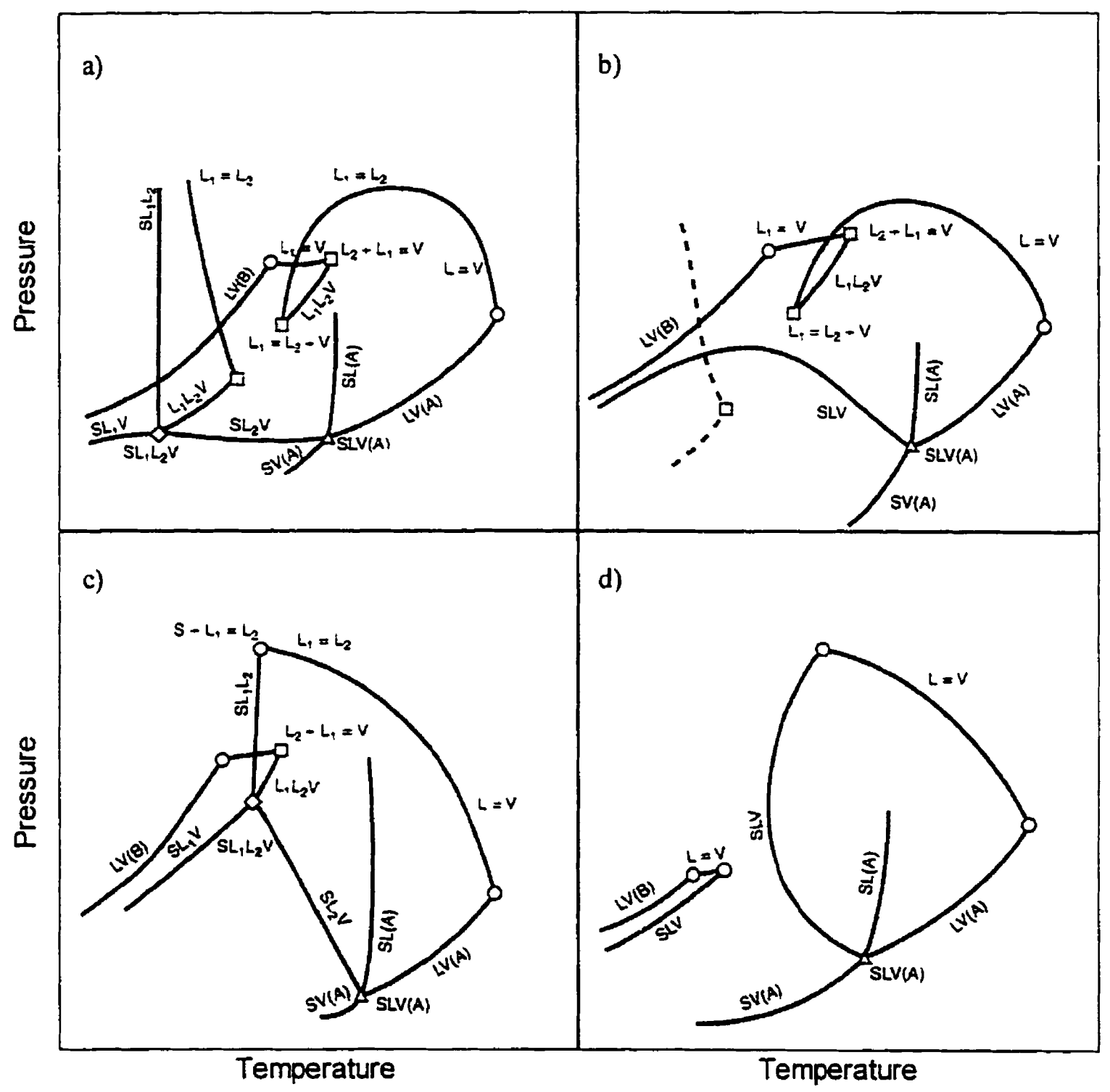

Figure 4 - Type IV binary phase projection with solidification of the heavier component

\section{Multicomponent Systems}

To extend the Peng-Robinson equation of state to mixtures, it must be modified to include variables of composition. The P-R EOS uses mixing rules, which essentially average the pure component constants, to obtain constants that hopefully characterize the 
mixture. At least one extra parameter is added to the mixing rules to account for poor characterization of the mixture by averaging. The mixing rules for the P-R are outlined below.

$$
\begin{aligned}
& a_{m}=\sum_{i} \sum_{i} y_{i} y_{,}\left(a_{i} a_{j}\right)^{1 / 2}\left(1-k_{i j}\right) \\
& b_{m}=\sum_{i} y_{i} b_{i}
\end{aligned}
$$

Once $a_{m}$ and $b_{m}$ are determined, they are used in place of the $a$ and $b$ parameters as though they were for a pure component. This assumes the mixture is a hypothetical "pure fluid."

As outlined above, the binary interaction parameter $k_{i j}$ is the only fitting parameter. In some instances the second binary interaction $l_{i j}$ is included in the mixing rule for the $b$ parameter (Gregorowicz and de Loos, 1996). Strictly speaking binary interaction parameters are constants; although, many authors suggest that binary interaction parameters are strongly dependent on temperature (Moysan et al., 1983; Park et al., 1996). Others suggest that temperature dependent interaction parameters introduce inconsistencies in energy calculations and are undesirable, (Satyro and Trebble, 1996). Interaction parameters and mixing rules are hotly debated topics in phase behaviour prediction.

Binary interaction parameters are typically determined by fitting vapour pressure data. Large databases of binary interaction parameters are available; however, these databases are limited to simple or commonly used materials. Finding binary interaction parameters for complex or rarely used materials is difficult. In many instances a value of zero is the best estimate. Another method is to correlate binary interaction parameters of similar species. Computer Modelling Group, developers of CMG WinProp software, developed alkane-alkane correlations based on critical molar volume ratios for binary interaction parameter regressed by Ollerich et al. (1981). The correlation is expressed as

$$
\left(1-k_{i j}\right)=\left(\frac{2 v_{c i}^{1 / 6} v_{c j}^{1 / 6}}{v_{c i}^{1 / 3}+v_{c j}^{1 / 3}}\right)^{\theta}
$$


where the "hydrocarbon interaction coefficient exponent" $(\theta)$ is 1.2. Although CMG recommends the user to determine the best $\theta$ for the system to be modelled, the program default is 1.2 for all hydrocarbon-hydrocarbon systems. In general, this correlation gives non alkane-alkane $k_{i j}$ 's that are too low. The use of equation 14 for polycyclic aromatic-alkane systems is discussed further in Chapter 4.

The Peng-Robinson equation of state leads to good phase equilibria calculations and is particularly useful in refinery and reservoir simulations since it gives accurate vapour pressure predictions for hydrocarbons. Moreover, the equation is widely used for complex materials since it requires very little information (only the critical properties and the acentric factor). The P-R EOS does, however, have some shortcomings. It is not accurate in the critical region, nor does it predict accurate liquid densities. Also, care should be exercised in calculating PVT relationships of polar fluids, associated fluids and long-chain molecules. Despite these shortcomings the P-R EOS is widely used; thus, binary interaction parameters for complex systems are valuable.

\section{Summary}

Underlying physics of coke deposition and incubation periods associated with kinetic models appear to be poorly understood. Anecdotal observation and kinetic data suggest a strong link with multiphase behaviour. Data for related fluid systems suggest that modelcoking fluids ought to exhibit Type II. IV, or III phase behaviour. Thus, the literature provides a sound basis for the principal thrust of this thesis. 


\section{Chapter 3 - Experimental}

This chapter details the procedures, data analysis, and results obtained for the phase equilibrium experiments. The first section deals with the system containing anthracene + hexadecane + hydrogen. The second section presents qualitative phase equilibria data for the system with pyrene + hexadecane + hydrogen. These experiments show no evidence of LLV phase behaviour over the range of conditions studied, highlight shortcomings in the interaction parameter database for aromatic-aliphatic hydrocarbon pairs, and provide a sound basis for the phase behaviour modelling described in Chapter 4 .

\section{Anthracene + n-Hexadecane + Hydrogen}

The purpose of the experiments with anthracene is to recreate initial conditions in catalyst pores of typical model-coking experiments and to show whether liquid-liquid-vapour phase behaviour arises at the outset. The experiments also provide useful liquid densities for anthracene + hexadecane + hydrogen mixtures. For ideal mixtures the liquid density is expected to follow Amegate's Rule where the liquid density is determined by a weight fraction average of the pure component densities.

\section{Data Collection and Analysis}

The phase equilibrium experiments were performed in an $\mathrm{X}$-ray view cell in the absence of catalyst. Figure 5 presents a schematic of the experimental set-up. Abedi et al. (1999) provide complete specifications of the view cell and image capture equipment. The view cell is fitted with a stainless steel bellows that allows for changes to the internal volume effectively permitting investigation of a wide range of pressures. An electric heating jacket allows for even and accurate heating to desired set-point temperatures. In addition, a magnetic stirrer ensures equilibrium and minimizes the formation of metastable phases.

Before the view cell is sealed, a weighed sample of solid anthracene is placed into the cell. Once sealed, adding hydrogen to approximately 2000 psig allows for sufficient leakage testing, and has the added benefit of diluting air trapped in the system. The entire system is then purged with a vacuum pump to remove air, which minimizes the extent of oxidation reactions during the experiment. The resulting sub-atmospheric condition also 
facilitates the injection of liquid hexadecane. Hydrogen is accurately added to the view cell by measuring the pressure change of a fixed volume reservoir that is allowed to equilibrate in a constant temperature water bath; the calculations are outlined below. The hydrogen addition method (Cai et al., 2000) is accurate to \pm 0.0005 moles of hydrogen.

Hydrogen mole fraction is calculated from a pressure difference in the gas reservoir using a compressibility based gas law. The gas reservoir, having a fixed volume of $281 \mathrm{~cm}^{3}$, is heated to a typical temperature of $35^{\circ} \mathrm{C}$. The amount of hydrogen added is caiculated by equation 15 , where $\Delta(P / z)$ is the difference between the initial pressure divided by the compressibility and the final pressure divided by the compressibility. The compressibility factor is evaluated at the pressure and temperature of the gas reservoir at the initial state and the final state.

$$
n=\frac{V}{R T}[\Delta(P / z)]=\frac{V}{R T}\left[\frac{P_{i}}{z_{i}}-\frac{P_{f}}{z_{f}}\right]
$$

After the desired amount of hydrogen is added to the view cell, the heater is turned on. At the desired temperature and pressure the system is allowed to equilibrate, and images are taken using an X-ray imaging system. Since beryllium is transparent to $\mathrm{X}$-rays. passing the X-ray beam through the view cell to a digital camera provides images of the material inside the view cell. A desktop computer stores the digital signal as an 8-bit grey scale image. Higher density materials record as black, since more $\mathrm{X}$-rays are absorbed or scattered, and lower density material record as white, since more $\mathrm{X}$-rays pass through.

Figure 6 is a sample image showing liquid-vapour equilibrium. The image is oriented on its side such that the bottom of the cell is situated to the left and the top of the cell is to the right. The liquid phase is represented by the middle grey area, above which, is the vapour phase, represented by the light grey area. In this image, the bellows is extended and can be seen above the liquid. The stirrer bar is visible at the bottom of the cell.

Images like these provide qualitative as well as quantitative information. It is easy to discern the existence of separate phases, the relative amount of each phase, and the direction a phase boundary moves with changing process conditions. This real-time, 
qualitative information is useful when attempting to determine the type of phase behaviour a system exhibits. One can also process the images to provide measurements such as, phase volume, liquid density, gas solubility and elemental composition (Abedi et al., 1999). Measuring gas solubility and elemental composition is beyond the scope of this thesis.

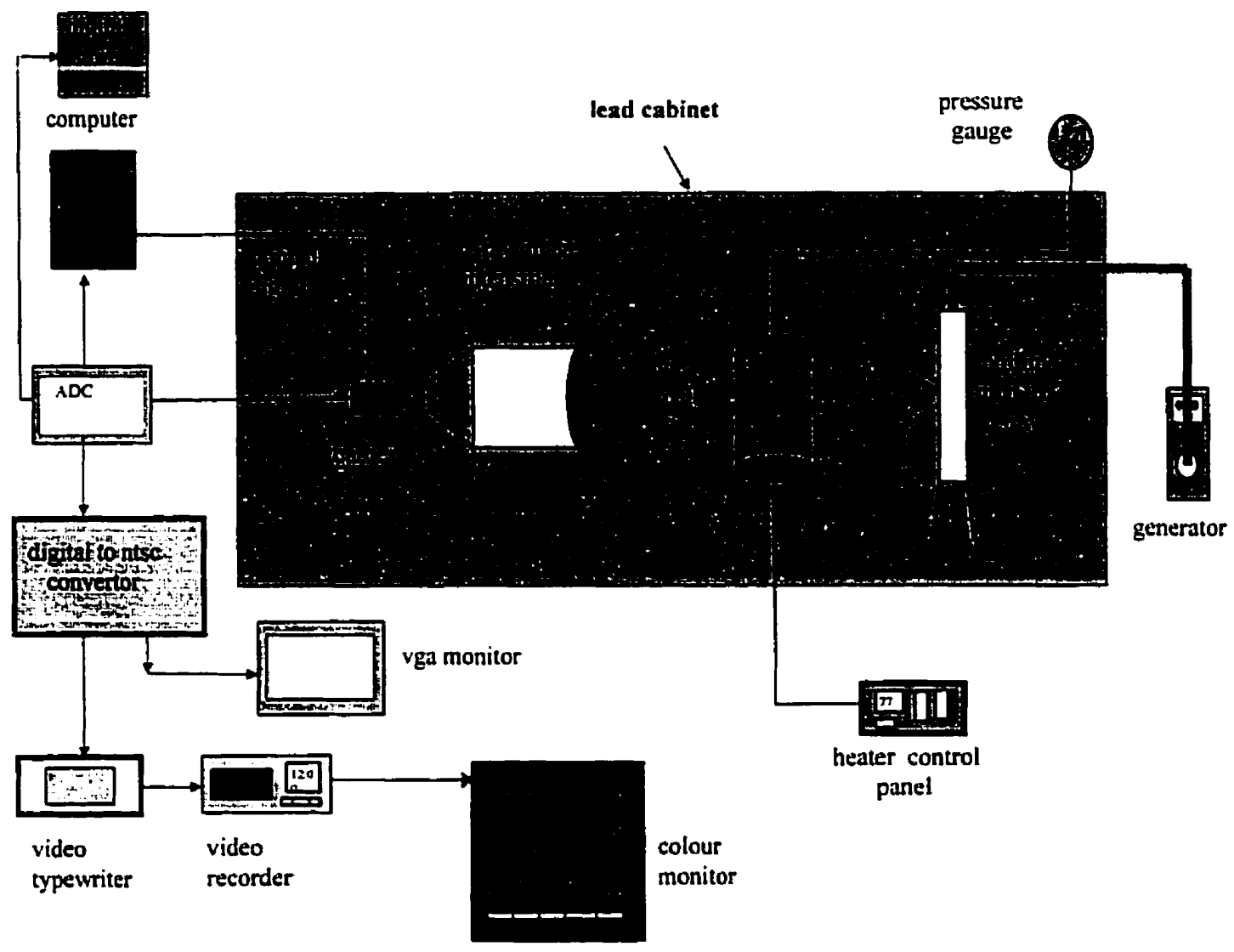

Figure 5- Schematic representation of the view cell, imaging equipment and auxiliary equipment.

Determining the phase volume requires two calibrations of the view cell, namely liquid volume and total volume. Liquid volume correlates with liquid boundary position, and total volume correlates with bellows position. Thus, by measuring the height of the liquid boundary, one can determine the liquid phase volume, and by measuring the position of the bellows, one can determine the total cell volume. The total cell volume is useful since the vapour phase volume is simply the difference of the total liquid volume from the total cell volume. Calibration plots are provided in Appendix A. 


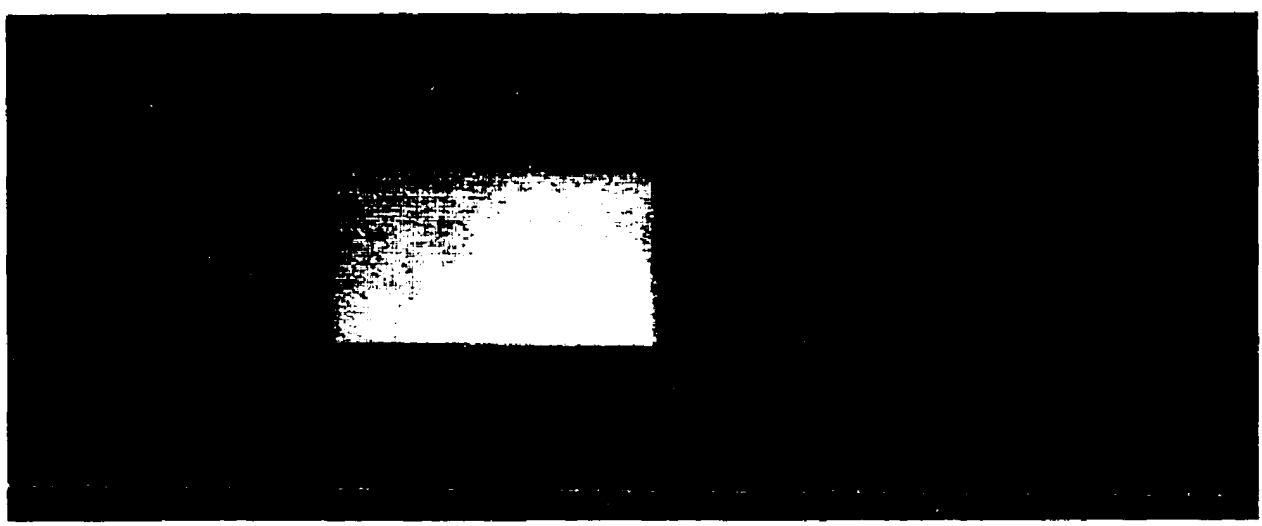

Figure 6 - Sample image of view cell contents (oriented on its side with the bottom of the cell towards the left side of the image)

There are two methods for determining liquid density. The first method requires calibration of density with grey scale intensity and a background image for each experiment. Abedi et al. (1999) have successfully calibrated the view cell for the systems that they studied. The calibration of density with intensity is a factor of many conditions including material carbon to hydrogen ratio and $x$-ray input voltage. Although this type of analysis is possible through careful calibration and many background readings, the extra effort and time is not justified for the purpose of this thesis.

An alternative method for measuring liquid density is available and is sufficiently accurate. This method calculates density by the dividing the liquid mass by the liquid volume. The liquid volume correlation easily and accurately provides the liquid volume. The liquid mass however, is more complicated. In an ideal case, one can assume that the liquid is composed of all the anthracene and $\mathrm{n}$-hexadecane, and that the mass of hydrogen in the liquid phase is negligible. This provides an over estimate of the true liquid density since a small fraction of the anthracene and $n$-hexadecane vaporize. The amount of vaporization can be estimated and accurate densities obtained. Sample calculations are provided in the appendix. This is the method chosen for density estimation.

Figure 7 summarizes the thirty experiments performed with anthracene $+n$-hexadecane + hydrogen. Seven of these experiments, (hollow circles), are not used for the quantitative density measurements since the images from these experiments were obtained differently than all other images. Use of these images in the quantitative analysis introduces 
significant errors; however, these images provide useful qualitative information, as none show liquid-liquid-vapour phase behaviour. All experiments were performed at approximately $646 \mathrm{~K}$ and range in pressure from $3.2 \mathrm{MPa}$ to $16.8 \mathrm{MPa}$. Anthracene composition on a hydrogen free basis ranges from $0 \mathrm{~mol} \%$ to $83.5 \mathrm{~mol} \%$; moreover, the total hydrogen was varied from $48.1 \mathrm{~mol} \%$ to $84.0 \mathrm{~mol} \%$. Anthracene and $\mathrm{n}$-hexadecane. with purity $>99 \%$, were provided by Sigma. Hydrogen, having a purity of $99.5 \%$, was obtained from BOC Gases.

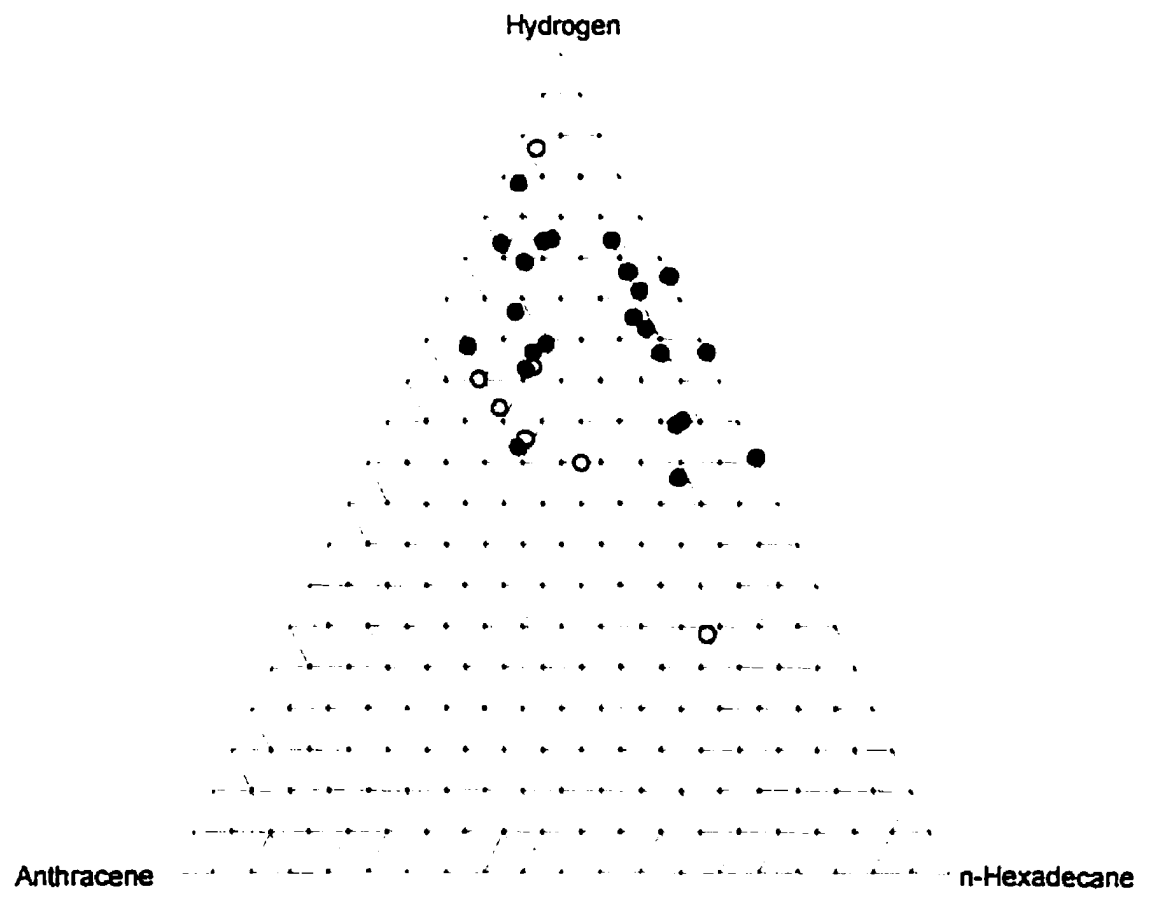

Figure 7 - Location in composition space (mole fraction) of experiments with anthracene, $\left(\bullet\right.$ used for density measurements; ${ }^{\circ}$ qualitative experiments.)

\section{Findings}

From direct observation, none of the 30 experiments showed liquid-liquid-vapour phase behaviour. Figure 8 presents liquid density as a function of hydrogen free anthracene composition at $5 \mathrm{MPa}$, (the complete series of nine figures for pressures from $5 \mathrm{MPa}$ to $13 \mathrm{MPa}$ in $1 \mathrm{MPa}$ increments can be found in Appendix B). The liquid densities closely follow Amegate's idealized case, and also support the direct observations. The same 
pattern was observed for all the pressure ranges studied. Had LLV phase behaviour arisen, three distinct density zones comprising of $\mathrm{L}_{1}, \mathrm{~L}_{1} \mathrm{~L}_{2}$, and $\mathrm{L}_{2}$ would be expected, and these are illustrated in Figure 9.

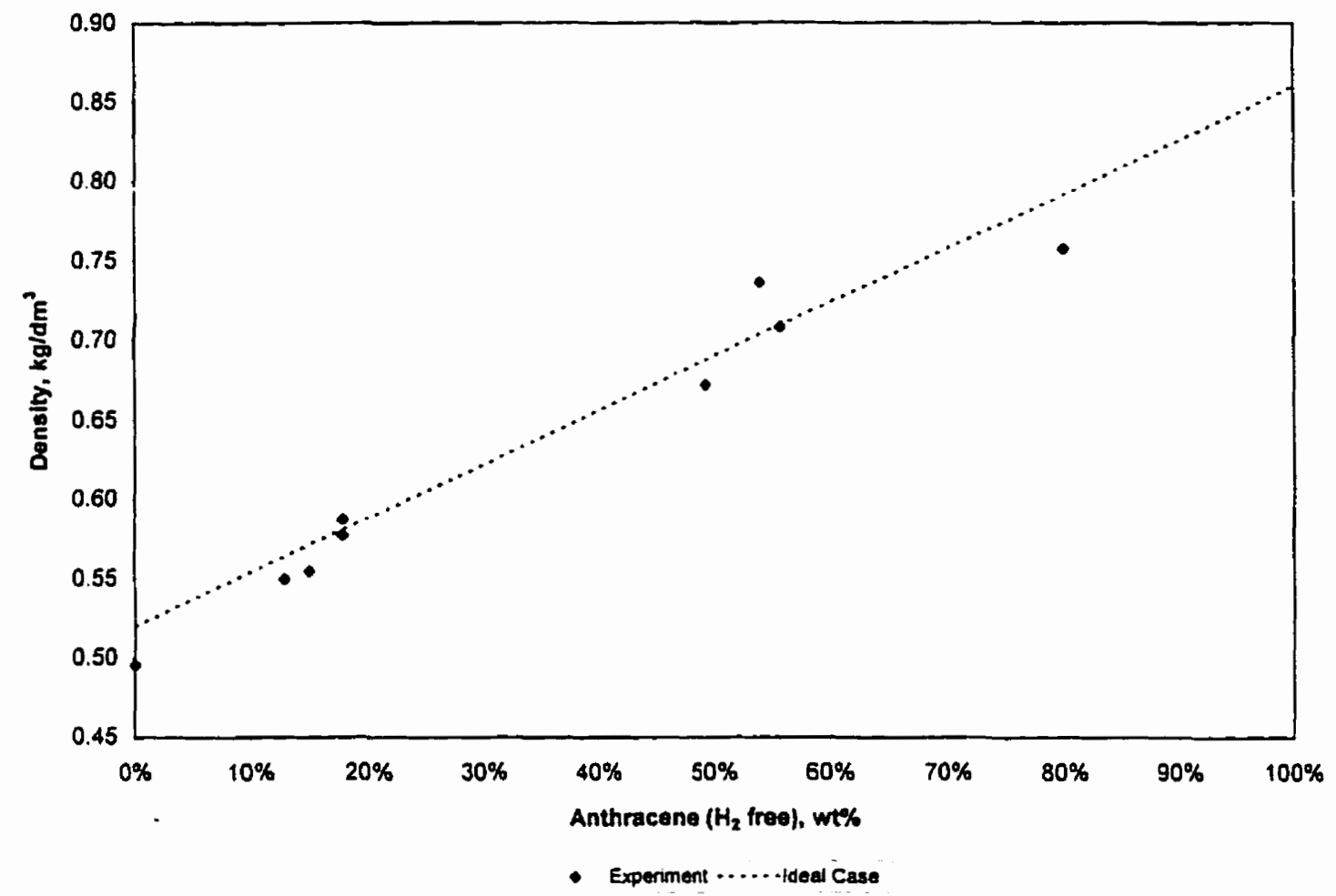

Figure 8 - Density measurements for anthracene + hexadecane +hydrogen at $646 \mathrm{~K}$ and $5 \mathrm{MPa}$

System pressure has a minor effect on liquid density for single component systems; however, for multicomponent system pressure has a major effect on the composition (thus indirectly on the liquid density for multicomponent systems). Also, if the composition changes enough for a liquid-liquid-vapour zone to appear, the liquid density can change dramatically. With some liquid-liquid-vapour zone spanning small pressure ranges, liquid phase splitting may go unnoticed if all data is processed together. Therefore, nine separate pressure ranges of $1 \mathrm{MPa}$ are used to report the liquid densities. The chosen $1 \mathrm{MPa}$ range satisfies the compromise between number of data available to observe trends and likeliness that only a fraction of data is within a liquid-liquid-vapour zone. 


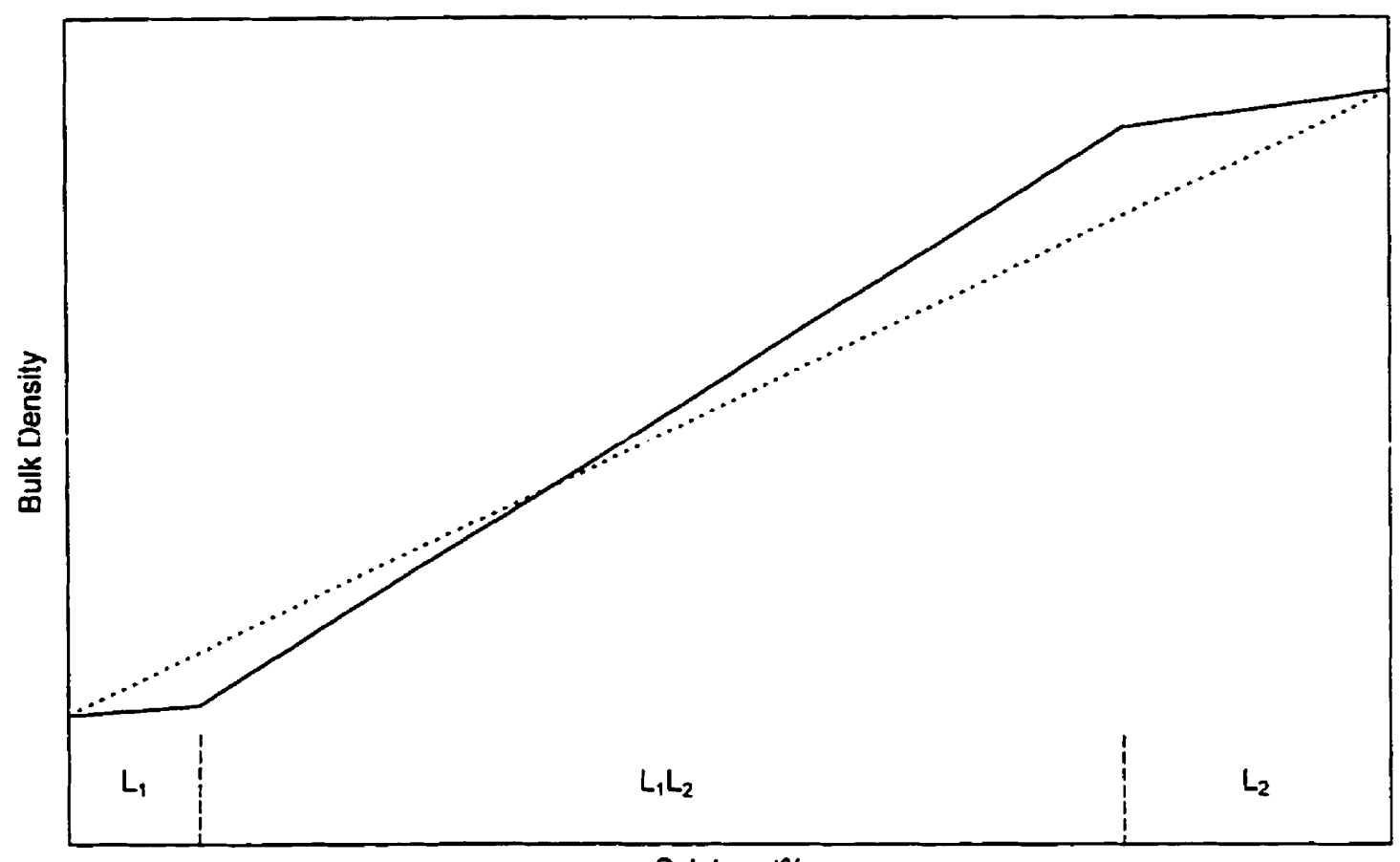

Solute, wt\%

-Non-ideal mixture with three phase eqilibrium $\therefore .$. Idealized Case

Figure 9 - Hypothetical case showing three distinct density zones if LLV phase behaviour is present.

The liquid density obtained for the binary n-hexadecane + hydrogen in the pressure range $50.9 \mathrm{MPa}$ to $127.1 \mathrm{MPa}$ and hydrogen composition ranging $14.0 \mathrm{~mol} \%$ to $36.6 \mathrm{~mol} \%$ at $646 \mathrm{~K}$ is $0.515 \mathrm{~g} / \mathrm{cm}^{3}$. Hydrogen has a negligible effect on the hexadecane liquid density since the mass ratio of hydrogen in the liquid phase is very small. Graaf et al. (1992) provide a correlation for hexadecane liquid density in the $374.6 \mathrm{~K}$ to $537.5 \mathrm{~K}$ range. Extrapolating to $646 \mathrm{~K}$ gives a predicted density of $0.519 \mathrm{~g} / \mathrm{cm}^{3}$. These values are in good agreement, thus validating the accuracy of the method used to determine liquid density from the view cell images.

The findings of the experiments with anthracene + hexadecane + hydrogen direct the study toward understanding the phase behaviour of alternative systems that arise due to coking reactions of anthracene or cracking reactions of hexadecane. This aspect is addressed in chapter 4 using computer simulated phase behaviour models. The following section is an experimental investigation of the pyrene + hexadecane + hydrogen system. 


\section{Pyrene $+n$-Hexadecane + Hydrogen}

In this section, phase behaviour experiments with pyrene + hexadecane + hydrogen are presented. The objective of these experiments was to determine whether the system was sufficiently asymmetric to exhibit Type III, Type II, or Type IV phase behaviour, (i.e. whether we could observe liquid-liquid-vapour behaviour for this system). The study uses pyrene since its price is low relative to the expected reaction products and intermediates of anthracene, which are not easily isolated and would put the cost of one experiment at over $\$ 10000$ for materials alone!

\section{Data Collection and Analysis}

The equipment and set-up used to study the phase behaviour of the pyrene system is the same as the anthracene system; however, a density analysis was not performed. The objective is simply observe liquid-liquid-vapour on captured images near the solidus curve for pyrene $+n$-hexadecane mixtures. Eight experiments were performed. The pyrene composition, on a hydrogen free basis, ranged from $49.1 \mathrm{~mol} \%$ to $57.5 \mathrm{~mol} \%$, and the hydrogen content varied from $0.0 \mathrm{~mol} \%$ to $29.4 \mathrm{~mol} \%$. Operating conditions for each pyrene experiment are summarized in Table 1. Pyrene, with a purity of $>99 \%$, was obtained from Caledon.

Table 1 - Pyrene phase equilibria experiments.

\begin{tabular}{cccccccc}
\hline Experiment & $\begin{array}{c}\text { Pyrene } \\
\text { mol\% }\end{array}$ & $\begin{array}{c}\text { Hexadecane } \\
\text { mol\% }\end{array}$ & $\begin{array}{c}\text { Hydrogen } \\
\text { mol\% }\end{array}$ & $\begin{array}{c}\text { Minimum } \\
\text { Temperature } \\
K\end{array}$ & $\begin{array}{c}\text { Maximum } \\
\text { Temperature } \\
K\end{array}$ & $\begin{array}{c}\text { Minimum } \\
\text { Pressure } \\
k P a\end{array}$ & $\begin{array}{c}\text { Maximum } \\
\text { Pressure } \\
\mathrm{kPa}\end{array}$ \\
\hline 1 & $46.20 \%$ & $47.86 \%$ & $5.94 \%$ & 388 & 578 & $\max$ & $\max$ \\
2 & $44.27 \%$ & $45.86 \%$ & $9.87 \%$ & 393 & 653 & $\max$ & $\max$ \\
3 & $44.27 \%$ & $45.86 \%$ & $9.87 \%$ & 398 & 404 & 356 & 777 \\
4 & $41.65 \%$ & $43.15 \%$ & $15.20 \%$ & 394 & 395 & 584 & 1301 \\
5 & $39.36 \%$ & $40.77 \%$ & $19.87 \%$ & 390 & 396 & 811 & 1770 \\
6 & $34.66 \%$ & $35.90 \%$ & $29.44 \%$ & 386 & 430 & 1218 & 2990 \\
7 & $57.53 \%$ & $42.47 \%$ & $0.00 \%$ & 392 & 418 & 34 & 84 \\
8 & $48.88 \%$ & $36.08 \%$ & $15.04 \%$ & 403 & 454 & 1280 & 1535 \\
\hline
\end{tabular}

For experiment 1 and experiment 2, the bellows was set at its lowest position, (giving the maximum pressure the cell can obtain at the temperature and composition studied), and the temperature was ramped. It was hoped that the system would pass through a high- 
pressure high-temperature LLV zone characteristic of Type III or Type IV phase behaviour.

Experiments 3 to 8 study temperatures at or slightly higher than the expected melting temperature of the mixture $(384 \mathrm{~K})$. This temperature is predicted by procedures outlined by Shaw and Bẻhar, (2000). This low temperature region was studied because Type II phase behaviour was expected from preliminary phase equilibrium models. The pressures range from the minimum to the maximum pressure attainable for each experiment, and are strongly dependent on the amount of hydrogen in the vessel. Thus, low hydrogen composition experiments study lower pressure ranges.

\section{Findings}

Experiments 1 and 2, with hydrogen mole fractions 0.0594 and 0.0987 respectively, show no evidence of liquid-liquid-vapour phase behaviour for a pyrene to $n$-hexadecane weight ratio of 0.463 in the temperature range of 388 to $653 \mathrm{~K}$. The pressure conditions were not recorded as the volume was fixed and the ramping temperature resulted in changing pressure.

Experiments 3 to 8 also did not show any conclusive evidence that liquid-liquid-vapour phase behaviour exists for the conditions studied; however, some interesting phase behaviour was observed. At temperatures near the expected melting temperature of the mixture $(384 \mathrm{~K})$, a solid dispersion is present. Once the temperature in the cell reaches $433 \mathrm{~K}$ no solid is present and the contents must be cooled to $386 \mathrm{~K}$ before the crystals reform. Figure 10 shows data for one experiment exhibiting a dispersed solid phase. The ordinate gives an indication of the vertical position in the view cell. The data show the intensity and the associated derivative of the $\mathrm{X}$-rays passing through a single vertical cross-section of the cell. Since intensity is inversely proportional to density, lower intensity values represent denser material; moreover, significant jumps in intensity and the associated peak in the derivative represents an interface between two materials with different densities. The data in this figure identifies four materials with different densities: the cell bottom, the solid dispersion, the liquid phase, and the vapour phase, with respective intensity measurements of $0,75,95$, and 225 . 


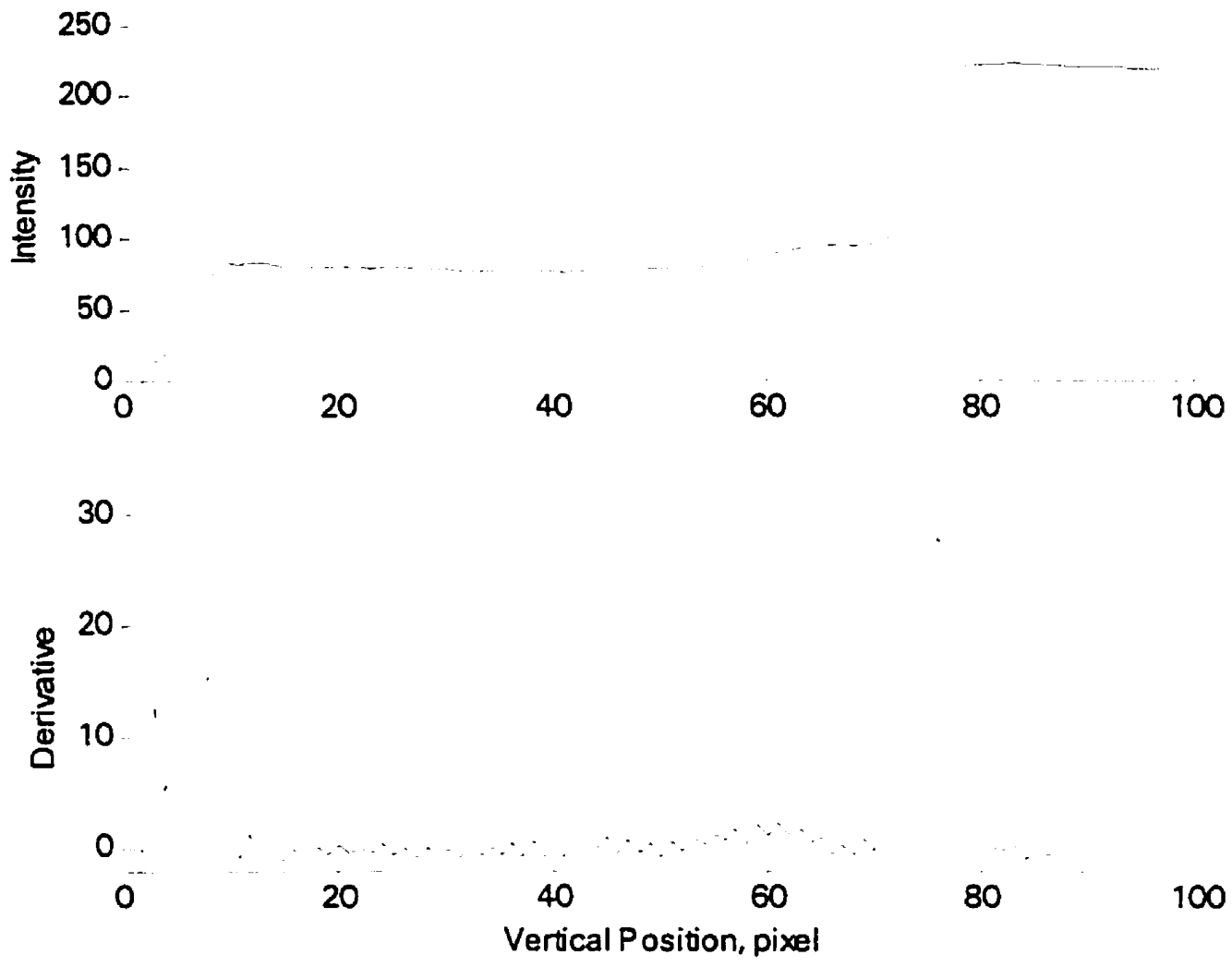

Figure 10 - Intensity data showing changes in the relative density of the contents of the view cell for pyrene + hexadecane at $120^{\circ} \mathrm{C}$ and $4.9 \mathrm{psia}$

Figure 11 shows the relative amount of solid to liquid present at different temperatures observed in experiment 7 . Since the solid is dispersed and liquid fills the dead volume between the settled crystals, it is difficult to make any conclusions on the solid density or the amount present. The solid/liquid interface decreases rapidly as the temperature increases; this is expected since the solid crystals are melting. There are two reasons for the significant scatter in these data: the solid does not settle as a flat interface rather as a mound of solid crystals, and a portion of the cell that coincides with the location of the interface at some temperatures is obscured by the stirrer bar. The liquid/vapour interface increases gradually with increasing temperature, as expected, due to the slight decrease in liquid density. There is very little scatter in these data, since the location of theliquid/vapour interface is easy to determine from the X-ray images 


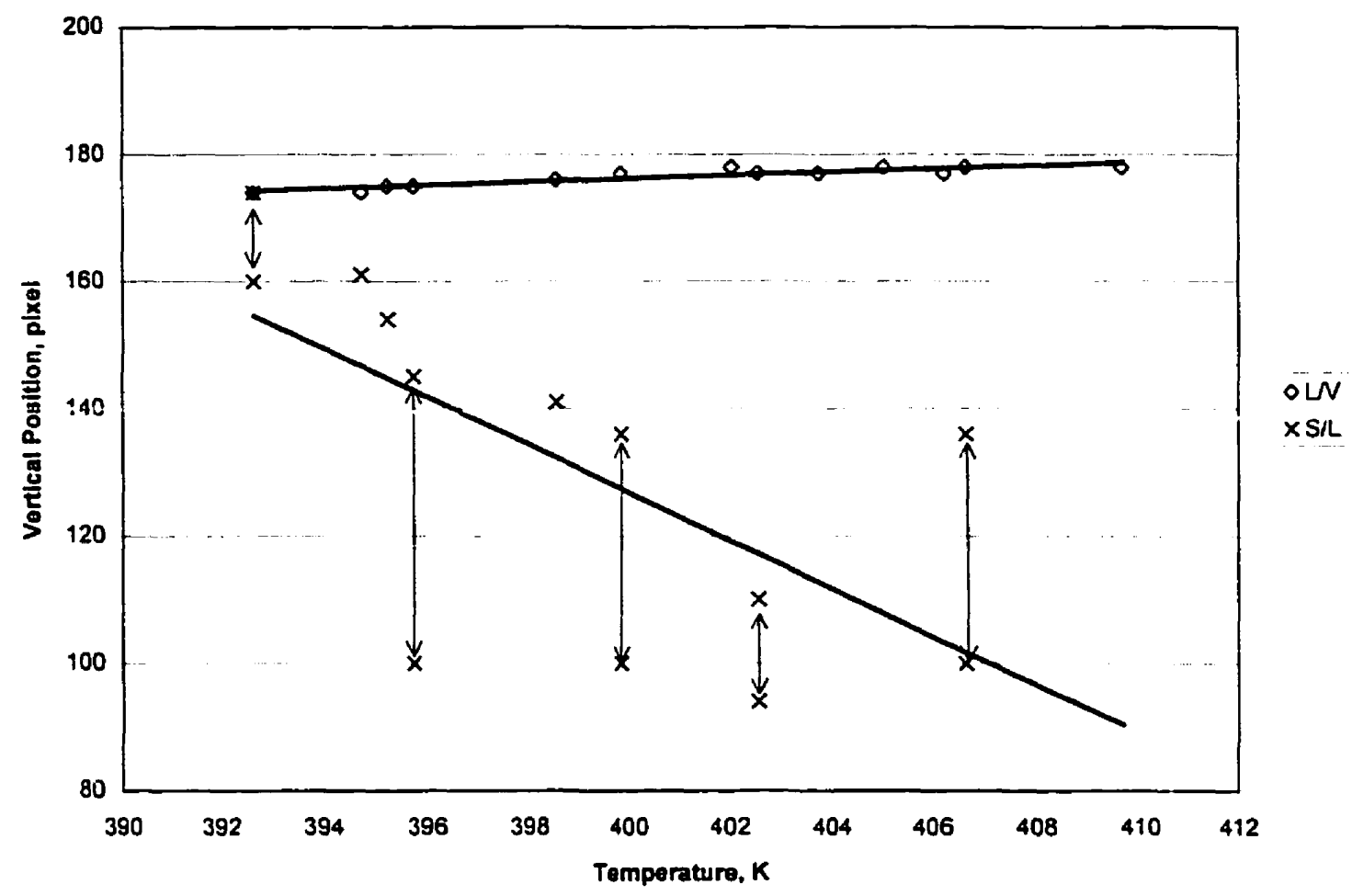

Figure 11 - Location of liquid-vapour and solid-liquid boundaries as a function of temperature for pyrene + hexadecane

\section{Summary of Experimental Findings}

The experimental work with anthracene + hexadecane + hydrogen and pyrene + hexadecane + hydrogen show that:

- The system anthracene + hexadecane + hydrogen does not exhibit liquid-liquidvapour phase behaviour at $646 \mathrm{~K}$.

- Anthracene + hexadecane density measurements (on a hydrogen free basis) are provided and show close agreement with idealized mixing and available liquid density data, supporting the observation that liquid-liquid-vapour phase behaviour is not present in this mixture.

- The mixture pyrene + hexadecane + hydrogen also does not exhibit liquid-liquidvapour phase behaviour near the solidus curve indicating that it does not exhibit Type II, Type III, or Type IV phase behaviour. 


\section{Chapter 4 - Phase Equilibria Models of PAH's with n-Alkanes}

\section{CMG Software and Modelling Parameters}

Phase equilibrium calculations were performed with the Computer Modelling Group's (CMG) phase property program WinProp. This software uses the Peng-Robinson EOS in conjunction with the tangent plane criterion (Michelsen, 1982) to perform phase equilibrium calculations. CMG WinProp has been successfully used to model complex phase equilibria in the past (Shaw et al., 1993). WinProp requires the input of critical pressure, critical temperature, acentric factor, and molecular weight for hydrocarbon components. Other optional data, including critical volume, critical compressibility, specific gravity, and normal boiling point, can be entered improving estimates of interaction parameters, enthalpy coefficients, and compressibility factors. All optional data that was available was entered as inputs. Input data and parameters are presented in Table 2.

Component properties for most of the species studied by this thesis have been tabulated by reputable sources; however, properties for some species have not been measured. Estimation of these values becomes a necessity. For the n-alkanes with carbon numbers greater than 20, critical temperature, critical pressure, and acentric factor have been estimated from correlations presented by Stamataki and Tassios (1998). In this carbon number range critical temperature, and acentric factor are correlated very well; while, values for the critical pressure are only satisfactory. Since no other values are at hand, these are the best available.

The critical pressure, critical temperature, and normal boiling point for hexaphene, has been estimated by the Joback group contribution method, (Reid et al., 1987). The acentric factor is determined from the Lee-Kesler vapour pressure relations, (Reid et al.. 1987). These methods of determining the critical properties and the acentric factor do not distinguish between isomers; therefore, the affect of molecule geometry is not modelled. The melting point of hexaphene is $324^{\circ} \mathrm{C}$ (Harvey, 1997). 
Table 2 - Critical properties, acentric factors, specific gravities, and normal boiling points used for computer simulations.

\begin{tabular}{|c|c|c|c|c|c|c|c|c|}
\hline Component & $\begin{array}{c}\mathrm{MW} \\
(\mathrm{g} / \mathrm{mol})\end{array}$ & $\begin{array}{c}P_{\varepsilon} \\
\text { (bar) }\end{array}$ & $\begin{array}{l}T_{\mathrm{s}} \\
(\mathrm{K})\end{array}$ & $\begin{array}{c}v_{c} \\
(\mathrm{ml} / \mathrm{mol})\end{array}$ & $=$ & $\omega$ & S.G. & $\begin{array}{l}T_{b} \\
(\mathrm{~K})\end{array}$ \\
\hline anthracene & 178.234 & 29.0 & 869.3 & 554 & & 0.4961 & & 613.1 \\
\hline phenanthrene & 178.234 & 33.0 & 873.0 & 554 & & 0.54 & & 613.0 \\
\hline pyrene & 202.3 & 26.0 & 938.2 & & & 0.83 & & 666.15 \\
\hline hexaphene & 328.42 & 20.3 & 1210 & & & 0.96 & & 935.78 \\
\hline$n-c 30$ & +22.820 & 7.6 & 842.5 & & & 1.26 & & \\
\hline$n-c 29$ & 408.793 & 7.9 & 836.2 & & & 1.24 & & \\
\hline$n-c 28$ & 394.766 & 8.2 & 827.5 & & & 1.19 & & \\
\hline$n-c 27$ & 380.739 & 8.6 & 817.5 & & & 1.14 & & \\
\hline$n-c 26$ & 366.713 & 9.1 & 811.2 & & & 1.10 & & \\
\hline$n-c 25$ & 352.686 & 9.6 & 805.0 & & & 1.06 & & \\
\hline$n-c 24$ & 338.659 & 10.0 & 800.0 & & & 1.04 & & \\
\hline$n-c 23$ & 324.632 & 10.4 & 790.0 & & & 1.00 & & \\
\hline$n-c 22$ & 310.605 & 10.9 & 780.0 & & & 0.95 & & \\
\hline$n-c 21$ & 296.579 & 11.3 & 767.5 & & & 0.94 & & \\
\hline n-cicosane & 282.556 & 11.1 & 767 & & & 0.907 & & 617 \\
\hline n-nonadecane & 268.529 & 11.1 & 756 & & & 0.824 & & $603 . !$ \\
\hline n-octadecane & 254.504 & 12.0 & 748 & & & 0.790 & & 589.5 \\
\hline n-heptadecane & 240.475 & 13.0 & 733 & 1000 & & 0.770 & 0.778 & 575.2 \\
\hline n-hexadecane & 226.448 & $1+.1$ & 722 & 960 & & 0.742 & 0.773 & 560.0 \\
\hline n-pentadecane & 212.421 & 15.2 & 707 & 880 & 0.23 & 0.706 & 0.769 & $5+3.8$ \\
\hline n-tetradecane & 198.394 & 14.4 & 693 & 830 & 0.23 & 0.581 & 0.763 & 526.7 \\
\hline n-tridecane & 184.367 & 17.2 & 676 & 780 & 0.24 & 0.619 & 0.756 & 508.6 \\
\hline n-dodecane & 170.34 & 18.2 & 658.2 & 713 & 0.24 & 0.575 & 0.748 & 489.5 \\
\hline n-undecane & 156.313 & 19.7 & 638.8 & 660 & 0.24 & 0.535 & 0.740 & +69.1 \\
\hline n-decane & 142.286 & 21.2 & 617.7 & 603 & 0.249 & 0.489 & 0.730 & 447.3 \\
\hline$n$-nonane & 128.259 & 22.9 & 594.6 & 548 & 0.26 & 0.445 & 0.718 & +24.0 \\
\hline n-octane & 114.232 & 24.9 & 568.8 & 492 & 0.259 & 0.398 & 0.703 & 398.8 \\
\hline n-heptane & 100.205 & 27.4 & 540.3 & +32 & 0.263 & 0.349 & 0.684 & 371.6 \\
\hline n-hexane & 86.178 & 30.1 & 507.5 & 370 & 0.264 & 0.299 & 0.659 & 341.9 \\
\hline$n$-pentane & 72.151 & 33.7 & 469.7 & 304 & 0.263 & 0.251 & 0.626 & 309.2 \\
\hline$n$-butane & 58.124 & 38.0 & +25.2 & 255 & 0.274 & 0.199 & 0.579 & 272.7 \\
\hline propane & +4.094 & 42.5 & 369.8 & 203 & 0.281 & 0.153 & & 231.1 \\
\hline ethane & 30.070 & 48.8 & 305.4 & 148.3 & 0.285 & 0.099 & & 184.6 \\
\hline methane & 16.043 & 46.0 & 190.4 & 99.2 & 0.288 & 0.011 & & 111.6 \\
\hline hydrogen & 2.016 & 13.0 & 33.2 & 65.1 & 0.306 & -0.218 & & 14.0 \\
\hline
\end{tabular}

la. All properties of methane through to n-eicosane from Reid et al., 1987

1b. Exception to Note la: $v_{c}$ of n-hexadecane from Octavian Micro Development Inc. database. 1997.

2. All properties of hydrogen from Reid et al.. 1987.

3. $T_{c}, v_{c}$ and $T_{b}$ of anthracene and phenanthrene from Reid et al.. 1987.

4. $P_{c}$ and $\omega$ of anthracene from Octavian Micro Development Inc. database. 1997.

5. $P_{c}, T_{c}$ and $\omega$ estimates of n-alkanes $\mathrm{c} 21$ through $\mathrm{c} 30$ from Stamataki \& Tassios, 1998.

6. $P_{c s}, T_{c}$ and $\omega$ of pyrene and $P_{c}$ and $\omega$ of phenanthrene from Park et al.. 1996.

7. $T_{b}$ of pyrene from Bjorseth. 1983.

8. $P_{c}, T_{c}$ and $T_{b}$ of hexaphene estimated by Joback group contribution method. Reid et al.. 1987.

9. $\omega$ of hexaphene estimated by Lee-Kesler vapour pressure relations, Reid et al., 1987.

\section{Binary Interaction Parameters for PAH's + n-Alkanes}

Standard binary interaction parameters, estimated using Equation 14, for alkane-alkane systems were used in the equilibrium calculations without correction. However, the standard interaction parameters, available in simulators, for polycyclic aromatic-alkane pairs were unsatisfactory. These values are one or two orders of magnitude smaller than 
those indicated in and do not fit the phase equilibrium data. Interaction parameters for polycyclic aromatic-alkane systems, reported in Table 3 were obtained either from the literature (for benzene, naphthalene, and phenanthrene with methane) or from the regression of solid-fluid equilibrium data (for anthracene with methane, ethane, propane and $\mathrm{n}$-pentane) or from LLV data (phenanthrene with propane).

The regression equations for solid-fluid equilibrium data are presented in Appendix C. Although many authors suggest that temperature dependent interaction parameters provide better results, the temperature dependence of the binary interaction parameters was not investigated. This is a consequence of the limited number of data available at specific temperatures. Also, since CMG WinProp does not accept temperature dependent interaction parameters, ultimately an averaged value would be used. Lumping all the data together produces a much larger data set and provides a weighted average of the calculated interaction parameter. Sample solubility fits for anthracene in propane, superimposed on the available data are provided in Figure 12. Similar fits are observed for the other data sets regressed in this work. Detailed results are presented in Appendix $C$. The solid-vapour phase boundaries associated with the standard interaction parameter obtained with equation 14 are also plotted in Figure 12. The standard value fails to accurately predict the solid-vapour boundary in most cases.

The interaction parameter for phenanthrene with propane has been fit to the liquid-liquidvapour data collected by Peters et al., (1989). In order to fit this data first the minimum interaction parameter that allows for the observed SLLV behaviour was determined. Any value smaller than 0.005 fails to predict the SLLV behaviour; moreover, smaller values of the interaction parameter moves the predicted K-point closer to the experimental point. Therefore the best phenanthrene-propane interaction parameter is 0.005 , which predicts the $\mathrm{K}$-point to within $5 \mathrm{~K}$ and 5 bar (an acceptable fit for K-points correlated with cubic equations of state).

Table 3 also shows a maximum value of -0.03 for the pyrene-hexadecane interaction parameter. More details on the determination of this value follow. 
Table 3 - Binary interaction parameters for PAH + n-alkane pairs.

\begin{tabular}{ccccc}
\hline Solute & Solvent & $k_{i j}$ & Temperature Range & $\begin{array}{c}\text { Equilibrium Data } \\
\text { Source }\end{array}$ \\
\hline Benzene & Methane & 0.0786 & $323.2-423.2 \mathrm{~K}$ & Darwish ct al. (1994) \\
\hline Naphthalene & Methane & 0.1146 & $373.2-423.2 \mathrm{~K}$ & $\begin{array}{c}\text { Darwish et al. (1994) } \\
\text { Hong et al. (1993) }\end{array}$ \\
& Methane & 0.101 & $\mathrm{~N} / \mathrm{A}$ & RoBling \& Franck (1983) \\
\hline Anthracene & Methane & $0.123^{\circ}$ & $298-430 \mathrm{~K}$ & Johnston et al. (1982) \\
& Ethane & $0.093^{\circ}$ & $303.2-343.2 \mathrm{~K}$ & RoBling \& Franck (1983) \\
& Propane & $0.107^{\circ}$ & $300-440 \mathrm{~K}$ & RoBling \& Franck (1983) \\
& n-Pentane & $n n 70^{\circ}$ & $293-323 \mathrm{~K}$ & Darwish et al. (1994) \\
& Methane & 0.1419 & $383.2-423.2 \mathrm{~K}$ & Peters et al. (1989) \\
\hline Phenanthrene & Propane & $0.005^{\circ}$ & $351.2-377.3 \mathrm{~K}$ & Darwish et al. (1994) \\
& Methane & 0.18 & $433.2 \mathrm{~K}$ & This work \\
\hline
\end{tabular}

Notes:

* Regressed in this work. Details in Appendix C

* Fit in this work to LLV data.

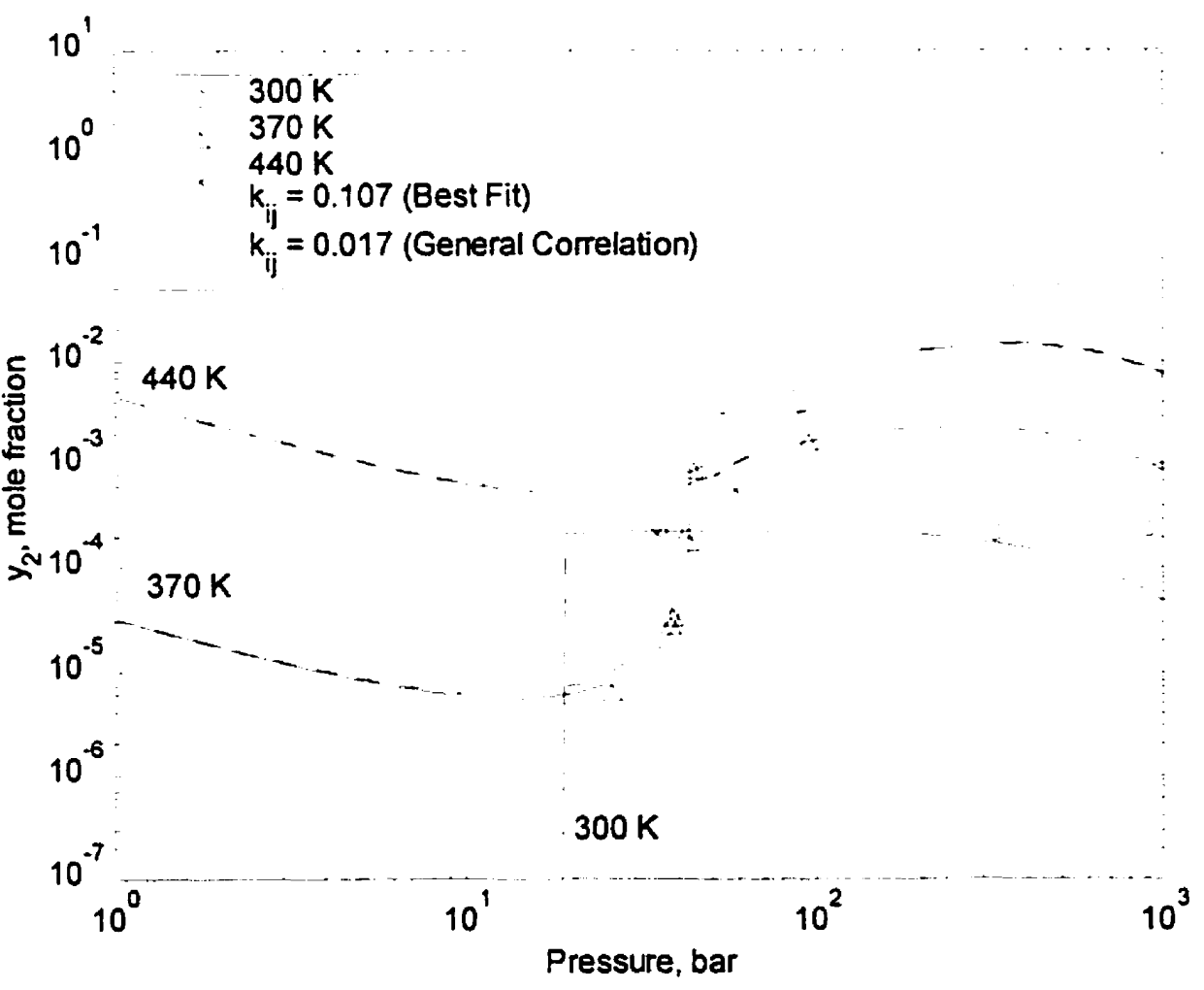

Figure 12 - Calculated solubiltiy model for anthracene + propane mixture at $420 \mathrm{~K}$ superimposed on available data. 
The anthracene $+n$-alkane interaction parameters have been correlated using a critical molar volume ratio,

$$
\zeta=\frac{2 v_{c i}^{1 / 6} v_{c j}^{1 / 6}}{v_{c i}^{1 / 3}+v_{c i}^{1 / 3}}
$$

This ratio is the same ratio used by CMG WinProp. Figure 13 presents the anthracene + $\mathrm{n}$-alkane interaction parameter correlation and shows a downward trend as the relative size of the two components become similar: it reaches a minimum value of approximately 0.08 when the solvent and anthracene have the same critical volume. Transforming the ordinate from the critical-molar-volume ratio to the carbon number of the solvent (using a linear fit through the available $k_{i j}$ 's for anthracene with n-alkanes) provides a better visualization of the trend. As seen in Figure 14, the anthracene + methane interaction parameter is large. As the size of the solvent molecule increases, the interaction parameter decreases and reaches a minimum at approximately nonane. As the solvent size continues to increase. the interaction parameter increases again. General interaction parameter correlations do follow this relative size trend; however they are unable to predict the trends determined by the differing structures of the two molecules. These standard correlations would predict a minimum value of zero at $\zeta=1$. Another example is the case of anthracene vs. phenanthrene + propane. Anthracene and phenanthrene have identical critical volumes, but their interaction parameters with propane are quite different. By correlating interaction parameters for families of molecules these structurally related problem are minimized. Including all available interaction parameters for PAH's + n-alkane systems creates a bias in the correlation since most of the data for PAH's other than anthracene are with methane. The results are also presented in Figure 13.

Hydrogen-hydrocarbon interactions are receiving a lot of attention recently since hydrogen is required for many industrial applications. However determining meaningful binary interaction parameters for hydrogen-hydrocarbon systems is difficult due to an apparent strong temperature dependence and low modelling sensitivity at higher temperatures. As an example, methane + hydrogen binary interaction parameters have been determined at $170 \mathrm{~K}$ by two authors, (Chokappa et al., 1985; Moysan et al., 1983). 
Chokappa determined a value of -0.163 , and Moysan determined a value of 0.15 . Contradicting results like these make it difficult to choose hydrogen-hydrocarbon interaction parameters. Moysan et al., (1983), performed a sensitivity analysis on hydrogen-hydrocarbon interaction parameters and determined that a single value of 0.485 gives acceptable correlation of the vapour-liquid equilibria at $190^{\circ} \mathrm{C}$, regardless of the solvent's paraffinic or aromatic nature. A hydrogen-hydrocarbon interaction parameter of 0.485 is used in all models containing hydrogen presented in this thesis.

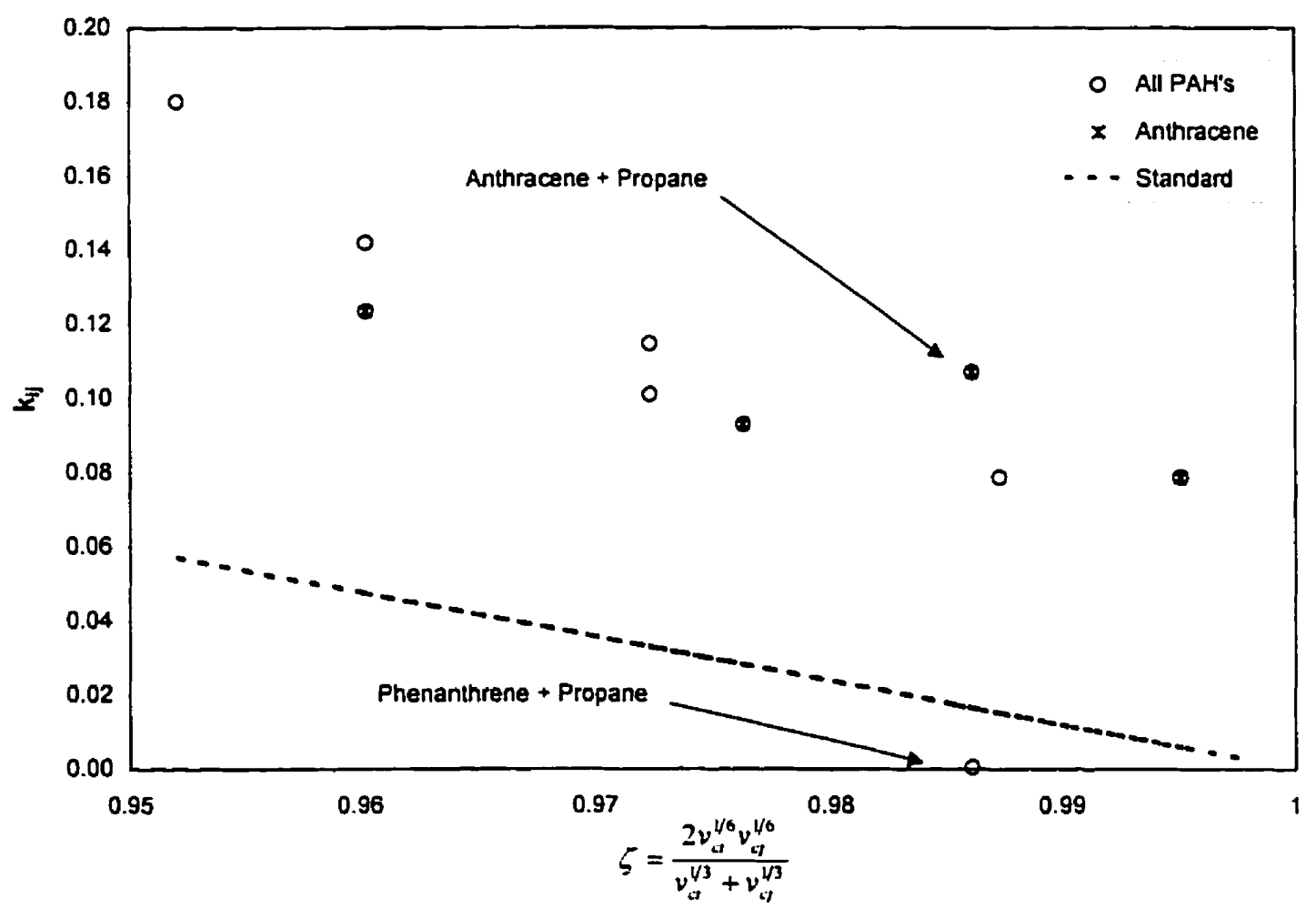

Figure 13 - P-R binary interaction parameter correlation for anthracene + nalkanes and PAH's + n-alkane families. 


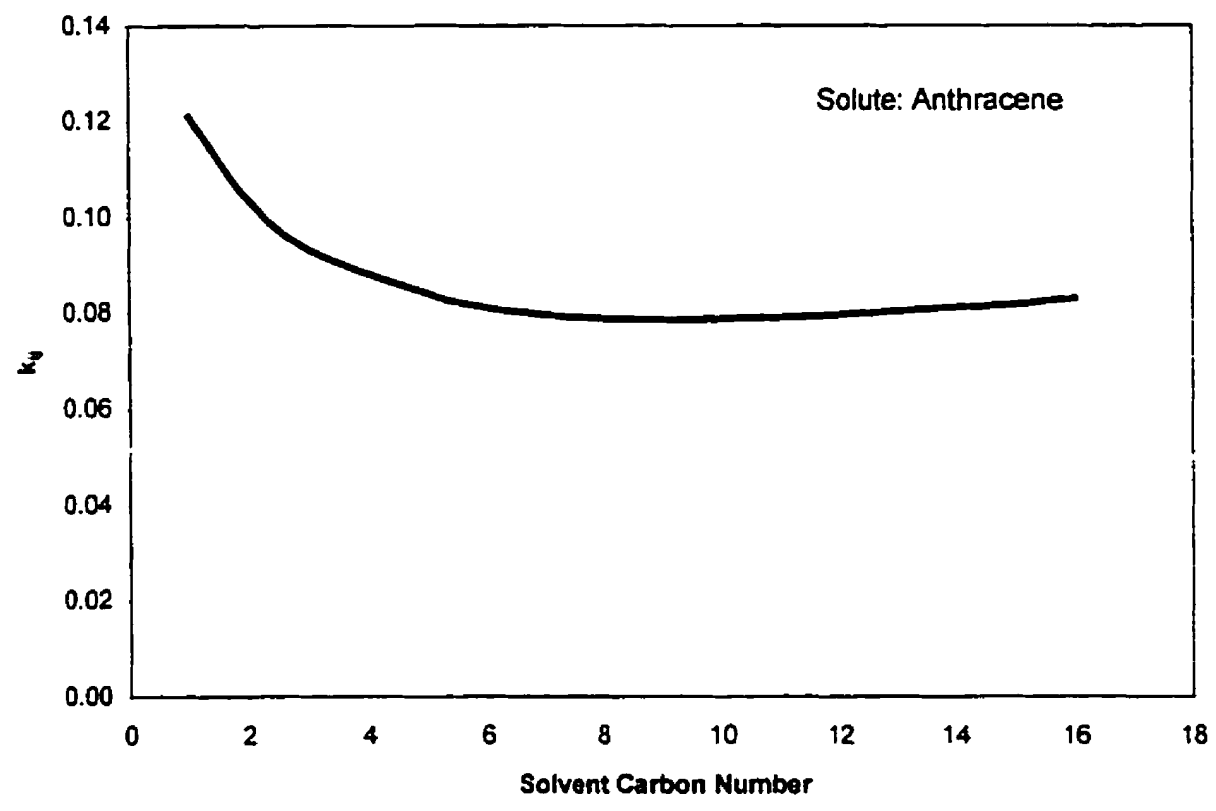

Figure 14 - Binary interaction parameters for anthracene + pseudo n-alkanes.

\section{Anthracene Critical Locus}

The predicted phase behaviour of anthracene $+n$-alkane binary and pseudo binary mixtures is presented in Figures 14 and 15. An anthracene + n-alkane interaction parameter of 0.08 is used. This value is chosen since Figure 14 predicts $k_{i j}=0.08 \pm 0.01$ for butane, pentane, hexane and heptane. The SLLV line is estimated by a method outlined by Shaw and Behar, (2000). The estimated temperature of the SLLV line is $443 \pm 5 \mathrm{~K}$. For mixtures of anthracene + (methane, ethane, propane, or butane) $L_{1} L_{2} V$ phase behaviour is suppressed and the phase projection depicted by Figure $4 \mathrm{~d}$ is predicted. For anthracene + pentane the phase projection depicted by Figure $4 \mathrm{c}$ is predicted. For anthracene + hexane the phase projection depicted by Figure $4 \mathrm{a}$ is predicted. For mixtures of anthracene + heptane and beyond Type II phase behaviour (where the $\mathrm{L}_{1} \mathrm{~L}_{2} \mathrm{~V}$ phase behaviour is suppressed by solid formation) is predicted. Therefore liquid-liquid-vapour phase behaviour is only possible for conditions within the region of limited miscibility, which is enclosed by the SLLV line, the K-locus, and the Llocus. In summary, $\mathrm{L}_{1} \mathrm{~L}_{2} \mathrm{~V}$ phase behaviour is predicted for mixtures of anthracene + ( -butane to -hexane). This supports the experimental finding that anthracene + hexadecane does not exhibit complex phase behaviour. 


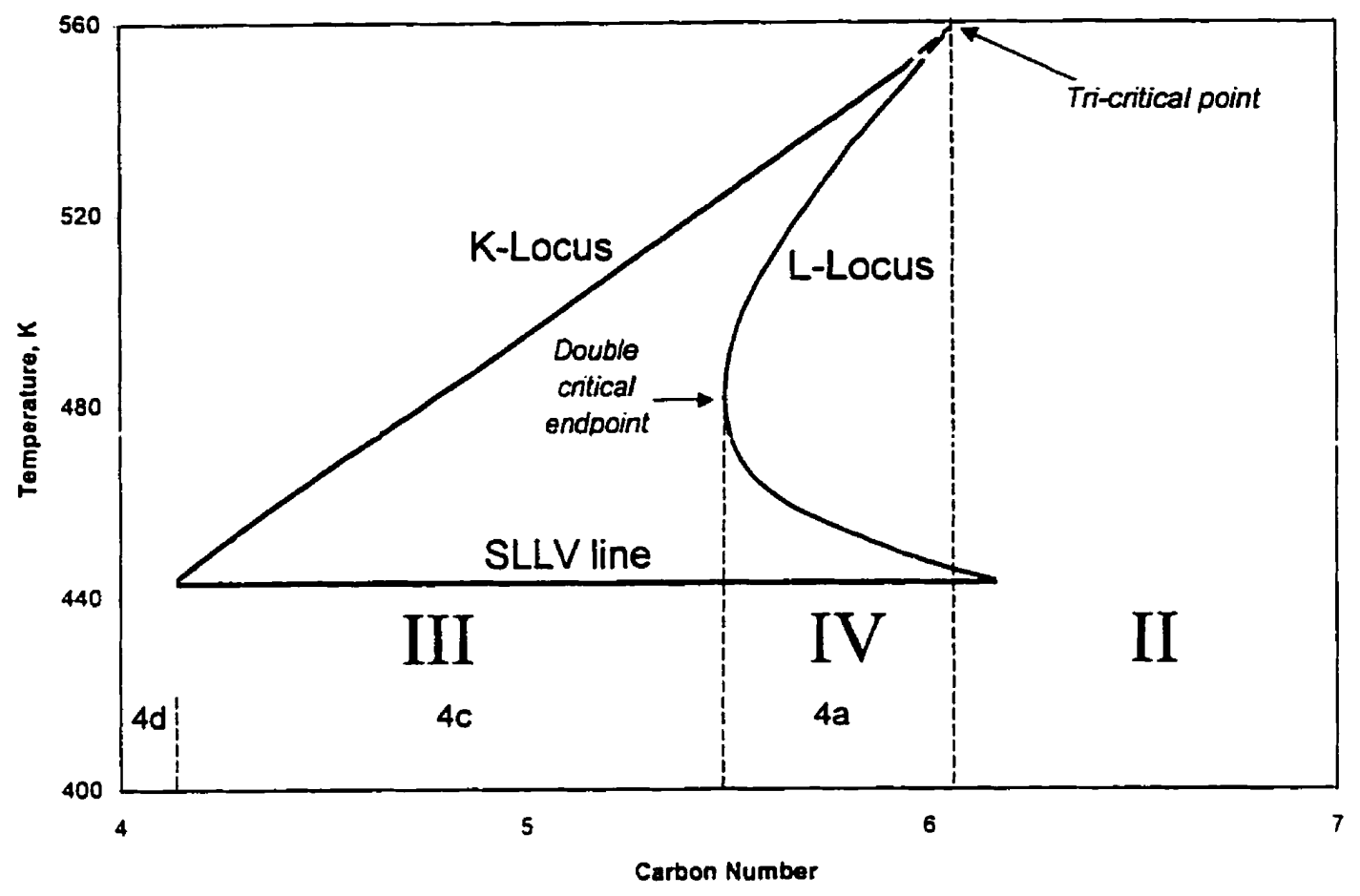

Figure 15 - Critical temperature loci for anthracene + n-alkane mixtures

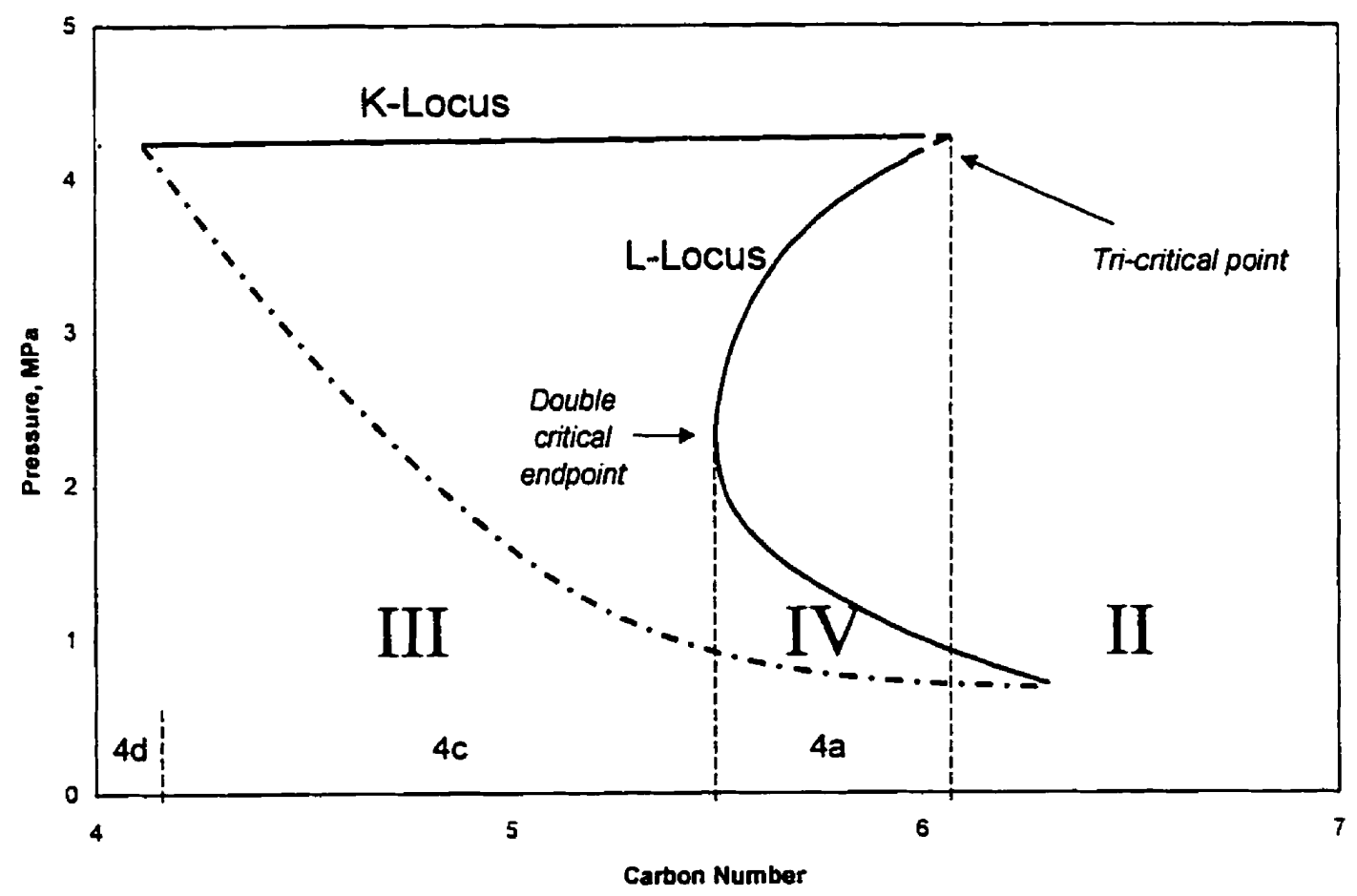

Figure 16 - Critical pressure loci for anthracene + n-alkane mixtures 


\section{Effect of Hydrogen on Critical Loci}

The above models are all determined in the absence of hydrogen; however, all hydrogenation processes use hydrogen to delay coke formation. The effect of hydrogen on the predicted phase behaviour is illustrated in Figure 17.

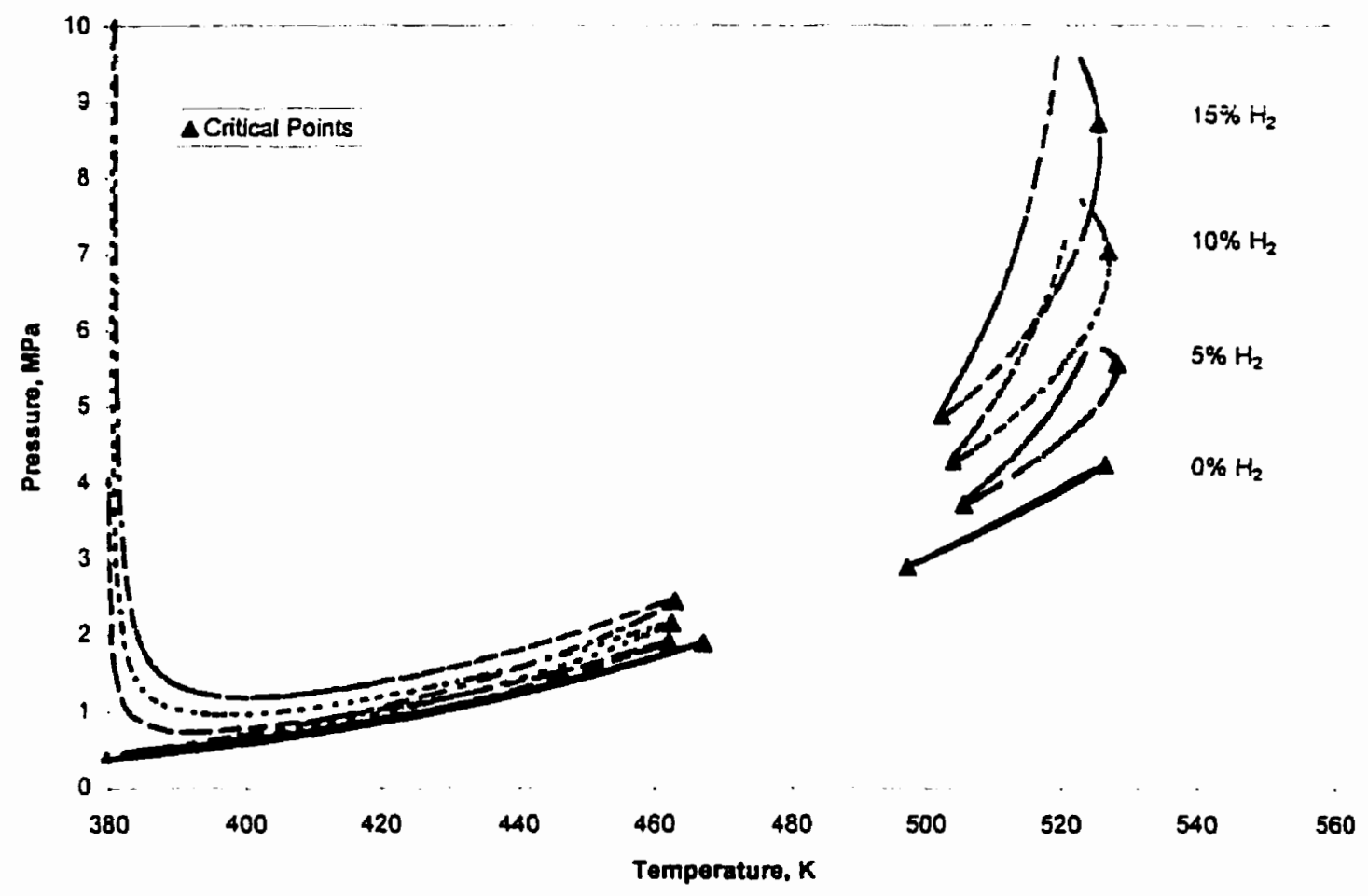

Figure 17 - $\mathrm{P}-\mathrm{T}$ diagram for anthracene + pseudo n-alkane $(\mathrm{CN}=5.6)$ showing the effect of hydrogen on $L_{1} L_{2} V$ phase boundary and location of $K$ - and $L$-points

Hydrogen does not alter the temperature of the K- and L-points significantly. It only affects the pressure range over which $L_{1} L_{2} V$ phase behaviour is predicted, and the magnitude of the effect is a function of the hydrogen mole fraction. Clearly, hydrogen does not change the type of phase behaviour exhibited. It only affects the pressure and range of the $\mathrm{L}_{1} \mathrm{~L}_{2} \mathrm{~V}$ region. Therefore, modelling of hydrogenation systems can be done without the added complexity of hydrogen in the mixture. Addition of hydrogen in the model is only necessary to predict the pressure range where $L_{1} L_{2} V$ phase behaviour arises. 
Since hydrogen does not alter the temperature of the $\mathrm{K}$ - and L-points, hydrogen does not raise the L-locus line in Figure 15 above the SLLV line for mixtures of anthracene + hexadecane. Again, this is consistent with the available experimental data showing complete liquid miscibility of anthracene + hexadecane + hydrogen mixtures at typical hydrogenation conditions.

The asymmetry of the mixture affects the type of phase behaviour observed and predicted. The asymmetry between anthracene and hexadecane is not large enough for liquid-liquid-vapour phase behaviour to occur. Thus the search for demixing phenomena, leading to rapid coke formation, must focus on larger coke precursors and anthracene dimers, etc. arising during coking reactions.

\section{Pyrene Critical Locus}

Since anthracene $+n$-hexadecane mixtures are not able to exhibit complex phase behaviour. one may ask how large a coke precursor needs to be before complex phase behaviour can exist. Anthracene is a three-ringed polycyclic aromatic hydrocarbon. Pyrene is a common four-ringed polycyclic aromatic hydrocarbon. The asymmetry of a pyrene + hexadecane mixture is larger than the asymmetry of an anthracene + hexadecane mixture. The predicted phase behaviour of pyrene + n-alkane binary and pseudo binary mixtures is presented in Figure 18. Again the SLLV line is estimated by procedures outlined by Shaw and Béhar, (2000). The estimated temperature of the SLLV line is $384 \pm 5 \mathrm{~K}$. From experiments with pyrene $+\mathrm{n}$-hexadecane, no liquid-liquid phase splitting is evident. However, as seen in Figure 18, in order for the model to be consistent with the experimental findings, the pyrene-hexadecane interaction parameter must be lowered to a value less than -0.03 (that is, when the L-locus falls below the SLLV line temperature of $384 \mathrm{~K}$ ). It is important to note that with the standard interaction parameter from equation $14\left(k_{i j}=0.002\right)$ Type II phase behaviour is falsely predicted.

As seen previously in Figure 13, PAH + (n-alkane) interaction parameters are a function of carbon number. It is expected that the L-loci in Figure 18 should level off as the solvent carbon number increases. However, at constant interaction parameters the 
L-point temperatures reach a minimum and begin to increase. Clearly, there are insufficient data to complete the pyrene $+\mathrm{n}$-alkane model. Useful experiments for completing this phase behaviour transition model are phase equilibria experiments with pyrene $+\mathrm{n}$-alkanes smaller than $\mathrm{n}$-hexadecane. Such experiments are currently being performed. The results will be presented in a subsequent thesis.

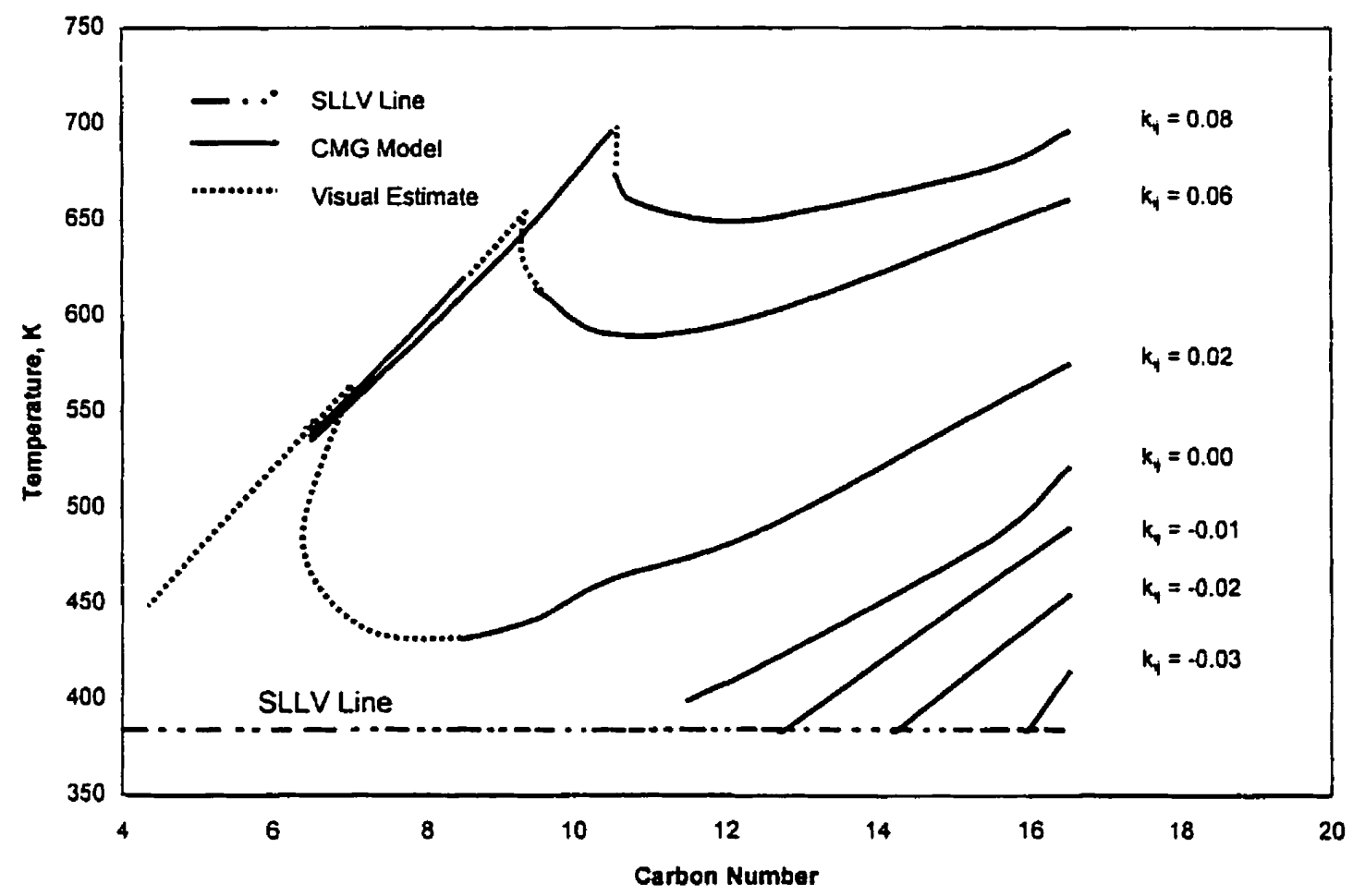

Figure 18 - Pyrene + pseudo n-alkane critical temperature loci

In the low carbon number range of Figure 18 , larger $k_{i j}$ values (as predicted by the correlations in Figure 13) should be meaningful. Therefore, for argument, using the $k_{i j}=$ 0.06 line of Figure 18 predicts that the tricritical point for pyrene $+n$-alkanes is at a higher temperature and more importantly a higher solvent carbon number than the tricritical point of anthracene $+n$-alkanes (Figure 15 ). Thus increasing the solute size allows for complex phase behaviour with larger solvent molecules.

\section{Reaction Products of Anthracene}

The dimerization of anthracene leads to a diversity of products. Lewis (1980) proposes 11 possible dimers of anthracene as the initial reaction products of the pyrolysis of 
anthracene; these dimers are composed of two anthryl radicals joined by one, two, or three aliphatic links (Figure 19). Other Anthra-aceanthrylene isomers have also been identified, (Harvey, 1997). From a modelling perspective it is unimportant which material is prominent since their critical properties and acentric factor are similar. What is important is that anthracene will react with itself to produce larger molecules. If this occurs in hydrogenation processes the asymmetry of the mixture increases; thus affecting the phase behaviour. Hexaphene has been chosen as the model dimer of anthracene to investigate the effect that the polymerization of simple model-coke precursors has on the formation of coke. According to Clar's aromatic sextet theory, hexaphene is one of the more stable of the six-ringed benzenoid hydrocarbons. Hexaphene's critical properties and acentric factor are also easily estimated.

The predicted phase behaviour of hexaphene and pseudo n-alkane binaries is depicted in Figure 20. For comparison, the predicted phase behaviour of anthracene + pseudo $\mathrm{n}$-alkane binaries is also plotted. Again the SLLV line is estimated by procedures outlined by Shaw and Béhar, (2000). The estimated value is $563 \pm 5 \mathrm{~K}$. A $\mathrm{k}_{\mathrm{ij}}$ value of 0 is used for the phase equilibrium models with hexaphene because no experimental data is available for these systems. It has been shown that pyrene $+n$-alkane $k_{i j}$ 's range from 0.18 with methane to $<-0.03$ with $n$-hexadecane. Using a value of zero is the best available $k_{i j}$ estimate for hexaphene $+n$-alkane systems. As seen on Figure 20, only Type III phase behaviour is predicted for hexaphene + pseudo $n$-alkane systems from $\sim \mathrm{n}$-octane to beyond eicosane. That is, only the K-locus is predicted, and the tricritical and double critical endpoint are not present. Phase behaviour calculations with hexaphene + pseudo n-alkanes to $\mathrm{C} 30$ were also performed and continue the trend observed in Figure 20. The K-locus for hexaphene moves to higher temperatures than the $\mathrm{K}$-locus for anthracene. Typical hydrogenation temperatures of $646 \mathrm{~K}$ are below the predicted K-points and above the predicted SLLV line (i.e. within the region of limited miscibility) for a large range of solvents from n-octane to at least C30 n-alkanes. This is not so for anthracene. Therefore as anthracene is allowed to react, producing more dimers (and possibly trimers or polymers), the DCEP and TCP begin moving towards higher temperatures and larger solvent carbon numbers. Thus, the hexaphene $+n$-alkane Type III/IV and IV/II transitions occur at larger solvent carbon numbers and the possible 
$\mathrm{L}_{1} \mathrm{~L}_{2} \mathrm{~V}$ phase behaviour arises at higher temperatures than for anthracene $+\mathrm{n}$-alkane mixtures.

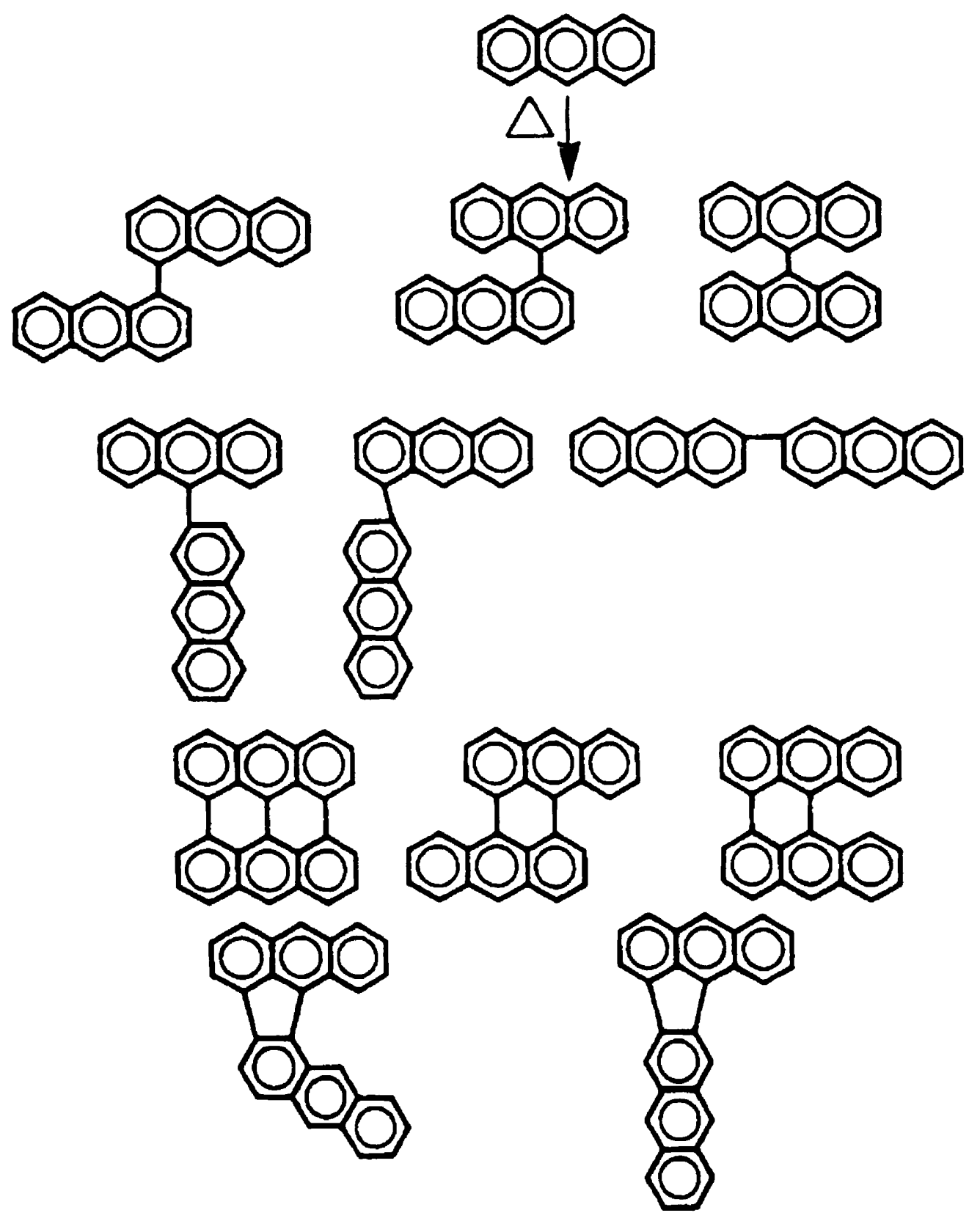

Figure 19 - Possible initial reaction products of anthracene (Lewis, 1980) 


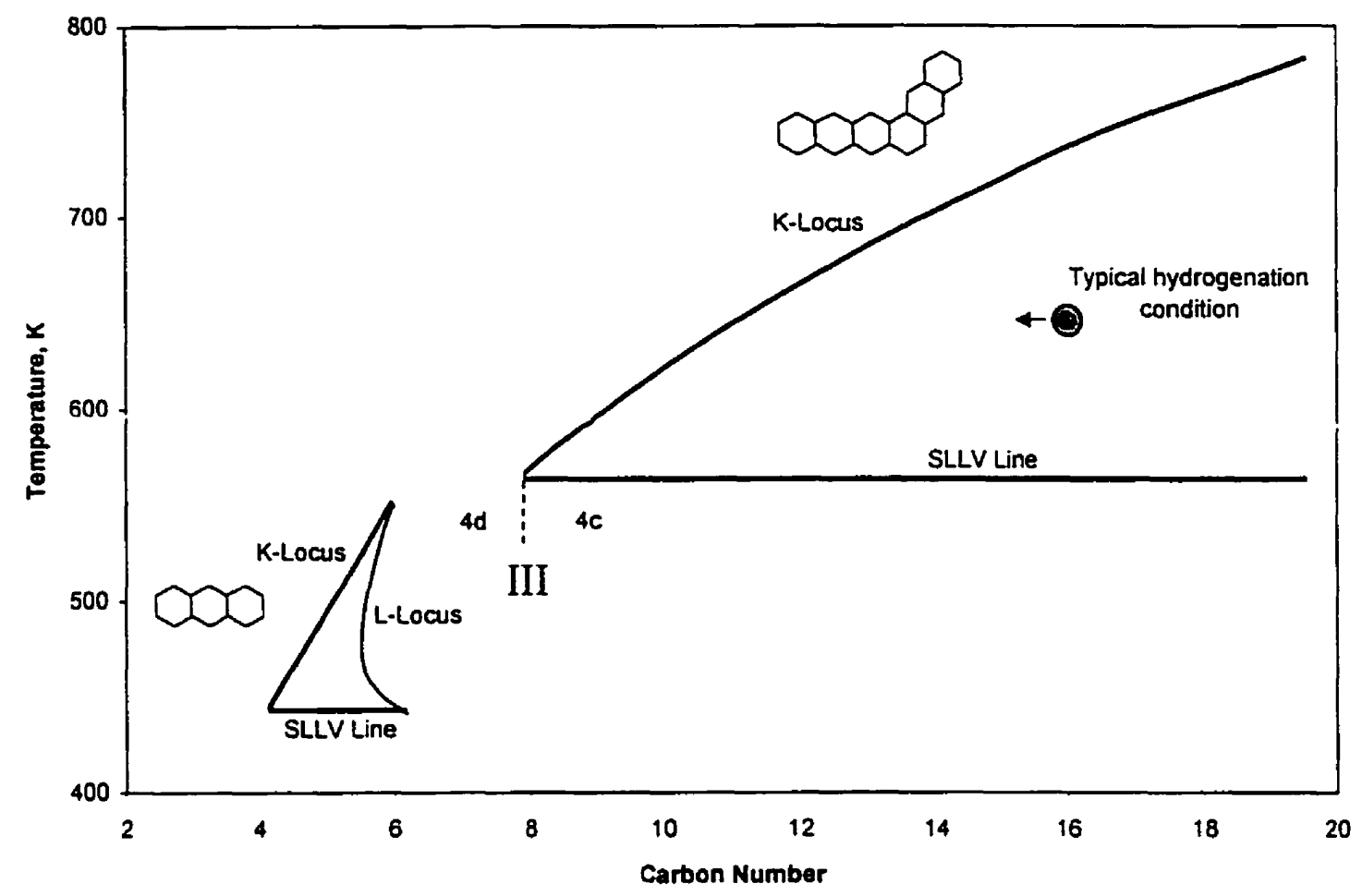

Figure 20 - Predicted phase behaviour of hexaphene and anthracene + pseudo n-alkanes

A P-x diagram of hexaphene $+50: 50 \mathrm{n}$-pentadecane:n-hexadecane $(\mathrm{CN}=15.5)$ at $646 \mathrm{~K}$ (conditions within the region limited miscibility) shows that $\mathrm{L}_{1} \mathrm{~L}_{2} \mathrm{~V}$ phase behaviour is possible for compositions ranging from near $0 \mathrm{~mol} \%$ to approximately $86 \mathrm{~mol} \%$ hexaphene (Figure 21). Similar $\mathrm{P}-\mathrm{x}$ diagrams are predicted for anthracene $+\mathrm{n}$-alkane mixtures for conditions within the region of limited miscibility. As an example, the P-x diagram of anthracene $+25: 75 \mathrm{n}$-pentane:n-hexane $(\mathrm{CN}=5.75)$ at $448 \mathrm{~K}$ is included (Figure 22). Since the behaviour of these two systems is similar, one can imagine a continuous shift in the region of limited miscibility as initial coke precursors react and intermediates accumulate.

It is important to note that the solvents in catalytic hydrogenation process crack; therefore in the example of a typical process, the average carbon number $(\mathrm{CN})$ of the solvent declines. So as the $\mathrm{K}$ - and L-loci continuously shift toward the right on Figure 20, the experimental conditions move horizontally towards the 'eft. Once the experimental conditions intersect the region of limited miscibility, $\mathrm{L}_{1} \mathrm{~L}_{2} \mathrm{~V}$ phase behaviour or $\mathrm{L}_{2} \mathrm{~V}$ 
phase behaviour, similar to the regions shown in Figure 21 and Figure 22, arise. The impact of the phase behaviour on the formation and deposition of coke on catalyst pellets or reactor walls and on the induction times for coke formation observed in such systems is addressed in the next chapter.

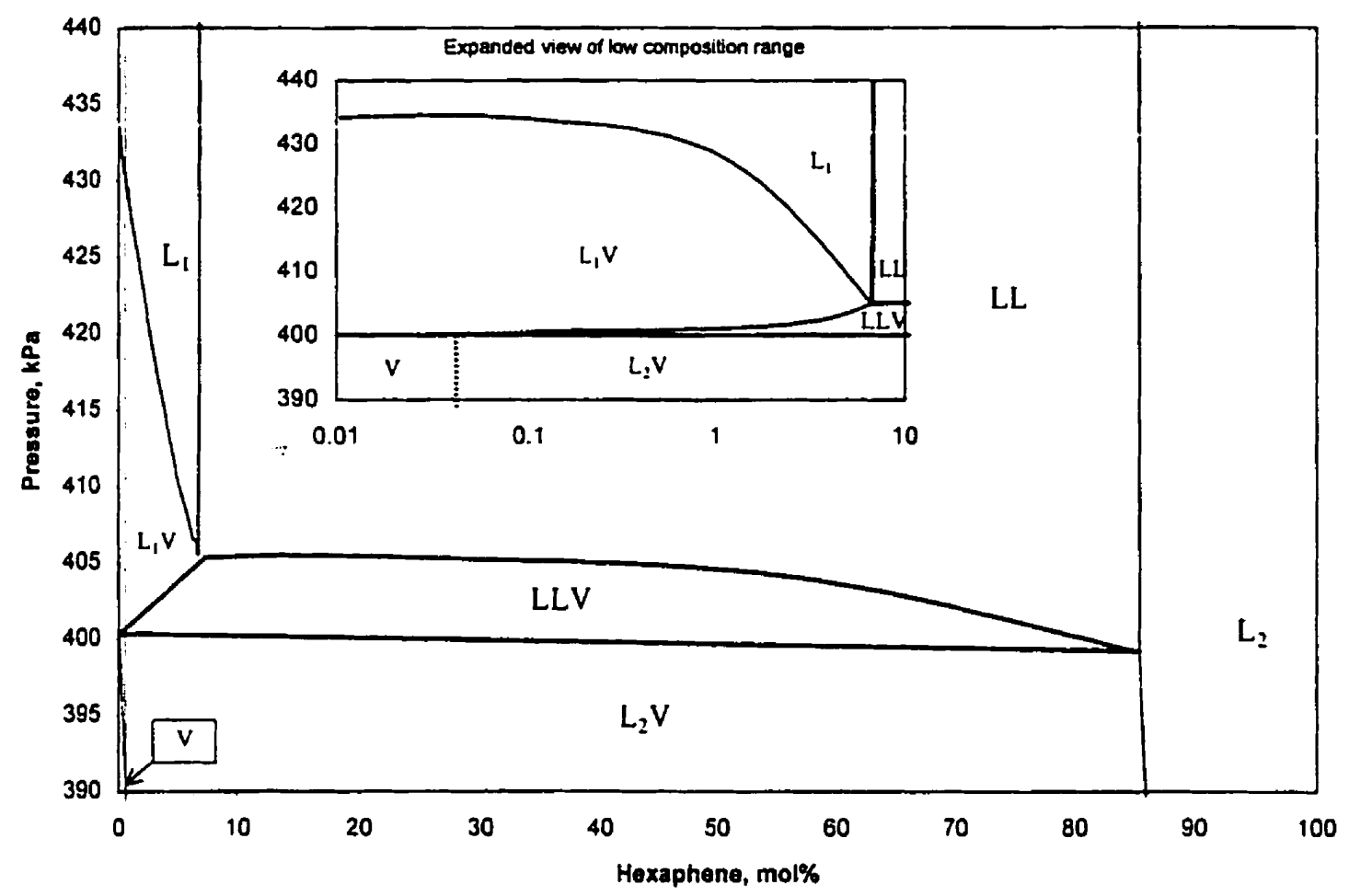

Figure 21 - P-x diagram for hexaphene + 50:50 n-pentadecane:n-hexadecane at $646 \mathrm{~K}$, and expanded log-scale view of the low composition range. 


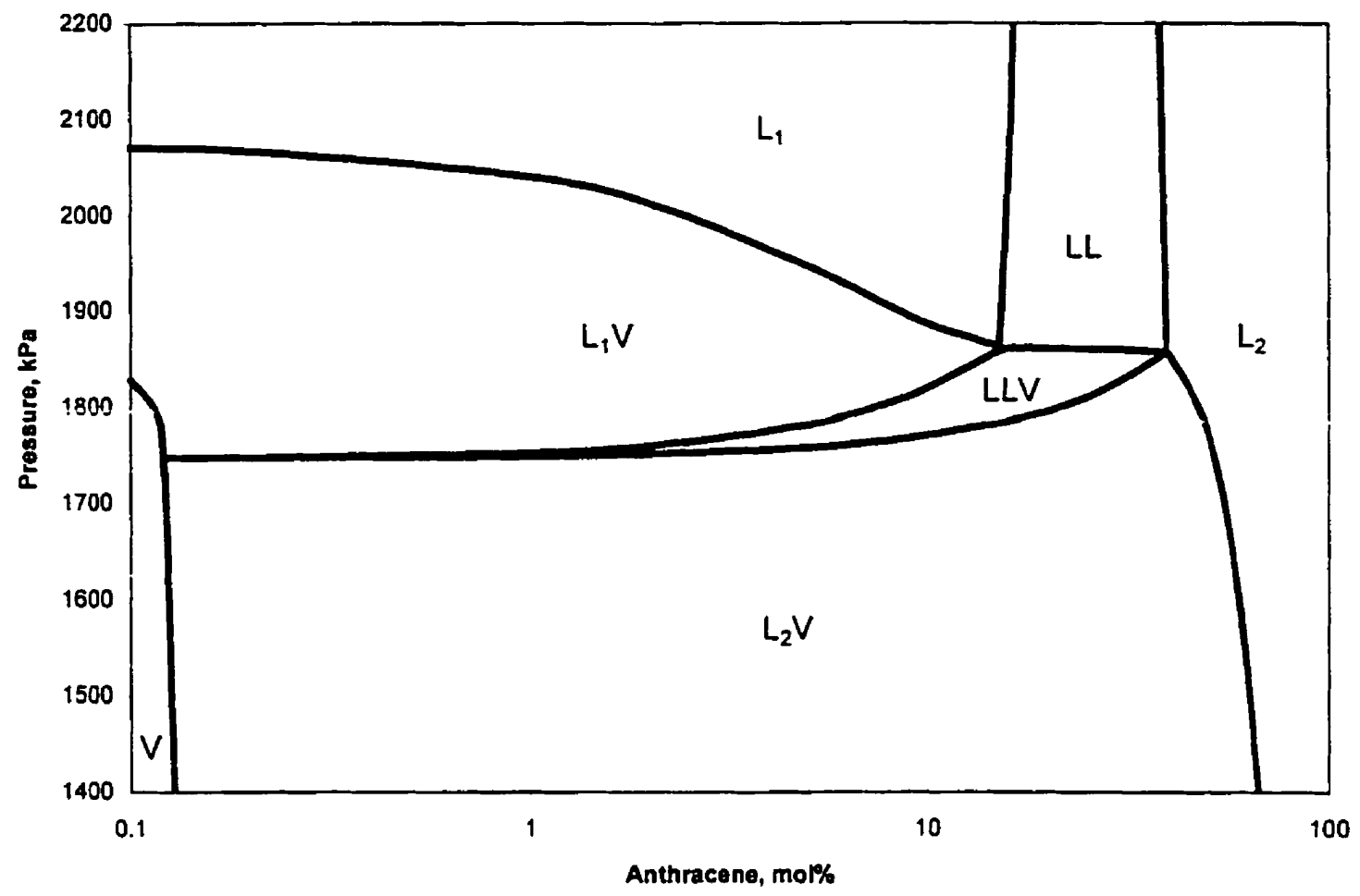

Figure 22 - P-x diagram for anthracene + 25:75 n-pentane:n-hexane at $448 \mathrm{~K}$

\section{Summary of Chapter Findings}

The key findings from the phase behaviour simulations presented in this chapter are:

- To fit available experimental data for pyrene + hexadecane, binary interaction parameters for the Peng-Robinson EOS must be negative. This suggests a strong correlation with carbon number for the n-alkane solvents not predicted by simple interaction parameter correlations. In addition, the fit of the phenanthrene + propane LLV data yields an interaction parameter two orders of magnitude smaller than for the anthracene + propane binary pair. This highlights the impact of solute structure on interaction parameters for $\mathrm{PAH}+\mathfrak{n}$-alkane systems. Clearly, binary interaction parameters for such systems cannot be extrapolated far from available data.

- Hydrogen does not affect the type of phase behaviour predicted so much as the pressure of phase boundaries. 
- Anthracene exhibits liquid-liquid-vapour phase behaviour with $\sim$ butane to $\sim$ hexane solvents.

- Anthracene dimers affect the asymmetry of the mixture enough to induce liquidliquid-vapour phase behaviour with n-hexadecane, and the predicted temperature of the SLLV line does not interfere with this phase behaviour arising under typical hydrogenation processing conditions. 


\section{Chapter 5 - Impact of Multiphase Behaviour on Coking Kinetics}

Catalyst deactivation and coke formation in hydrogenation processes for heavy oils have been modeled using the system anthracene $+\mathrm{n}$-hexadecane + hydrogen running at $\sim 646 \mathrm{~K}$. This mixture does not exhibit multiphase behaviour at these operating conditions; however, at processing conditions, anthracene polymerizes and the solvent cracks. Computer simulated phase equilibria models exhibit Type ill phase behaviour with n-octane and above for a model dimer (hexaphene). Thus multiphase behaviour is expected to arise as reactions progress. The impact on coke formation or deposition rates and induction times, observed in batch experiments, can be explained through a series of cases. Based on the phase diagram shown in Figure 21, these cases are illustrated in Figure 23.

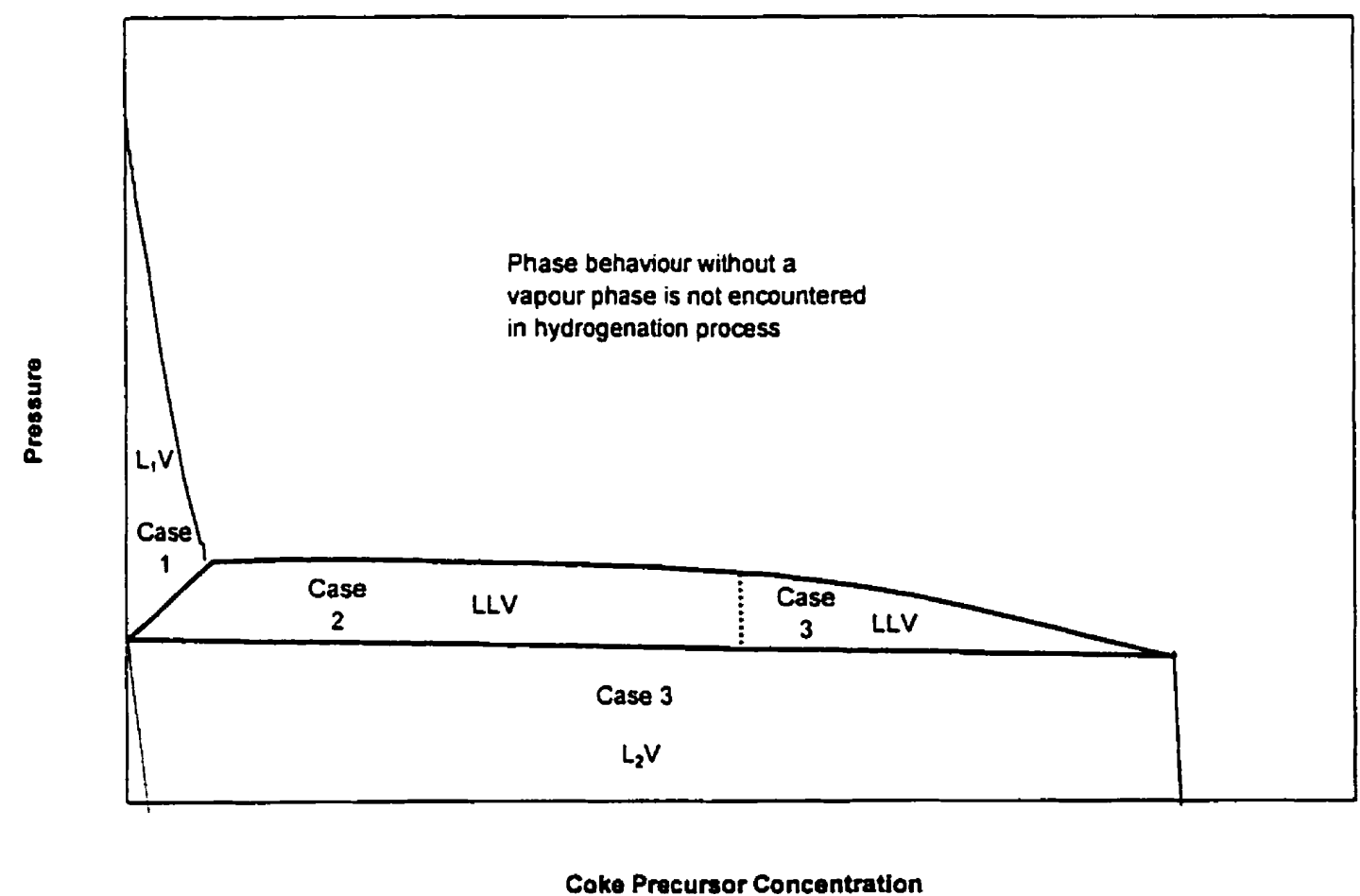

Figure 23 - Location of phase behaviour cases that impact coking kinetics.

At very low coke precursor concentrations, only a light liquid phase $\left(L_{l}\right)$ is present. No $\mathrm{L}_{1} \mathrm{~L}_{2} \mathrm{~V}$ zones arise regardless of operating pressure. Since coking rates are positive, the 
polymerization sequence progresses slowly from monomer to dimer etc. until an insoluble solid is produced on an active catalyst surface. For batch experiments, long induction periods are expected for coke formation. This behaviour is classified as case 1 . Uniform coke deposition is expected since coke will tend to form only at active catalyst sites.

At intermediate coke precursor concentrations, $L_{1} L_{2} V$ phase behaviour, where $L_{1}$ is the continuous phase, may be encountered in the feed or as reactions progress, depending on the operating conditions. This is termed Case 2. If a $\mathrm{L}_{1} \mathrm{~L}_{2} \mathrm{~V}$ region is encountered at an intermediate stage in the polymerization sequence, the coking rate will increase significantly and the induction period will shorten significantly compared to the previous case because the coke precursors will concentrate in the $L_{2}$ phase and therefore react more quickly. From the P-x diagram for hexaphene $+\mathrm{CN} 15.5$ the concentration of the precursor in $L_{1}$ and $L_{2}$ phases are approximately $<0.1$ and $86 \mathrm{~mol} \%$ respectively. The reactions will appear to be autocatalytic. Dispersed drops of $\mathrm{L}_{2}$ phase will appear then polymerize homogeneously and plug constrictions in pores physically. This type of deposition will arise in addition to deposition on internal catalyst surfaces noted above. This situation is consistent with pore-mouth plugging models. If the feed exhibits $L_{1} L_{2} V$ phase behaviour, where $L_{2}$ is dispersed, coke deposition arising from homogenous reaction of $L_{2}$ drops in the bulk begins to appear on all reactor surfaces: vessel walls and external catalyst surfaces, in addition to the deposition models noted above. This generalized deposition occurs because dispersed drops in multiphase flow that are denser than the continuous fluid are driven toward stationary surfaces (Shahrokhi and Shaw, 2000).

A third case arises, primarily at low pressure over a broad range of compositions and also at intermediate pressures at high precursor concentrations, where $L_{2}$ is the continuous liquid phase. Under these conditions, rapid external pore plugging, as well as, coke deposition on reactor walls is expected. Process operation is unlikely to be successful under these conditions. 
The cases outlined above provide a framework for analysing coking phenomena reported in the literature. For example, Case 1 is consistent uniform coke deposition. Coke forms from the polymerization of coke precursors, which takes place at active catalytic sites. Once the extent of polymerization reaches a critical point, irreversible solidification of the products occurs, and the active site is then blocked. Another example is the poremouth plugging phenomena; Case 2 provides the necessary scenario. Drops produced within the pore network can solidify and travel the pore network until an internal poremouth is encountered. $L_{2}$ drops present in the feed tend to block external pore-mouths, and deposit on all vessel surfaces.

The cases above are also consistent with observed phenomena concerning induction periods for coke formation arising in batch experiments. Case 1 exhibits the longest induction period because of the low concentration of coke precursors in contact with the catalyst. Case 2 exhibits a much shorter induction period than Case 1. The appearance of an $L_{2}$ phase at or near the catalyst surface concentrates the coke precursor, significantly increasing the coke formation rate. Case 3 has the shortest induction period because the continuous liquid phase in contact with the catalyst $\left(L_{2}\right)$ is pre-saturated with coke precursors at a high concentration.

These scenarios illustrate the importance of phase behaviour in the development of kinetic theories and models for hydrogenation processes. Each of the cases illustrated have been noted anecdotally in the literature, (Richardson et al., 1996; Mugger et al., 1991; Thakur and Thomas, 1985; Absi-Halabi and Stanislaus, 1991). This thesis places these findings in context and shows that diverse coking rated and deposition physics can apply even at fixed composition and temperature. For example, by varying the pressure, one can pass from Case 3, through to Case 2, and finally to Case 1. In practical situations, hydrogen addition or pressure control can be used as simple but effective coke abatement strategies. 


\section{Chapter 6 - Summary and Conclusions}

Anthracene is a highly reactive polycyclic aromatic hydrocarbon used in many laboratory simulations to study the long-term effect of coking on hydrogenation catalysts. Unfortunately, phase equilibria issues are often ignored or assumed not to influence the simulation results. These issues are important because a change in the phase equilibria can greatly affect system dynamics. For example, coking rates may suddenly increase with the appearance of a liquid phase, rich in coke precursor, as observed by Abedi et al. (1998). With highly reactive species, it is not sufficient to determine the phase behaviour of the initial feed materials but also mixtures of intermediate or final products. Phase behaviour changes continually during the coking sequence as products form. These transitions have numerous ramifications for formation and deposition of coke on hydrogenation catalysts and within reactors more generally, which are not included in coking kinetic models. The phase behaviour of anthracene and its reaction intermediates in n-alkane solvents has been studied using a combination of experiments and computer simulations. The results obtained illustrate these points and place the coking phenomena, observed in the literature, in context.

From the results of this thesis, the following specific conclusions are drawn:

1. Anthracene derived coke precursors exhibit liquid-liquid-vapour phase behaviour as polymerization reactions proceed. The predicted liquid-liquid-vapour phase behaviour spans a large composition, temperature, and pressure range.

2. Depending on operating conditions and initial coke precursor concentration, three distinct cases for the effect of phase behaviour on coking kinetics are identified. These cases encompass the wide variety of coking phenomena reported in the literature and place them in context.

3. Generalized interaction parameter correlations provide inadequate predictions for the phase behaviour of polycyclic aromatic $+n$-alkane mixtures. They fail to take into account the structural differences within and between the two families of molecules and can yield incorrect phase diagram types. 
4. Investigation of the phase behaviour of pyrene + hexadecane + hydrogen establish the pyrene $+\mathrm{n}$-hexadecane interaction parameter to be less than -0.03 .

5. Liquid density data for anthracene + hexadecane mixtures closely follow Amegate's idealized case. Measured n-hexadecane density at $646 \mathrm{~K}$ is in agreement with density predictions found in the literature. 


\section{Chapter 7 - Recommendations for Further Work}

1. Models for anthracene $+n$-alkane binary mixtures presented in this thesis are accurate; although, experimental verification of the predicted span for liquid-liquidvapour phase behaviour is recommended.

2. Phase behaviour experiments with anthracene derived coking intermediates are rccommended so that the existence of liquid-liquid-vapour phase behaviour at typical hydrogenation conditions can be verified experimentally.

3. The absence of meaningful binary interaction parameters for polycyclic aromatic hydrocarbons $+n$-alkane pairs is a major limiting factor in producing phase behaviour models with a high degree of confidence for these systems. Vapour pressure measurements or high-pressure solubility data for PAH's + common solvents are required to complete binary interaction correlations for the PAH family of molecules. Such correlations would be useful in industrial and academic applications.

4. More precise temperature control of the view cell, and automated image capture and processing would allow experiments to run more quickly.

5. A geared, variable height X-ray source would be useful in solving the compromise between the ability to "see" the very bottom of the view cell contents and the ability to capture clear liquid-liquid or liquid-vapour interfaces. 


\section{Nomenclature}

\section{Variables}

\section{$a$}

$b$

C

$\mathrm{CN}$

F

$f$

G

I

$k$

l

m

$M W$

$N$

$n$

$P$

$R$

$S$

S.G.

$T$

$v$

V

$x$

$y$

$z$

$\alpha$

$\phi$

$\mu$

$\pi$

$\theta$

$\rho$

$\omega$

$\zeta$

\section{Subscripts}

\section{$b$}

$c$

$f$

$i$

$j$

$m$
Peng-Robinson parameter

Peng-Robinson parameter constant in Equation 6

carbon number

number of degrees of freedom

fugacity

Gibbs energy

performance index

binary interaction parameter

binary interaction parameter

mass

molecular weight

number of components

number of moles

pressure; $\mathrm{P}_{c}$, critical pressure; $P^{*}$, pure solute vapour pressure

gas constant

entropy

specific gravity

temperature; $T_{c}$, critical temperature; $T_{b}$, normal boiling point; $T_{r}$. reduced temperature

molar volume; $v_{c}$, critical molar volume

volume

mole fraction or liquid phase mole fraction

vapour phase mole fraction

compressibility factor

temperature dependent parameter in Equation 8

fugacity coefficient

chemical potential

number of phases

standard binary interaction parameter equation coefficient

density

acentric factor

critical molar volume ratio in Equation 14

normal boiling

critical

final condition

component $i$ or initial condition

component $j$

mixture 


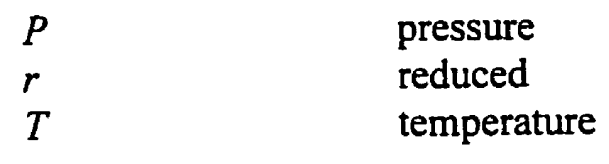

\section{Superscripts}

\begin{tabular}{ll}
\hline exp & experimental \\
$g$ & gas phase \\
$l$ & liquid phase \\
mod & modelled \\
$o$ & initial or feed condition \\
pure & pure \\
sat & saturation \\
solid & solid \\
solv & solvent \\
$t$ & total \\
$v$ & vapour phase \\
$\alpha$ & $\alpha$ phase \\
$\beta$ & $\beta$ phase \\
$\pi$ & $\pi$ phase \\
, & equilibrium condition
\end{tabular}

\section{Acronyms}

ABVB
CMG
DCEP
EOS
L
$\mathrm{L}_{1}$
$\mathrm{~L}_{2}$
LCEP
PAH
P-R
P-T
PvT
P-x
S
TCP
T-x
UCEP
V

Athabasca Bitumen Vacuum Bottoms

Computer Modelling Group

double critical endpoint

equation of state

liquid phase

low density liquid phase

high density liquid phase

lower critical endpoint

polycyclic aromatic hydrocarbon

Peng-Robinson

pressure-temperature phase diagram (const. $\mathbf{x}$ )

pressure-molar volume-temperature relationship

pressure-composition phase diagram (const. T)

solid phase

tricritical point

temperature-composition phase diagram (const. P)

upper critical endpoint

vapour Phase 


\section{References}

Abedi, S J.; Cai, H.-Y.; Seyfaie, S.; Shaw, J. M. "Simultaneous phase behaviour, elemental composition and density measurement using X-ray imaging." Fluid Phase Equilibria, 158-160, 775-781, (1999).

Abedi, S. J.; Seyfaie, S.; Shaw, J. M. "Unusual retrograde condensation and asphitene precipitation in a model heavy oil system." Pet. Sci. \& Tech., 16, 209-226, (1998).

Absi-Halabi, M.; Stanislaus, $\Lambda$. "Coke formation on catalysts during the hydrogenation processing of heavy oils." Appl. Catal., 72, 193-215, (1991).

Bjørseth, A. (ed.) "Handbook of polycyclic aromatic hydrocarbons." QD341.H9H317. Marcel Dekker, New York, (1983).

Cai, H. -Y.; Shaw, J. M.; Chung, K. H. "Hydrogen solubility measurments in heavy oils and bitumen cuts." Fuel, In Press, (2000).

Chokappa, D.; Clancy, P.; Streett, W. B. "Theoretical methods for the prediction of phase equilibria in hydrogen-containing mixtures." Chem. Eng. Sci., 40, 1831-1841. (1985).

Computer Modelling Group, WinProp ver. 2000.1, Computer Modelling Group, Calgary Alberta. (2000)

Darwish, N. A.; Gasem, A. M.; Robinson. R. L. Jr. "Solubility of methane in benzene, naphthalene, phenanthrene, and pyrene at temperatures from 323 to $433 \mathrm{~K}$ and pressures to $11.3 \mathrm{MPa}$." J. Chem. Eng. Data, 39, 781-784, (1994).

Graaf, G. H.; Smit. H. J.; Stamhuis, E. J.: Beenackers. A. C. M. "Gas-liquid solubilities of the methanol synthesis components in various solvents." J. Chem. Eng. Data, 37. 146-158, (1992).

Gray, M. R.; Khorasheh, F.; Wanke, S. E.; Achia, U.; Srzywicki, A.; Sanford. E. C.: Sy, O.K. Y.; Ternam, M. "Role of catalyst in hydrocracking of residues from Alberta bitumens." Energy \& Fuels, 6, 478-485, (1992).

Gregorowicz, J.; de Loos, Th. W. "Modelling of the three phase LLV region for ternary hydrocarbons mixtures with the Soave-Redlick-Kwong equation of state." Fluid Phase Equilibria, 118, 121-132, (1996).

Harvey, R. G. "Polycyclic aromatic hydrocarbons." QD341.H9H34, Wiley-VCH, Toronto, (1997).

Hong, S.-P.; Green, K. A.; Luks, K. D. "Phase equilibria of the mixtures methane + $\mathrm{n}$-hexane $+\mathrm{n}$-hexatriacontane, methane + toluene + naphthalene, and methane + n-hexane + naphthalene." Fluid Phase Equilibria, 87, 255-272, (1993).

Johnston, K. P.; Ziger, D. H.; Eckert, C. A. "Solubilities of hydrocarbon solids in supercritical fluids. The augmented van der Waals treatment." Ind. Eng. Chem. Fundam., 21, 191-197, (1982). 
Lewis, I. C. "Thermal polymerization of aromatic hydrocarbons." Carbon, 18, 191-196, (1980).

Michelsen, M. L. "The isothermal flash problem. Part I. Stability." Fluid Phase Equilibria, 9, 1-19, (1982).

Moysan, J. M.; Huron, M. J.; Paradowski, H.; Vidal, J. "Prediction of the solubility of hydrogen in hydrocarbon solvents through cubic equations of state." Chem. Eng. Sci., 38, 1085-1092, (1983).

Muegge, B. D.; Massoth, F. E. "Basic studies of deactivation of hydrogenation catalysts with anthracene." Fuel Proc. Tech., 29, 19-30, (1991).

Octavian Micro Development Inc., public database, (1987).

Oellrich, L.; Plöcker, U.; Prausnitz, J. M.; Knapp. H. "Equation-of-state methods for computing phase equilibria and enthalpies." Intern. Chem. Eng., 21, 1-16, (1981).

Park, J.; Robinson, R. L. Jr.; Dasem, A. M. "Solubilities of hydrogen in aromatic hydrocarbons from 323 to $433 \mathrm{~K}$ and pressures to $21.7 \mathrm{MPa}$." J. Chem. Eng. Data, 41, 70-73, (1996).

Peng, D. Y.; Robinson, D. B. "A new two-constant equation of state." Ind. Eng. Chem. Fund., 15, 59-64, (1976).

Peters, C. J.; Rijkers, M. P. W. M.; deRoo, J. L.; de Swaan Arons, J. "Phase equilibria in binary mixtures of near-critical propane and poly-aromatic hydrocarbons." Fluid Phase Equilibria, 52, 373-387, (1989).

Peters, T. J.: Jenkins, R. G.; Scaroni, A. W.; Walker, P. L. Jr. "The importance of carbonization conditions on the character of phenanthrene coke and its graphitizability." Carbon. 29, 981-990. (1991).

Raeissi, S.; Gauter. K.; and Peters, C. J. "Fluid multiphase behaviour in quasi-binary mixtures of carbon dioxide and certain 1-alkanols." Fluid Phase Equilibria, 147, 239-249, (1998).

Reid, R. C.; Prausnitz, J. M.; Poling, B. E. "The properties of gases and liquids." $4^{\text {th }}$ ed., TP242.R4, McGraw-Hill, Toronto, (1987).

Richardson, S. M.; Nagaishi, H.; Gray, M. R. "Initial coke deposition on a $\mathrm{NiMo} / \mathrm{g}-\mathrm{Al} 2 \mathrm{O} 3$ bitumen hydrogenation processing catalyst." Ind. Eng. Chem. Res, 35, 3940-3950, (1996).

Rößling, G. L.; Franck, E. U. "Solubility of anthracene in dense gases and liquids to $200^{\circ} \mathrm{C}$ and 2000 bar." Ber. Bunsenges. Phys. Chem., 87, 882-890, (1983).

Sasaki, T.; Jenkins, R. G.; Eser, S.; Schobert, H. H. "Carbonization of anthracene and phenanthrene. 1. Kinetics and mesophase development." Energy \& Fuels, 7, 10391046, (1993).

Satyro, M. A.; Trebble, M. A. "On the applicability of the Sandler-Wong mixing rules for the calculation of thermodynamic excess propertes $-\mathrm{V}^{\mathrm{E}}, \mathrm{H}^{\mathrm{E}}, \mathrm{S}^{\mathrm{E}}, \mathrm{C}_{\mathrm{p}}{ }^{\mathrm{E}}$." Fluid Phase Equilibria, 115, 135-164, (1996). 
Scaroni, A. W.; Jenkins, R. G.; Walker, P. L. Jr. "Carbonization of anthracene in a batch reactor." Carbon, 29, 969-980, (1991).

Schneider, G. M. "High-pressure investigations on fluid systems - A challenge to experiment, theory, and application." J. Chem. Thermodynam., 23, 301-326, (1991).

Shahrokhi, H.; Shaw, J. M. "Fine drop recovery in batch gas-agitated liquid-liquid sytems." Chem. Eng. Sci., 55, 4719-4735, (2000).

Shaw, J M.; de Loos, Th. W.; de Swaan Arons, J. "Prediction of unusual retrograde condensation in model reservoir fluids." Fluid Phase Equilibria, 84, 251-266, (1993).

Shaw, J. M.; Béhar, E. "On prediction of SL1L2V phase behaviour in complex asymmetric hydrocarbon fluids." Inst. Franç. du Pétrole, Report 52 926. January. (2000).

Stamataki, S.; Tassios, D. "Performance of cubic EOS at high pressure." Rev. Inst. Franç. du Pétrole, 53. 367-377, (1998).

Thakur, D. S.; Thomas. M .G. "Catalyst deactivation in heavy petroleum and synthetic crude processing: a review." Appl. Catal.. 15. 197-225. (1985).

van Konynenburg, P. H.; Scott. R. L. "Critical lines and phase equilibria in binary van der Waals mixtures." Philos. Trans. R. Soc. London, 298. 495-540. (1980).

Wisniak, J.: Apelblat. A.; Segura, H. "Prediction of gas-solid equilibrium using equations of state." Fluid Phase Equilibria, 147, 45-64, (1998). 


\section{APPENDIX A - View Cell Calibration}

Placing a known volume of water in the cell and measuring the height of the liquid/air interface in pixels calibrated the view cell for liquid volume. A calibration plot follows.

Table A1 - Liquid volume as a function of interface beight.

\begin{tabular}{ccccccc}
\hline Point & $\begin{array}{c}a \\
\mathrm{plx}\end{array}$ & $\begin{array}{c}\mathrm{b} \\
\mathrm{plx}\end{array}$ & $\begin{array}{c}c \\
\mathrm{plx}\end{array}$ & $\begin{array}{c}\text { Average } \\
\mathrm{plx}\end{array}$ & $\begin{array}{c}\text { Volume } \\
\mathrm{mI}\end{array}$ & $\begin{array}{c}\text { Std. Dev. } \\
\mathrm{plx}\end{array}$ \\
\hline 1 & 77.5 & 77.5 & 77.5 & 77.5 & 20 & 0.0 \\
2 & 59.5 & 39.5 & 39.5 & 39.5 & 30 & 0.0 \\
3 & 119.5 & 120.5 & 122.5 & 120.8 & 40 & 1.5 \\
4 & 144.5 & 144.5 & 142.5 & 143.8 & 50 & 1.2 \\
5 & 165.5 & 166.5 & 164.5 & 165.5 & 60 & 1.0 \\
6 & 187.5 & 187.5 & 187.5 & 187.5 & 70 & 0.0 \\
7 & 209.5 & 209.5 & 209.5 & 209.5 & 80 & 0.0 \\
8 & 232.5 & 232.5 & 231.5 & 232.2 & 90 & 0.6 \\
9 & 255.5 & 255.5 & 254.5 & 255.2 & 100 & 0.6 \\
\hline
\end{tabular}

Placing a known amount of hydrogen in the cell and calculating the volume from the $P v T$ relationship calibrated total view cell volume as a function of bellows position. This was done with a compressibility based gas law. The amount of hydrogen added to the cell was $0.0329 \pm 0.0005 \mathrm{~mol}$. The volume is calculated from

$V=\frac{z n R T}{P}$

A calibration plot follows.

Table A2 - Total volume as a function of bellows position

\begin{tabular}{|c|c|c|c|c|c|c|c|c|c|}
\hline Point & $\begin{array}{c}a \\
p d x\end{array}$ & $\begin{array}{c}0 \\
p 1 x\end{array}$ & $\begin{array}{c}c \\
p 1 x\end{array}$ & $\begin{array}{c}\text { Average } \\
p(x\end{array}$ & $\begin{array}{c}\text { Pressure } \\
\text { psia }\end{array}$ & $\begin{array}{c}\text { Temperature } \\
{ }^{\circ} \mathrm{C}\end{array}$ & 2 & $\begin{array}{c}\text { Volume } \\
\mathrm{mL}\end{array}$ & $\begin{array}{l}\text { Sid. Dev. } \\
\text { pix }\end{array}$ \\
\hline 1 & 453.5 & 453.5 & 453.5 & 453.5 & 50.9 & 21.1 & 1.0030 & 230.0 & 0.0 \\
\hline 2 & 427.5 & 427.5 & 427.5 & 427.5 & 52.9 & 21.4 & 1.0031 & 221.6 & 0.0 \\
\hline 3 & 378.5 & 379.5 & 379.5 & 379.2 & 57.3 & 21.6 & 1.0033 & 204.8 & 0.6 \\
\hline 4 & 354.5 & 353.5 & 354.5 & 354.2 & 60.0 & 21.8 & 1.0035 & 195.7 & 0.6 \\
\hline 5 & 299.5 & 299.5 & 299.5 & 299.5 & 66.5 & 22.1 & 1.0039 & 176.8 & 0.0 \\
\hline 6 & 235.5 & 237.5 & 236.5 & 236.5 & 75.5 & 22.2 & 1.0044 & 155.9 & 1.0 \\
\hline 7 & 185.5 & $\uparrow 85.5$ & 185.5 & 185.5 & 84.5 & 22.4 & 1.0049 & 139.4 & 0.0 \\
\hline 8 & 134.5 & 134.5 & 134.5 & 134.5 & 95.6 & 22.6 & 1.0055 & 123.4 & 0.0 \\
\hline 9 & 95.5 & 95.5 & 95.5 & 95.5 & 106.3 & 22.7 & 1.0062 & 111.1 & 0.0 \\
\hline
\end{tabular}




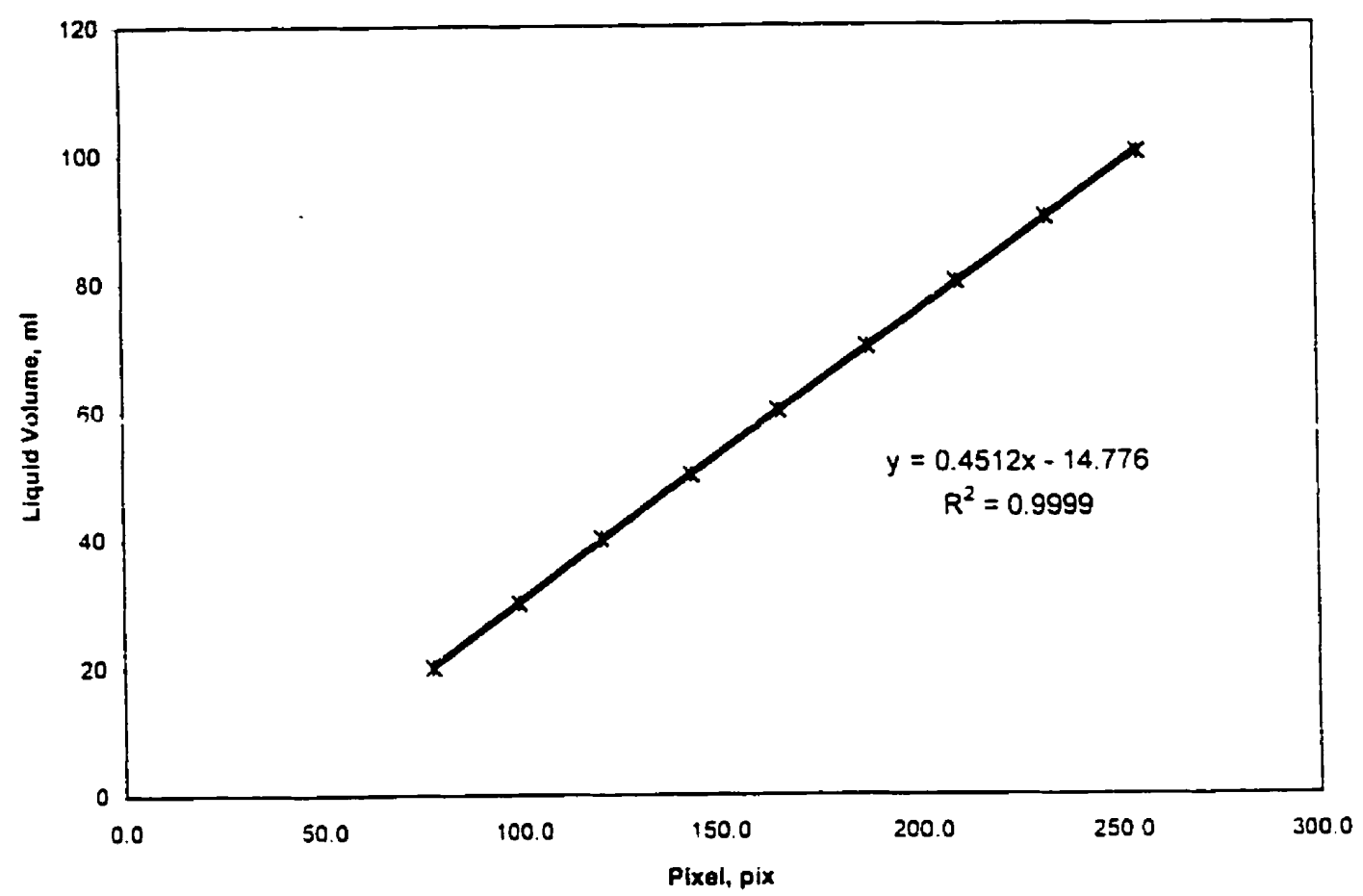

Figure A1 - Liquid volume calibration plot.

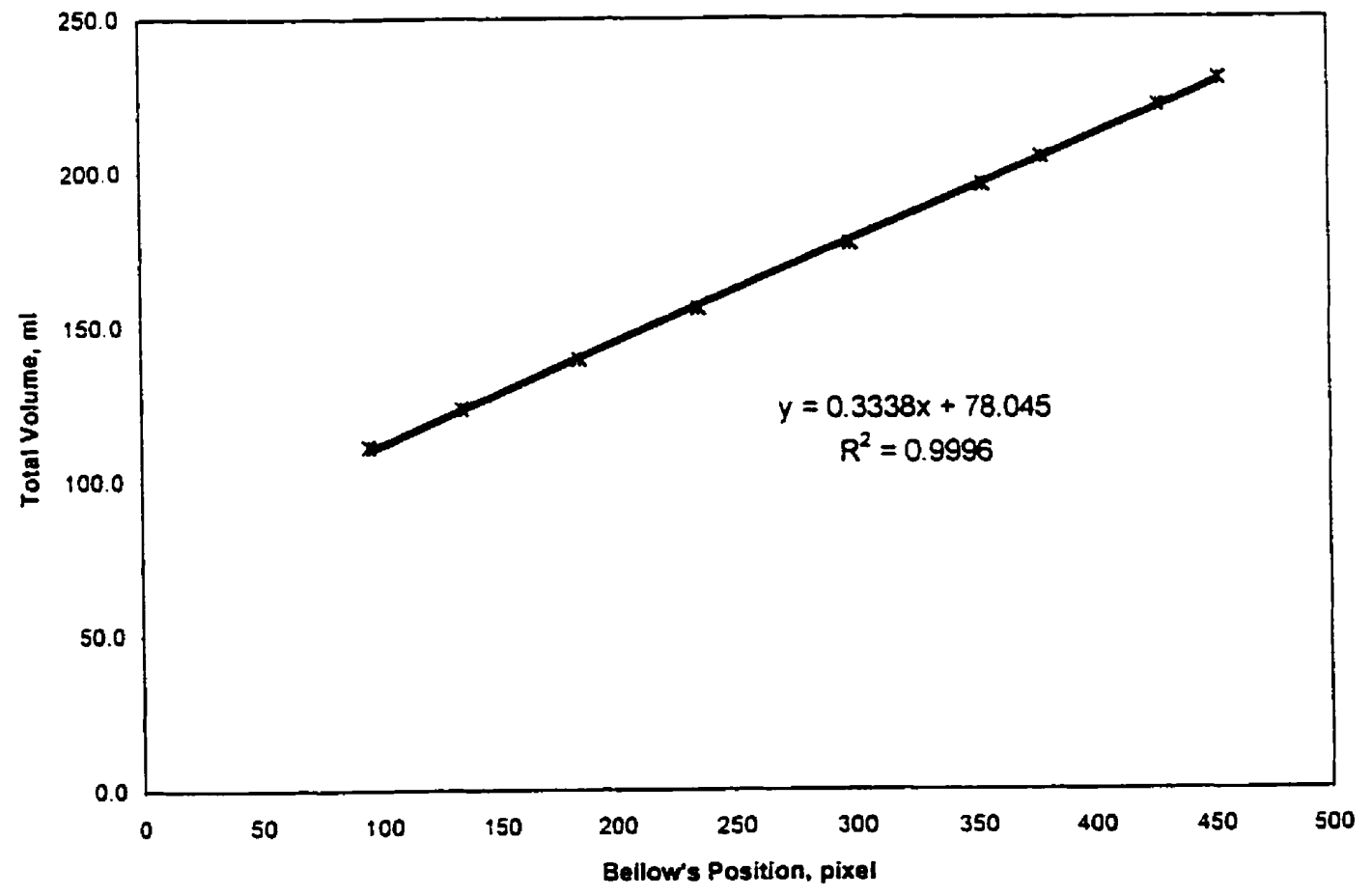

Figure A2 - Total volume calibration plot. 


\section{Appendix B - Liquid Density Estimation}

The liquid density of the materials in view cell has been estimated by dividing the liquid mass by the liquid volume. Liquid volume is obtained from the pixel height and liquid volume calibration in Appendix A. Liquid mass is estimated by using the total mass of anthracene and hexadecane and adjusting for vapourization. The procedure is as follows.

The mass of $i$ in the gas phase is estimated by

$m_{1}^{g}=n_{1}^{g} \cdot L W=\frac{P_{i} !^{g}(. K W)}{R T}$

The partial pressure of $i$ is estimated from Raoult's Law

$P_{t}=x_{1} P_{t}^{\prime}$

The vapour pressures of anthracene and n-hexadecane have been correlated (Reid et al. 1987).

For anthracene:

$P^{\circ}=\exp \left[11.0499-\frac{6492.44}{T-26.13}\right]$

For n-hexadecane:

$\ln P^{\circ}=89.06-\frac{12411.3}{T}-10.58 \ln T+15200 \frac{P^{\circ}}{T^{2}}$

Then the adjusted mass of the liquid is

$m^{\prime}=\sum_{i}^{2} m_{1}^{\prime \prime}-\sum_{i}^{\dot{2}} m_{i}^{*}$

Here $m^{\circ}$ is the initial mass of 1 and 2 placed in the view cell, and assumes that the weight of soluble hydrogen in the liquid is negligible. Species 1 and 2 are anthracene and n-hexadecane.

The liquid density is then calculated from

$\rho^{\prime}=m^{\prime} / V^{\prime}$

The results are presented as a series of figures. 


\begin{tabular}{|c|c|c|c|c|c|c|c|c|c|c|c|c|c|c|}
\hline Run & $\begin{array}{c}\text { Total } \\
\text { Anthracene } \\
\text { yiariks }\end{array}$ & $\begin{array}{c}\text { Total } \\
\text { Hoxadocane } \\
\text { Ulalns }\end{array}$ & Hydrogen & $\begin{array}{c}\text { Anthracente } \\
\text { (112 lrout } \\
w \%\end{array}$ & $\begin{array}{l}\text { Arillidacene } \\
(1+2 \text { frew }) \\
\text { muslis }\end{array}$ & Gas Volunits & $\begin{array}{l}\text { Anthracent } \\
\text { Vapour } \\
\text { rilassury } \\
\text { bar }\end{array}$ & $\begin{array}{l}\text { Anthe acteries } \\
\text { in Gas } \\
\text { glanils }\end{array}$ & $\begin{array}{l}\text { Tleradecatio } \\
\text { Vapour } \\
\text { f'ressule } \\
\text { bast }\end{array}$ & $\begin{array}{l}\text { fluxduecans } \\
\text { in Gas } \\
\text { yiullis }\end{array}$ & Pressuro & Teriperaluit & $\begin{array}{c}\text { liquid } \\
\text { Volumne } \\
\text { mil }\end{array}$ & $\begin{array}{l}\text { Adjusled } \\
\text { Densily } \\
\text { untinl }\end{array}$ \\
\hline 1 & 19.90 & 11.59 & 0.2124 & $6319 \%$ & $6 8 \longdiv { 5 7 \% }$ & 1938 & 1754 & 0774 & $4 \overline{695}$ & 1208 & 6.1 & 645 & 42.27 & 0.6982 \\
\hline 1 & 1990 & 1159 & 02124 & $6319 \%$ & $6857 \%$ & 1678 & 1754 & 0670 & 4695 & 1045 & 68 & 645 & 4227 & 07045 \\
\hline 1 & 1990 & 1159 & 02124 & $6319 \%$ & $6857 \%$ & 1276 & 1754 & 0510 & 4695 & 0795 & (1) & 645 & 4272 & 07067 \\
\hline 1 & 1990 & 11.59 & 02124 & $6319 \%$ & $6857^{2} x$ & 1078 & 1754 & 04.31 & 4695 & 0672 & 91 & 645 & 4362 & 06967 \\
\hline 1 & 19.90 & 11.59 & 0.2124 & $63.19 \%$ & $68.57 \%$ & 894 & 1754 & 0357 & 4695 & 0.557 & 102 & 645 & 4362 & 0.7010 \\
\hline 2 & 19.90 & 11.59 & 0.3515 & $6319 \%$ & $6857 \%$ & 1955 & 1.754 & 0.781 & 4695 & 1.218 & 9.0 & 645 & 43.17 & 0.6832 \\
\hline 2 & 19.90 & 11.59 & 0.3515 & $63.19 \%$ & $6857 \%$ & 1657 & 1.754 & 0662 & 4695 & 1032 & 103 & 645 & 41.81 & 0.7126 \\
\hline 3 & 19.90 & 11.59 & 0.4737 & $63.19 \%$ & $6857 \%$ & 1748 & 1.754 & 0699 & 4695 & 1.089 & 133 & 645 & 43.17 & 0.6881 \\
\hline 3 & 1990 & 11.59 & 0.4737 & $6319 \%$ & $6857 \%$ & 1889 & 1754 & 0755 & 4695 & 1177 & 124 & 645 & $4181^{\circ}$ & 0.7069 \\
\hline 3 & 1990 & 11.59 & 0.4737 & $63.19 \%$ & $6857 \%$ & 1986 & 1754 & 0794 & 4695 & 1237 & 116 & 645 & 4181 & 0.7045 \\
\hline$\overline{4}$ & 12.17 & 3.06 & 0.1459 & $79.91 \%$ & $8348 \%$ & 2062 & 1.724 & 0.988 & 4620 & 0.666 & 4.5 & 644 & 17.92 & 0.7577 \\
\hline 4 & 12.17 & 3.06 & 0.1459 & $79.91 \%$ & $8348 \%$ & 1661 & 1724 & 0.796 & 4620 & 0.536 & 56 & 644 & 17.92 & 0.7757 \\
\hline 4 & 12.17 & 306 & 01459 & $79.91 \%$ & $8348 \%$ & 1241 & 1724 & 0.594 & 4620 & 0400 & 71 & 644 & 18.37 & 0.7750 \\
\hline 4 & 12.17 & 3.06 & 01459 & $79.91 \%$ & $8348 \%$ & 1006 & 1724 & 0482 & 4620 & 0325 & 85 & 644 & 1792 & 08050 \\
\hline 4 & 12.17 & 3.06 & 01459 & $79.91 \%$ & $83.48 \%$ & 914 & 1724 & 0438 & 4620 & 0.295 & 90 & 644 & 1701 & 0.8520 \\
\hline 5 & 12.17 & 3.06 & 0.2693 & $79.91 \%$ & $8348 \%$ & 2133 & 1754 & 1.038 & 4.695 & 0698 & 65 & 645 & 17.01 & 0.7931 \\
\hline 5 & 12.17 & 3.06 & 0.2693 & $7991 \%$ & $83.48 \%$ & 1451 & 1754 & 0706 & 4695 & 0.475 & 9.2 & 645 & 1792 & 0.7841 \\
\hline 5 & 12.17 & 3.06 & 0.2693 & $79.91 \%$ & $8348 \%$ & 1169 & 1754 & 0569 & 4695 & 0383 & 111 & 645 & 1792 & 07969 \\
\hline 5 & 12.17 & 3.06 & 0.2693 & $7991 \%$ & $83.48 \%$ & 961 & 1754 & 0467 & 4695 & 0315 & 131 & 645 & 1701 & 0.8491 \\
\hline 6 & 12.17 & 306 & 0.4283 & $7991 \%$ & $83.48 \%$ & 1939 & 1754 & 0943 & 4695 & 0635 & 101 & 645 & 1792 & 07619 \\
\hline 6 & 1217 & 306 & 04283 & $7991 \%$ & $8348 \%$ & 1782 & 1754 & 0867 & 4695 & 0584 & 110 & 645 & 1701 & 0.8099 \\
\hline 6 & 1217 & 3.06 & 04283 & $7991 \%$ & $8348 \%$ & 1621 & 1754 & 0789 & 4695 & 0531 & 118 & 645 & 1792 & 07764 \\
\hline 6 & 12.17 & 306 & 0.4283 & $79.91 \%$ & $8348 \%$ & 1460 & 1754 & 0710 & 4695 & 0478 & 129 & 645 & 17.01 & 08252 \\
\hline 6 & 12.17 & 306 & 0.4283 & $7991 \%$ & $83.48 \%$ & 1232 & 1754 & 0599 & 4695 & 0404 & 145 & 645 & 1882 & 07560 \\
\hline 6 & 12.17 & 3.06 & 0.4283 & $79.91 \%$ & $8348 \%$ & 1097 & 1754 & 0533 & 4695 & 0359 & 159 & 645 & 1792 & 08002 \\
\hline 6 & 12.17 & 3.06 & 0.4283 & $79.91 \%$ & $8348 \%$ & 1002 & 1754 & 0.487 & 4695 & 0.328 & 168 & 645 & 1837 & 07848 \\
\hline 7 & 0 & 31.08 & 0.1404 & $0.00 \%$ & $000 \%$ & 1289 & 1783 & 0000 & 4769 & 2.591 & 51 & 646 & 5747 & 0.4957 \\
\hline 7 & 0 & 31.08 & 0.1404 & $0.00 \%$ & $000 \%$ & 1033 & 1783 & 0000 & 4769 & 2076 & 59 & 646 & 5702 & 05086 \\
\hline 7 & 0 & 31.08 & 0.1404 & $000 \%$ & $000 \%$ & 906 & 1754 & 0000 & 4695 & 1796 & 6.3 & 645 & 5702 & 0.5136 \\
\hline 7 & 0 & 31.08 & 0.1404 & $0.00 \%$ & $000 \%$ & 823 & 1.783 & 0000 & 4769 & 1.654 & 6.9 & 646 & 57.02 & 0.5160 \\
\hline 8 & 0 & 31.08 & 0.2375 & $000 \%$ & $0.00 \%$ & 1427 & 1.783 & 0.000 & 4769 & 2.669 & 6.6 & 646 & 55.22 & 0.5109 \\
\hline 8 & 0 & 31.08 & 0.2375 & $000 \%$ & $000 \%$ & 1159 & 1783 & 0000 & 4769 & 2331 & 74 & 646 & 55.22 & 05207 \\
\hline 8 & 0 & 3108 & 0.2375 & $0.00 \%$ & $000 \%$ & 1036 & 1.783 & 0000 & 4769 & 2083 & 79 & 646 & 55.22 & 0.5251 \\
\hline 8 & 0 & 3108 & 0.2375 & $0.00 \%$ & $000 \%$ & 930 & 1783 & 0000 & 4769 & 1869 & 84 & 646 & 5612 & 0.5205 \\
\hline
\end{tabular}




\begin{tabular}{|c|c|c|c|c|c|c|c|c|c|c|c|c|c|c|}
\hline Ruin & $\begin{array}{c}\text { Total } \\
\text { Arilhracene } \\
\text { grams }\end{array}$ & $\begin{array}{c}\text { Total } \\
\text { Hexadecant } \\
\text { grams }\end{array}$ & Hydlogon & $\begin{array}{c}\text { Anthracent } \\
\text { (112 fitu) } \\
\text { w\% }\end{array}$ & $\begin{array}{l}\text { Anitilacene } \\
\text { (Ii2 lrous } \\
\text { mals }\end{array}$ & Gas Volume & $\begin{array}{l}\text { Anthraceno } \\
\text { Vapout } \\
\text { Prossulte } \\
\text { toar }\end{array}$ & $\begin{array}{l}\text { Animracene } \\
\text { wh Gads } \\
\text { grams }\end{array}$ & 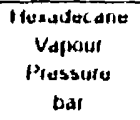 & $\begin{array}{l}\text { Ilexalderafios } \\
\text { in Gads } \\
\text { Urallis }\end{array}$ & Plessulg & Temporallute & $\begin{array}{l}\text { Linuid } \\
\text { Volume } \\
\text { mi }\end{array}$ & $\begin{array}{l}\text { Adjusled } \\
\text { Densily } \\
\text { utnisl }\end{array}$ \\
\hline 9 & 0 & 31.08 & 0.3664 & $0.00 \%$ & $000 \%$ & 1463 & 1.783 & 0.000 & 4.769 & 2941 & 97 & $\overline{646}$ & 55.22 & 0.5096 \\
\hline 9 & 0 & 31.08 & 0.3664 & $0.00 \%$ & $000 \%$ & 1261 & 1783 & 0.000 & 4.769 & 2534 & 10.6 & 646 & 55.22 & 0.5170 \\
\hline $\mathbf{9}$ & 0 & 31.08 & 0.3664 & $0.00 \%$ & $0.00 \%$ & 1073 & 1783 & 0.000 & 4769 & 2.156 & 11.6 & 646 & 55.22 & 0.5238 \\
\hline 9 & 0 & 31.08 & 0.3664 & $0.00 \%$ & $0.00 \%$ & 923 & 1783 & 0.000 & 4769 & 1854 & 12.7 & 646 & 56.12 & 0.5208 \\
\hline 10 & 3.4 & 15.7 & 0.082 & $17.80 \%$ & $21.58 \%$ & 1592 & 1783 & 0203 & 4.769 & 2509 & 3.2 & 646 & 28.62 & 0.5727 \\
\hline 10 & 3.4 & 157 & 0082 & $1780 \%$ & $2158 \%$ & 1349 & 1783 & 0172 & 4769 & 2127 & 37 & 646 & 2862 & 05871 \\
\hline 10 & 34 & 157 & 0.082 & $17.80 \%$ & $2158 \%$ & 1189 & 1783 & 0152 & 4769 & 1874 & 41 & 646 & 2952 & 0.5785 \\
\hline 10 & 3.4 & 15.7 & 0.082 & $17.80 \%$ & $2158 \%$ & 1040 & 1783 & 0133 & 4769 & 1640 & 45 & 646 & 29.52 & 05870 \\
\hline 10 & 3.4 & 15.7 & 0.082 & $1780 \%$ & $2158 \%$ & 900 & 1783 & 0116 & 4769 & 1432 & 50 & 646 & 3042 & 0.5770 \\
\hline 11 & 34 & 15.7 & 0.1849 & $17.80 \%$ & $2158 \%$ & 1722 & 1783 & 0.220 & 4769 & 2715 & 63 & 646 & 30.42 & 05314 \\
\hline 11 & 34 & 15.7 & 0.1849 & $17.80 \%$ & $2158 \%$ & 1548 & 1783 & 0198 & 4769 & 2441 & 69 & 646 & 3042 & 05412 \\
\hline 11 & 3.4 & 15.7 & 0.1849 & $17.80 \%$ & $2158 \%$ & 1418 & 1783 & 0181 & 4769 & 2236 & 76 & 646 & 2862 & 0.5830 \\
\hline 11 & 3.4 & 15.7 & 0.1849 & $1780 \%$ & $2158 \%$ & 1301 & 1783 & 0.166 & 4769 & 2050 & 81 & 646 & 29.52 & 05720 \\
\hline 11 & 34 & 157 & 0.1849 & $1780 \%$ & $2158 \%$ & 1140 & 1783 & 0146 & 4769 & 1797 & 90 & 646 & 3042 & 05641 \\
\hline 11 & 3.4 & 157 & 0.1849 & $1780 \%$ & $2158 \%$ & 1010 & 1783 & 0.129 & 4769 & 1591 & 100 & 646 & 3042 & 05714 \\
\hline 12 & 3.4 & 15.7 & 0.298 & $17.80 \%$ & $2158 \%$ & 1860 & 1783 & 0.237 & 4769 & 2931 & 93 & $\overline{646}$ & 3042 & 0.5237 \\
\hline 12 & 3.4 & 15.7 & 0298 & $17.80 \%$ & $2158 \%$ & 1687 & 1754 & 0212 & 4695 & 2622 & 102 & 645 & 2997 & 05428 \\
\hline 12 & 3.4 & 15.7 & 0.298 & $17.80 \%$ & $2158 \%$ & 1586 & 1783 & 0.203 & 4769 & 2501 & 108 & 646 & 2952 & 05555 \\
\hline 12 & 3.4 & 15.7 & 0.298 & $1780 \%$ & $21.58 \%$ & 1457 & 1783 & 0186 & 4769 & 2297 & 117 & 646 & 2907 & 05717 \\
\hline 12 & 3.4 & 15.7 & 0.298 & $1780 \%$ & $2158 \%$ & 1341 & 1.783 & 0171 & 4.769 & 2114 & 126 & 646 & 29.07 & 0.5785 \\
\hline 13 & 3.4 & 19.28 & 0.1252 & $14.99 \%$ & $18.30 \%$ & 1747 & 1.783 & 0189 & 4.769 & 2868 & 44 & $\overline{646}$ & 36.28 & 0.5409 \\
\hline 13 & 3.4 & 19.28 & 01252 & $14.99 \%$ & $1830 \%$ & 1443 & 1814 & 0159 & 4843 & 2402 & 52 & 647 & 3628 & 05545 \\
\hline 13 & 3.4 & 19.28 & 0.1252 & $1499 \%$ & $1830 \%$ & 1160 & 1783 & 0.126 & 4769 & 1905 & 62 & 646 & 3673 & 05622 \\
\hline 13 & 3.4 & 19.28 & 0.1252 & $14.99 \%$ & $1830 \%$ & 1050 & 1.783 & 0.114 & 4.769 & 1725 & 67 & 646 & 37.18 & 0.5605 \\
\hline 13 & 3.4 & 19.28 & 0.1252 & $14.99 \%$ & $18.30 \%$ & 960 & 1783 & 0104 & 4769 & 1576 & 72 & 646 & 37.18 & 0.5648 \\
\hline 14 & 3.4 & 19.28 & 0.2043 & $14.99 \%$ & $1830 \%$ & 1712 & 1754 & 0.183 & 4695 & 2773 & 70 & 645 & 3718 & 0.5305 \\
\hline 14 & 3.4 & 19.28 & 0.2043 & $1499 \%$ & $1830 \%$ & 1532 & 1754 & 0.163 & 4695 & 2481 & 77 & 645 & 3673 & 0.5455 \\
\hline 14 & 3.4 & 19.28 & 0.2043 & $1499 \%$ & $1830 \%$ & 1409 & 1783 & 0153 & 4769 & 2314 & 84 & 646 & 36.73 & 0.5503 \\
\hline 14 & 3.4 & 19.28 & 0.2043 & $14.99 \%$ & $1830 \%$ & 126.9 & 1783 & 0137 & 4769 & 2084 & 92 & 646 & 36.28 & 0.5639 \\
\hline 14 & 3.4 & 19.28 & 0.2043 & $14.99 \%$ & $1830 \%$ & 1155 & 1783 & 0125 & 4769 & 1897 & 99 & 646 & 37.18 & 05556 \\
\hline 14 & 3.4 & 19.28 & 0.2043 & $14.99 \%$ & $1830 \%$ & 1087 & 1783 & 0118 & 4769 & 1786 & 105 & 646 & 3673 & 05656 \\
\hline
\end{tabular}




\begin{tabular}{|c|c|c|c|c|c|c|c|c|c|c|c|c|c|c|}
\hline Run & $\begin{array}{c}\text { Total } \\
\text { Anthiacuno } \\
\text { grams } \\
\end{array}$ & $\begin{array}{c}\text { Total } \\
\text { Hoxadecsilu } \\
\text { grams }\end{array}$ & Hydlogen & $\begin{array}{c}\text { Anthrocunt } \\
\text { (II } 1 \text { fret) } \\
\text { w\% }\end{array}$ & 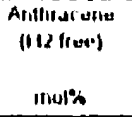 & 'sass Vollime & $\begin{array}{l}\text { Anlbiacune } \\
\text { Vapeuur } \\
\text { l'rossilis } \\
\text { tral }\end{array}$ & $\begin{array}{l}\text { Anthist ente } \\
\text { mosus } \\
\text { granis }\end{array}$ & 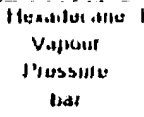 & 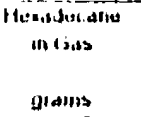 & Pricssule & 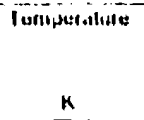 & 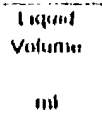 & $\begin{array}{l}\text { Adfustudi } \\
\text { Derisity }\end{array}$ \\
\hline 15 & 3.4 & 19.28 & 0.2853 & $14.99 \%$ & $1830 \%$ & 181.5 & 1783 & 0.197 & 4769 & 2.981 & 9.2 & $\overline{646}$ & 36.28 & 0.5375 \\
\hline 15 & 3.4 & 19.28 & 0.2853 & $14.99 \%$ & $18.30 \%$ & 1667 & 1783 & 0181 & 4769 & 2738 & 99 & 646 & 3628 & 0.5447 \\
\hline 15 & 3.4 & 19.28 & 0.2853 & $14.99 \%$ & $18.30 \%$ & 1522 & 1.783 & 0.165 & 4769 & 2500 & 108 & 646 & 36.28 & 0.5517 \\
\hline 15 & 3.4 & 19.28 & 0.2853 & $14.99 \%$ & $1830 \%$ & 137.8 & 1.783 & 0.149 & 4.769 & 2262 & 11.8 & 646 & 36.28 & 0.5587 \\
\hline 15 & 3.4 & 19.28 & 0.2853 & $1499 \%$ & $1830 \%$ & 1284 & 1.783 & 0.139 & 4769 & 2108 & 12.6 & 646 & 36.28 & 0.5632 \\
\hline 15 & 3.4 & 19.28 & 0.2853 & $1499 \%$ & $1830 \%$ & 1159 & 1814 & 0.127 & 4843 & 1930 & 136 & 647 & 37.18 & 05546 \\
\hline 16 & 3.4 & 23.03 & 0.1486 & $12.86 \%$ & $1579 \%$ & 1691 & 1783 & 0.158 & 4769 & 2.862 & 5.4 & 646 & 42.59 & 0.5496 \\
\hline 16 & 3.4 & 23.03 & 0.1486 & $1286 \%$ & $1579 \%$ & 1448 & 1783 & 0135 & 4769 & 2452 & 62 & 646 & 4259 & 0.5598 \\
\hline 16 & 3.4 & 23.03 & 0.1486 & $1286 \%$ & $1579 \%$ & 1333 & 1783 & 0125 & 4769 & 2256 & 67 & 646 & $4259^{\circ}$ & 0.5646 \\
\hline 16 & 3.4 & 23.03 & 0.1486 & $1286 \%$ & $1579 \%$ & 1145 & 1783 & 0107 & 4769 & 1937 & 75 & 646 & 4440 & 0.5493 \\
\hline 16 & 3.4 & 23.03 & 0.1486 & $1286 \%$ & $1579 \%$ & 1046 & 1.783 & 0098 & 4769 & 1771 & 80 & 646 & 44.85 & 0.5477 \\
\hline 16 & 3.4 & 23.03 & 0.1486 & $1286 \%$ & $1579 \%$ & 978 & 1783 & 0091 & 4769 & 1656 & 85 & 646 & 44.40 & 0.5560 \\
\hline 17 & 3.4 & 23.03 & 0.2078 & $1286 \%$ & $15.79 \%$ & 1662 & 1.783 & 0155 & 4769 & 2813 & 75 & 646 & 4259 & 0.5508 \\
\hline 17 & 3.4 & 23.03 & 0.2078 & $12.86 \%$ & $15.79 \%$ & 1499 & 1783 & 0140 & 4769 & 2537 & 81 & 646 & 4440 & 05350 \\
\hline 17 & 3.4 & 23.03 & 0.2078 & $1286 \%$ & $15.79 \%$ & 1373 & 1783 & 0128 & 4769 & 2323 & 88 & 646 & 44.40 & 0.5401 \\
\hline 17 & 3.4 & 23.03 & 0.2078 & $1286 \%$ & $1579 \%$ & 1256 & 1783 & 0117 & 4769 & 2126 & 95 & 646 & 4485 & 05393 \\
\hline 17 & 3.4 & 23.03 & 0.2078 & $12.86 \%$ & $15.79 \%$ & 1112 & 1783 & 0104 & 4769 & 1882 & 105 & 646 & 4440 & 0.5506 \\
\hline 17 & 34 & 23.03 & 0.2078 & $12.86 \%$ & $1579 \%$ & 103.2 & 1783 & 0096 & 4769 & 1746 & 111 & 646 & 44.85 & 0.5482 \\
\hline 18 & 3.4 & 23.03 & 0.2956 & $12.86 \%$ & $1579 \%$ & 1772 & 1.783 & 0.166 & 4769 & 3.000 & 99 & $\overline{646}$ & 41.69 & 05580 \\
\hline 18 & 3.4 & 23.03 & 0.2956 & $12.86 \%$ & $15.79 \%$ & 1632 & 1783 & 0153 & 4769 & 2762 & 106 & 646 & 4304 & 0.5463 \\
\hline 18 & 3.4 & 23.03 & 0.2956 & $12.86 \%$ & $1579 \%$ & 1516 & 1.783 & 0142 & 4769 & 2566 & 11.4 & 646 & 43.04 & 05511 \\
\hline 18 & 3.4 & 23.03 & 0.2956 & $1286 \%$ & $1579 \%$ & 1419 & 1783 & 0133 & 4769 & 2401 & 121 & 646 & 43.04 & 05552 \\
\hline 18 & 3.4 & 23.03 & 0.2956 & $1286 \%$ & $1579 \%$ & 1335 & 1783 & 0125 & 4769 & 2260 & 127 & 646 & 4304 & 05586 \\
\hline 18 & 34 & 23.03 & 0.2956 & $1286 \%$ & $15.79 \%$ & 1209 & 1783 & 0113 & 4769 & 2046 & 139 & 646 & 4304 & 0.5639 \\
\hline 19 & 8.99 & 7.66 & 0.1462 & $53.99 \%$ & $59.86 \%$ & 1917 & 1783 & 0679 & 4769 & 1.547 & 47 & 646 & 19.60 & 0.7360 \\
\hline 19 & 8.99 & 7.66 & 0.1462 & $53.99 \%$ & $5986 \%$ & 1541 & 1783 & 0546 & 4769 & 1243 & 57 & 646 & 1960 & 0.7583 \\
\hline 19 & 8.99 & 7.66 & 0.1462 & $53.99 \%$ & $59.86 \%$ & 1326 & 1783 & 0470 & 4.769 & 1070 & 64 & 646 & 20.50 & 0.7371 \\
\hline 19 & 8.99 & 7.66 & 0.1462 & $5399 \%$ & $59.86 \%$ & 1185 & 1.783 & 0420 & 4769 & 0956 & 70 & 646 & 2050 & 0.7451 \\
\hline 19 & 8.99 & 7.66 & 0.1462 & $53.99 \%$ & $59.86 \%$ & 1073 & 1783 & 0380 & 4769 & 0.866 & 7.6 & 646 & 21.85 & 07049 \\
\hline 19 & 8.99 & 766 & 0.1462 & $5399 \%$ & $5986 \%$ & 1005 & 1783 & 0356 & 4769 & 0811 & 79 & 646 & 21.85 & 0.7086 \\
\hline
\end{tabular}




\begin{tabular}{|c|c|c|c|c|c|c|c|c|c|c|c|c|c|c|}
\hline Run & $\begin{array}{c}\text { Total } \\
\text { Anthraceno } \\
\text { glams }\end{array}$ & $\begin{array}{l}\text { Total } \\
\text { Mexadecant } \\
\text { grams }\end{array}$ & Hydrogen & $\begin{array}{c}\text { Anthracene } \\
\text { (t 12 fieu] } \\
\text { wt\% }\end{array}$ & 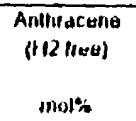 & Gas volutine & $\begin{array}{l}\text { Anthitacene } \\
\text { Vapour } \\
\text { Hossuly } \\
\text { bar }\end{array}$ & $\begin{array}{l}\text { Anthracene } \\
\text { in fias } \\
\text { gisuris }\end{array}$ & 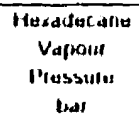 & $\begin{array}{l}\text { llexadecane } \\
\text { in fjas } \\
\text { yisulis }\end{array}$ & Pressule & Turmistativio & $\begin{array}{l}\text { Ilquid } \\
\text { volume } \\
\text { nil }\end{array}$ & $\begin{array}{l}\text { Adjusted } \\
\text { Density } \\
\text { ulyul }^{\prime}\end{array}$ \\
\hline 20 & 8.99 & 7.66 & 0.2823 & $5399 \%$ & $59.86 \%$ & 2009 & 1783 & 0712 & 4769 & 1621 & 83 & (i46 & 2050 & 0,6984 \\
\hline 20 & 8.99 & 7.66 & 02823 & $53.99 \%$ & $5986 \%$ & 1845 & 1783 & 0653 & 4769 & 1489 & 90 & $6 j 46$ & 1960 & 07403 \\
\hline 20 & 899 & 7.66 & 0.2823 & $53.99 \%$ & $5986 \%$ & 1695 & 1783 & 0600 & 4769 & 1367 & 97 & tj46 & 2050 & 0.7163 \\
\hline 20 & 8.99 & 7.66 & 0.2823 & $5399 \%$ & $59.86 \%$ & 1554 & 1783 & 0550 & 4769 & 1254 & 105 & 1346 & 20.50 & 0.7242 \\
\hline 20 & 8.99 & 766 & 0.2823 & $53.99 \%$ & $5986 \%$ & 1416 & 1783 & 0.502 & 4769 & 1143 & 114 & B46 & 2050 & 0.7320 \\
\hline 20 & 8.99 & 7.66 & 0.2823 & $5399 \%$ & $5986 \%$ & 1315 & 1783 & 0.466 & 4769 & 1061 & 122 & 5046 & 2050 & 0.7378 \\
\hline 20 & 8.99 & 7.66 & 0.2823 & $5399 \%$ & $5986 \%$ & 1193 & 1783 & 0422 & 4769 & 0963 & 131 & 646 & 21.85 & 0.6986 \\
\hline 20 & 6.99 & 7.66 & 02823 & $53.99 \%$ & $5986 \%$ & 1141 & 1783 & 0404 & 4769 & 0921 & 136 & 646 & 22.30 & 0.6871 \\
\hline 20 & 8.99 & 7.66 & 0.2823 & $53.99 \%$ & $5986 \%$ & 1095 & 1783 & 0388 & 4769 & 0884 & 141 & 646 & 2185 & 0.7038 \\
\hline 21 & 8.99 & 9.23 & 0.1651 & $49.34 \%$ & $5531 \%$ & 1895 & 1783 & 0620 & 4769 & 1702 & 54 & 646 & 2366 & 0.6721 \\
\hline 21 & 8.99 & 9.23 & 0.1651 & $49.34 \%$ & $5531 \%$ & 1588 & 1783 & 0520 & 4769 & 1427 & 64 & 646 & 25.01 & 0.6507 \\
\hline 21 & 899 & 9.23 & 01651 & $49.34 \%$ & $55.31 \%$ & 1438 & 1783 & 0471 & 4769 & 1292 & 70 & 646 & 24.11 & 06827 \\
\hline 21 & 8.99 & 9.23 & 0.1651 & $49.34 \%$ & $5531 \%$ & 1150 & 1783 & 0376 & 4769 & 1034 & 84 & 646 & 25.01 & 06722 \\
\hline 21 & 899 & 923 & 0.1651 & $49.34 \%$ & $5531 \%$ & 1053 & 1783 & 0345 & 4769 & 0946 & 91 & 646 & 25.01 & 0.6770 \\
\hline 22 & 8.99 & 9.23 & 0.3095 & $49.34 \%$ & $5531 \%$ & 1993 & 1783 & 0652 & 4769 & 1791 & 93 & 646 & 2501 & 0.6309 \\
\hline 22 & 899 & 923 & 03095 & $4934 \%$ & $5531 \%$ & 1771 & 1783 & 0579 & 4769 & 1591 & 105 & 646 & 2411 & 06658 \\
\hline 22 & 899 & 9.23 & 03095 & $4934 \%$ & $5531 \%$ & 1659 & 1783 & 0543 & 4769 & 1490 & 111 & 646 & 2411 & 06715 \\
\hline 22 & 8.99 & 923 & 03095 & $49.34 \%$ & $5531 \%$ & 1563 & 1783 & 0511 & 4769 & 1404 & 118 & 646 & 2320 & 07027 \\
\hline 22 & 899 & 9.23 & 0 3095 & $4934 \%$ & $5531 \%$ & 1469 & 1783 & 0481 & 4769 & 1319 & 125 & 646 & 2320 & 0.7076 \\
\hline 22 & 8.99 & 9.23 & 03095 & $49.34 \%$ & $5531 \%$ & 1370 & 1783 & 0448 & 4769 & 1231 & 132 & 646 & 2366 & 06992 \\
\hline 22 & 8.99 & 9.23 & 0.3095 & $49.34 \%$ & $5531 \%$ & 1293 & 1783 & 0423 & 4769 & 1162 & 139 & 646 & 2411 & 06901 \\
\hline 23 & 14.96 & 11.88 & 0.1464 & $55.74 \%$ & $6154 \%$ & 1888 & 1.783 & 0687 & 4769 & 1459 & 42 & 646 & 34.48 & 0.7162 \\
\hline 23 & 14.96 & 11.88 & 0.1464 & $55.74 \%$ & $6154 \%$ & 1568 & 1783 & 0571 & 4769 & 1212 & 49 & 646 & 35.38 & 0.7083 \\
\hline 23 & 14.96 & 11.88 & 0.1464 & $55.74 \%$ & $6154 \%$ & 1331 & 1783 & 0485 & 4769 & 1029 & 56 & 646 & 3628 & 0.6981 \\
\hline 23 & 14.96 & 11.88 & 0.1464 & $5574 \%$ & $61.54 \%$ & 1153 & 1783 & 0420 & 4769 & 0892 & 63 & 646 & 3628 & 07036 \\
\hline 23 & 1496 & 11.88 & 01464 & $5574 \%$ & $6154 \%$ & 1027 & 1783 & 0374 & 4769 & 0794 & 69 & 646 & 3628 & 07076 \\
\hline 23 & 14.96 & 11.88 & 01464 & $55.74 \%$ & $6154 \%$ & 909 & 1783 & 0331 & 4769 & 0703 & 76 & 646 & 3718 & 06940 \\
\hline 24 & 14.96 & 11.88 & 0.2159 & $55.74 \%$ & $6154 \%$ & 1801 & 1783 & 0656 & 4769 & 1392 & 64 & 646 & 36.28 & 0.6833 \\
\hline 24 & 14.96 & 11.88 & 0.2159 & $5574 \%$ & $61.54 \%$ & 1613 & 1783 & 0.587 & 4769 & 1247 & 70 & 646 & 36.28 & 0.6892 \\
\hline 24 & 14.96 & 11.88 & 02159 & $55.74 \%$ & $61.54 \%$ & 1475 & 1783 & 0537 & 4769 & || $4 \mid$ & 76 & 646 & 36.28 & 0.6935 \\
\hline 24 & 14.96 & 11.88 & 02159 & $55.74 \%$ & $6154 \%$ & 1323 & 1.783 & 0.482 & 4769 & 1.023 & 84 & 646 & 36.73 & 0.6898 \\
\hline 24 & 14.96 & 1188 & 0.2159 & $5574 \%$ & $6154 \%$ & 1219 & 1783 & 0444 & 4769 & 0942 & 90 & 646 & 36.28 & 0.7016 \\
\hline 24 & 1496 & 11.88 & 02159 & $55.74 \%$ & $6154 \%$ & 1098 & 1783 & 0400 & 4769 & 0849 & 98 & 646 & 3673 & 06967 \\
\hline 24 & 14.96 & 1188 & 02159 & $5574 \%$ & $6154^{\prime} x$ & 1007 & 1783 & 0367 & 4769 & 0779 & 104 & 646 & 3718 & 06911 \\
\hline 24 & 1496 & 1188 & 02159 & $55.74 \%$ & $6154 \%$ & 958 & 1783 & 0349 & 4769 & 0741 & 108 & 646 & 3628 & 0.7098 \\
\hline
\end{tabular}




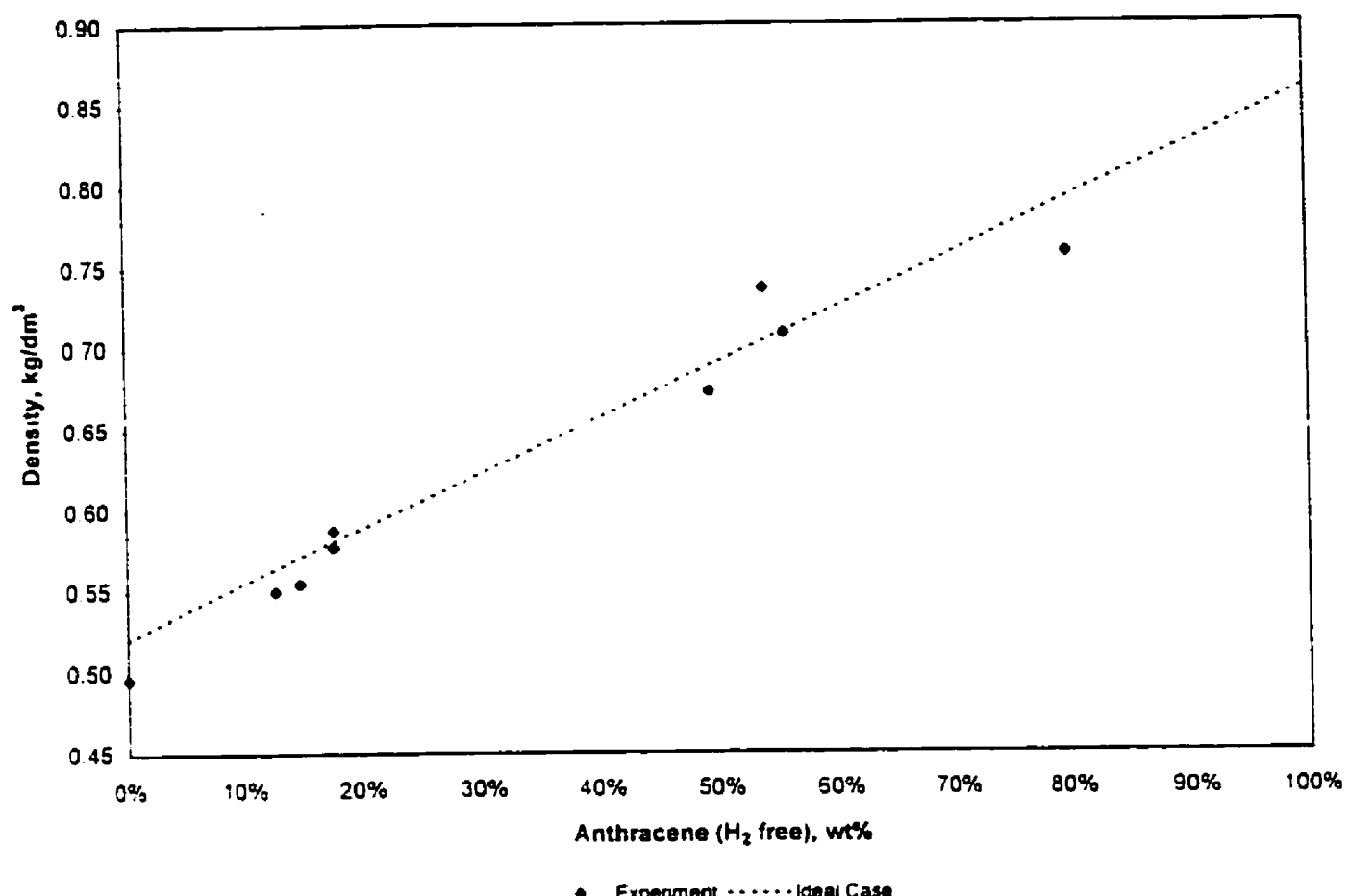

Figure B1 - Estimated liquid density at $5 \mathrm{MPa}$ and $646 \mathrm{~K}$

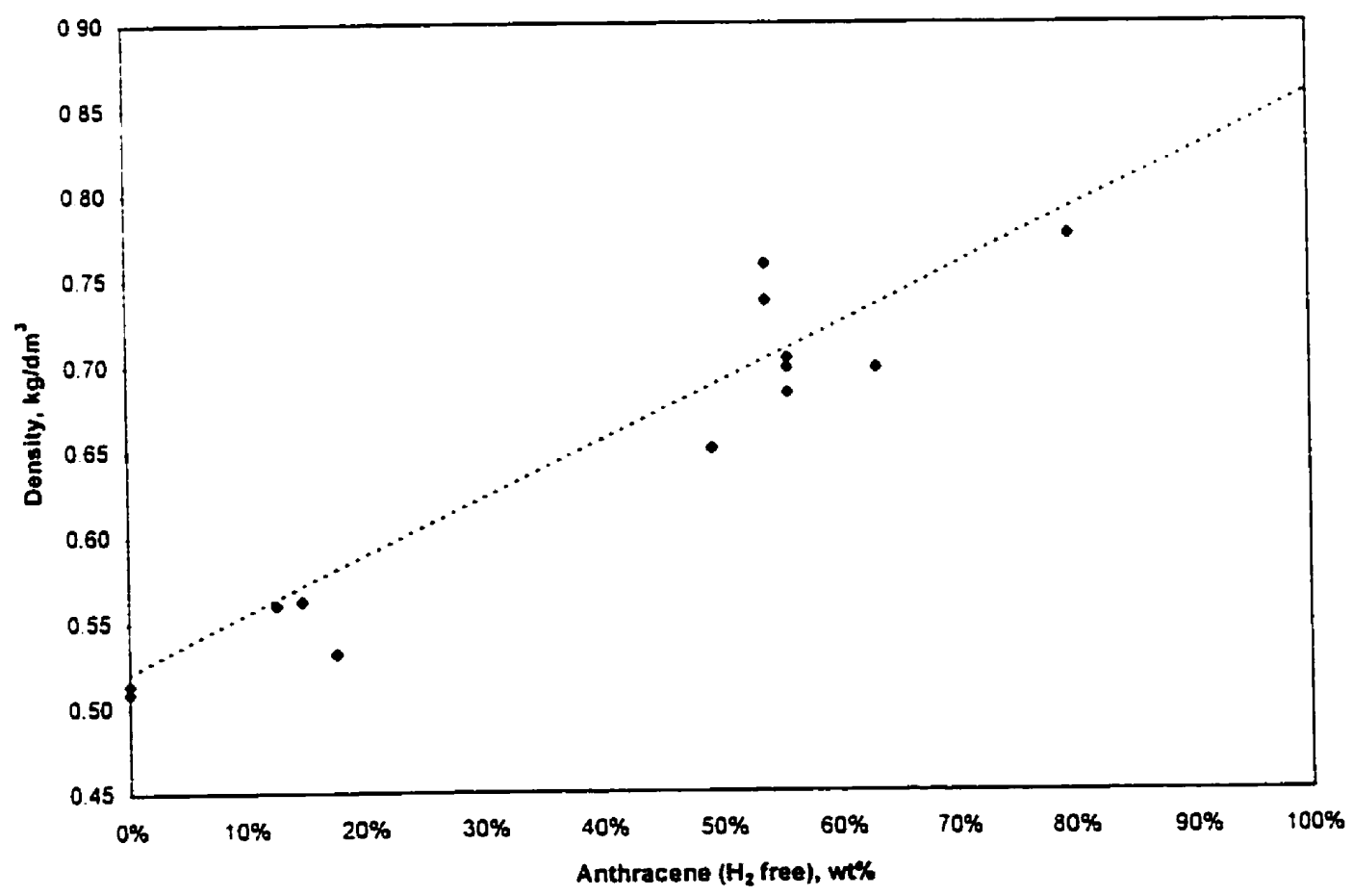

Figure B2 - Estimated liquid density at $6 \mathrm{MPa}$ and $646 \mathrm{~K}$ 


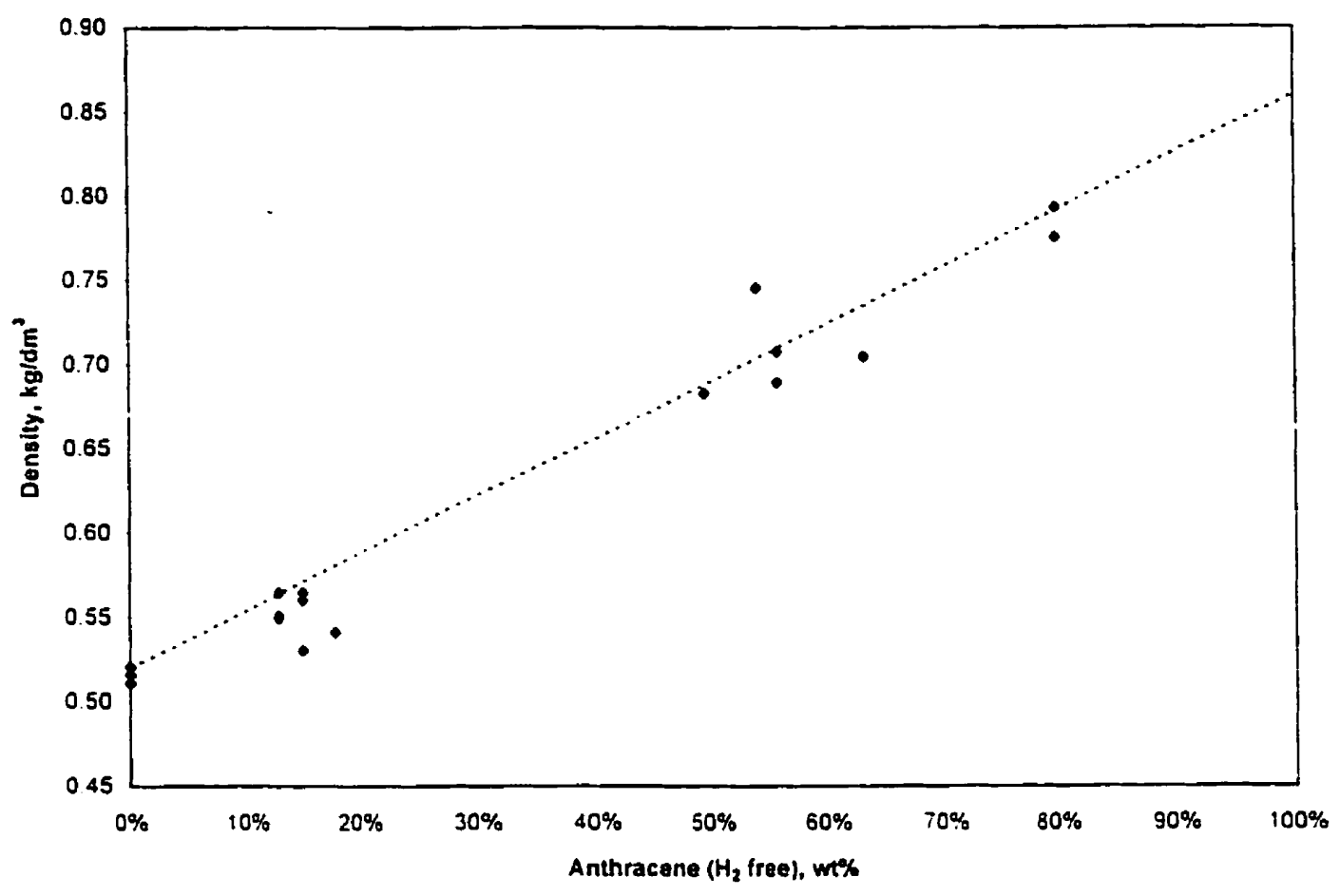

Figure B3 - Estimated liquid density at $7 \mathrm{MPa}$ and $646 \mathrm{~K}$

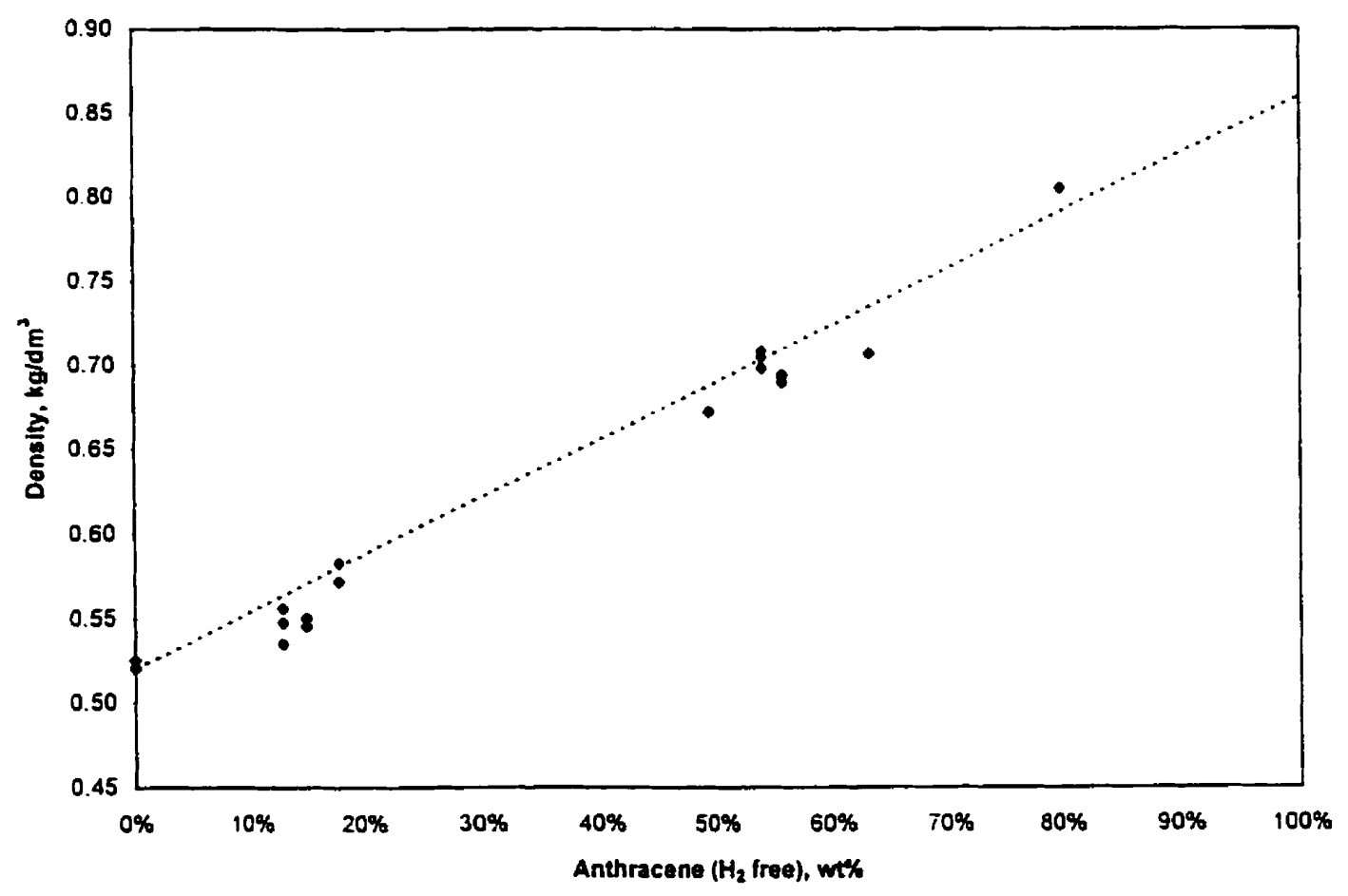

Figure B4 - Estimated liquid density at $8 \mathrm{MPa}$ and $646 \mathrm{~K}$ 


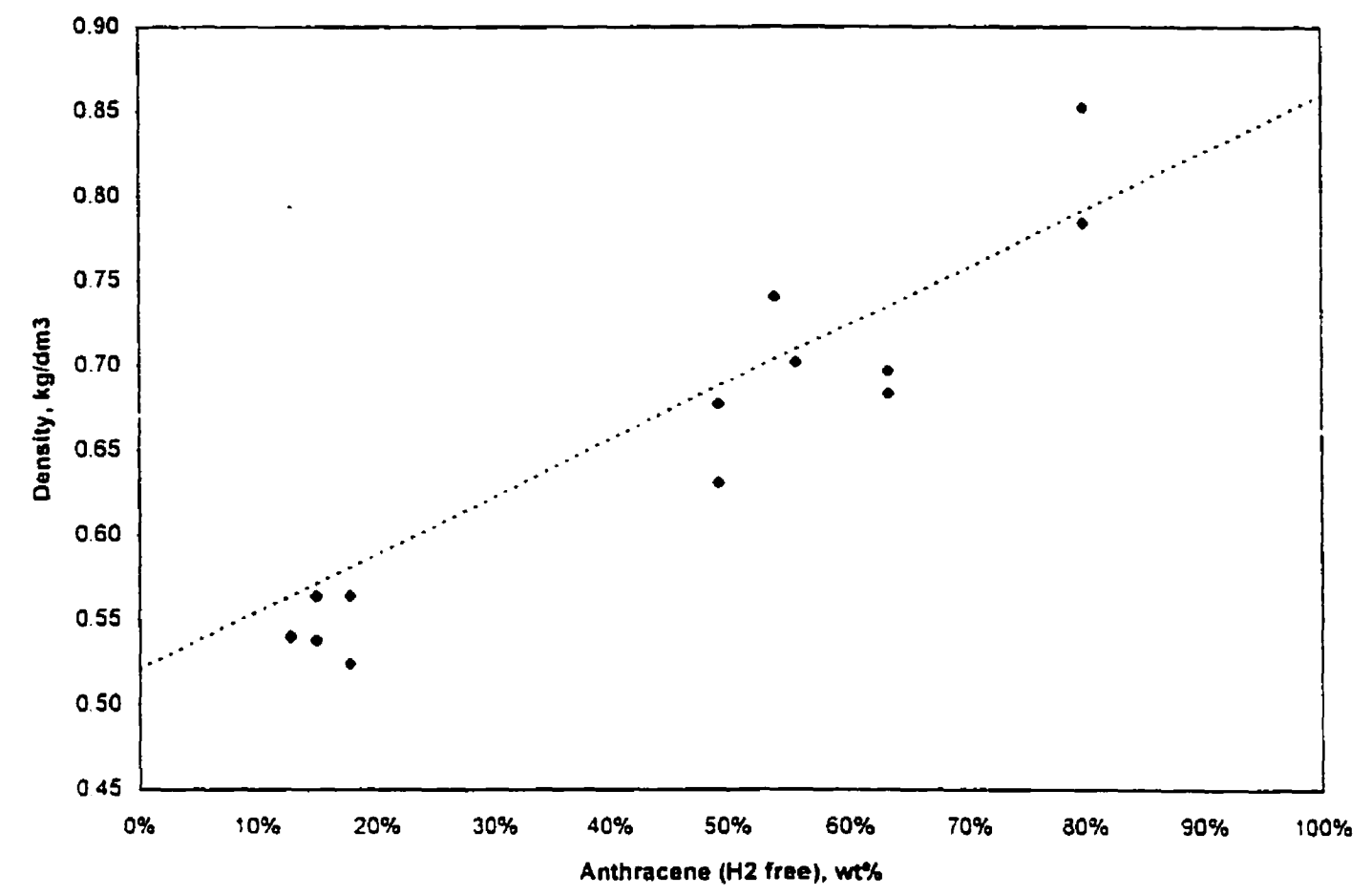

Figure B5 - Estimated liquid density at $9 \mathrm{MPa}$ and $6+6 \mathrm{~K}$

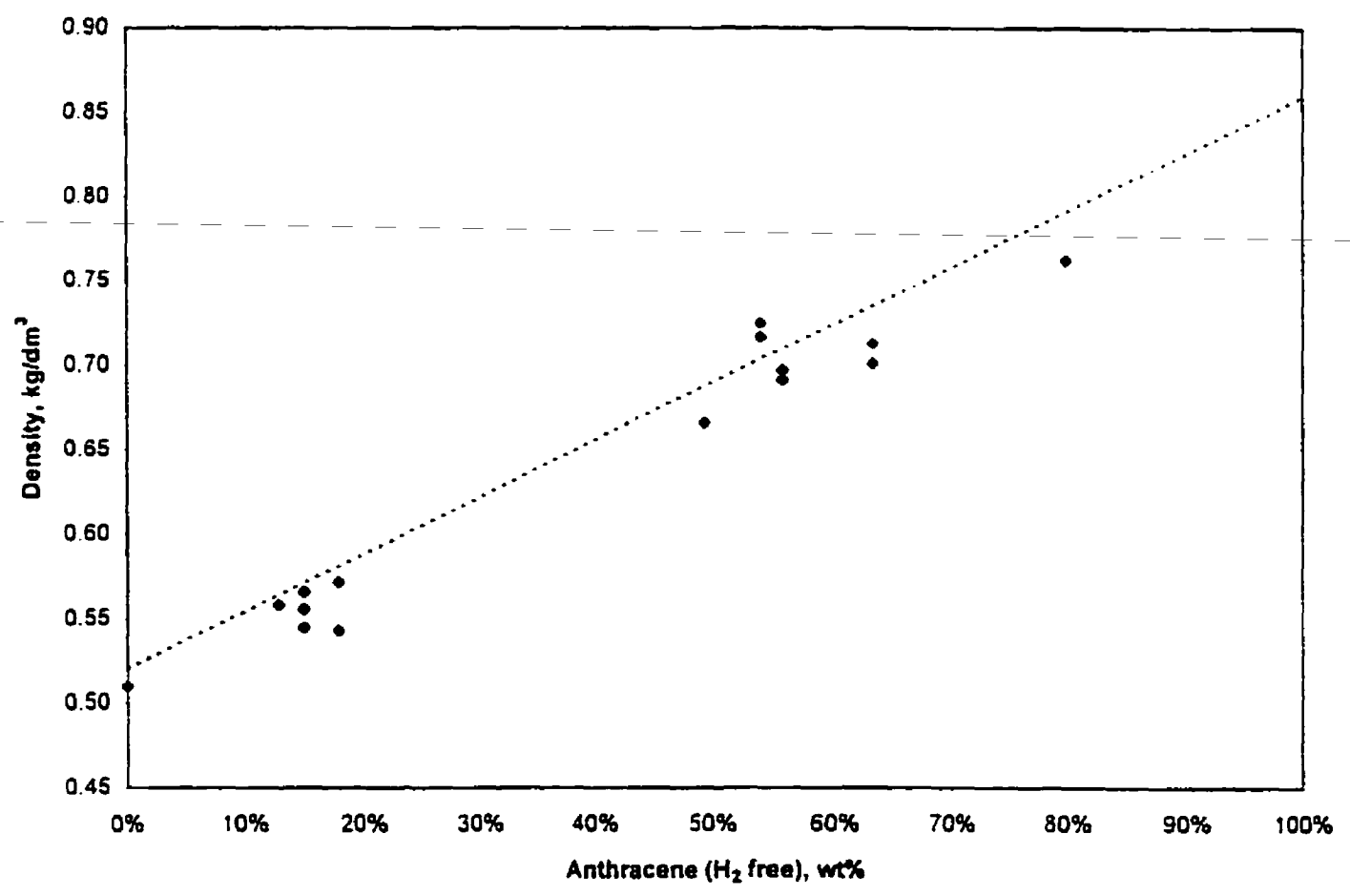

Figure B6 - Estimated liquid density at $10 \mathrm{MPa}$ and $646 \mathrm{~K}$ 


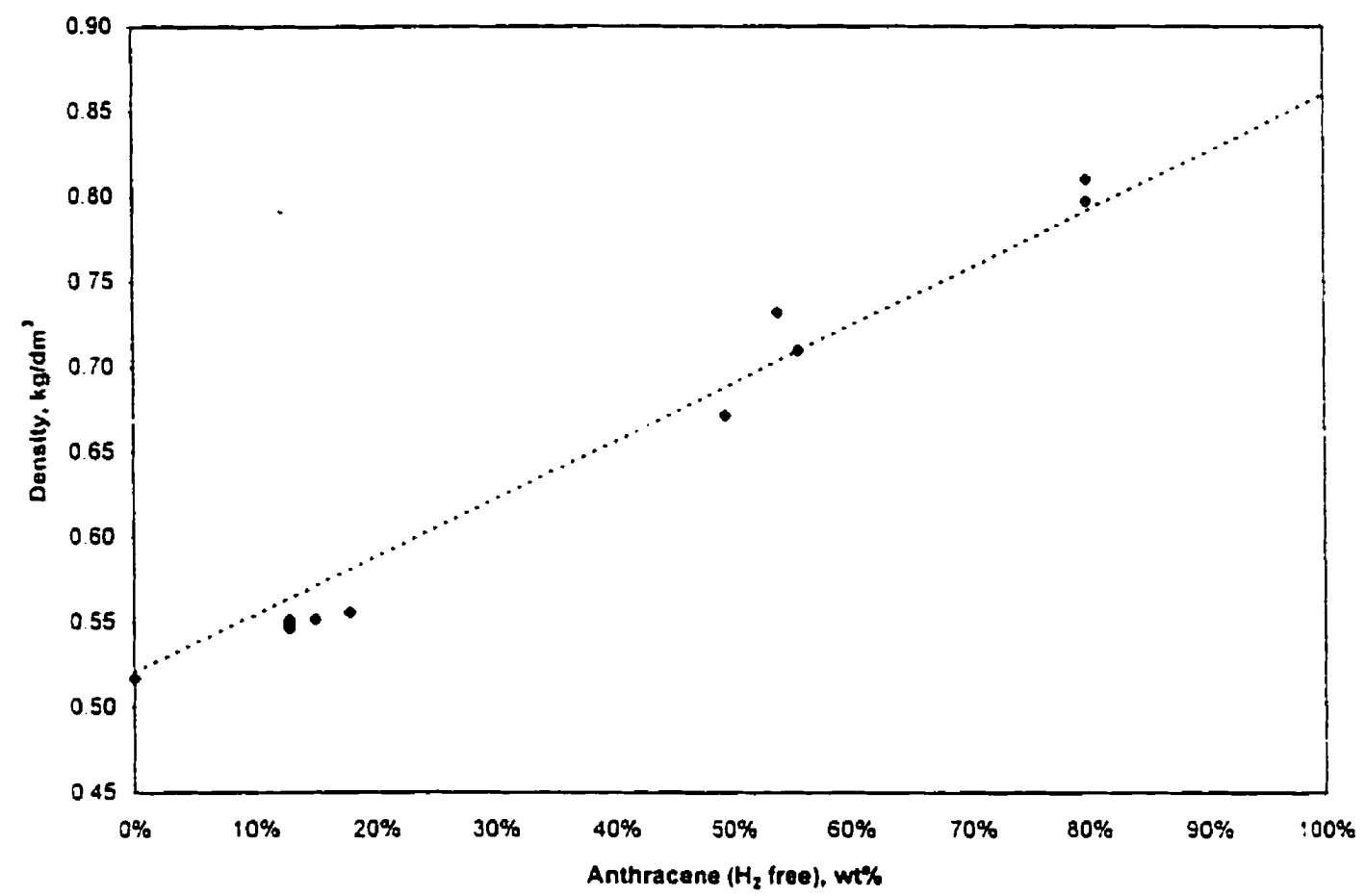

Figure B7 - Estimated liquid density at $11 \mathrm{MPa}$ and $646 \mathrm{~K}$

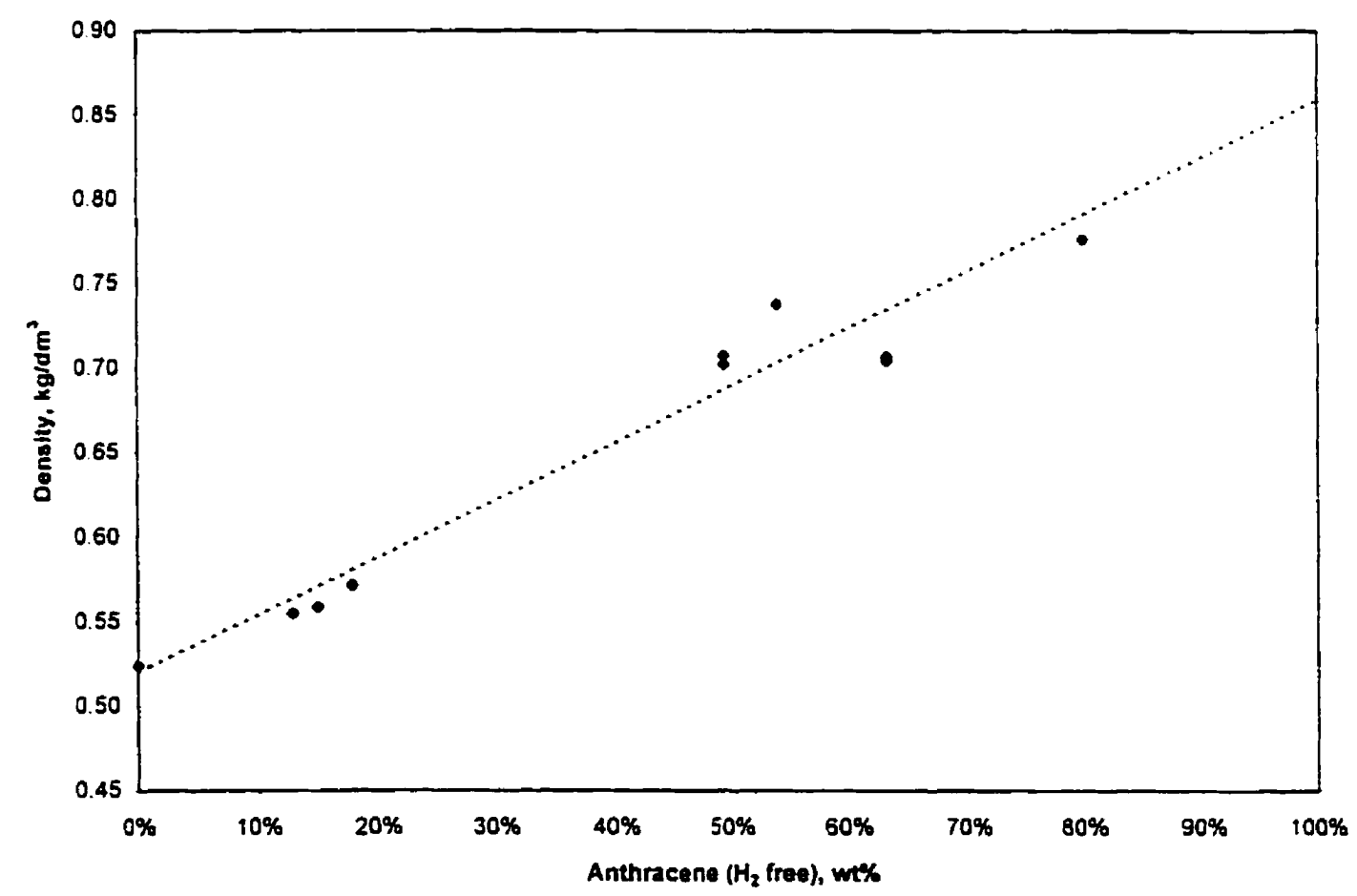

Figure B8 - Estimated liquid density at $12 \mathrm{MPa}$ and $646 \mathrm{~K}$ 


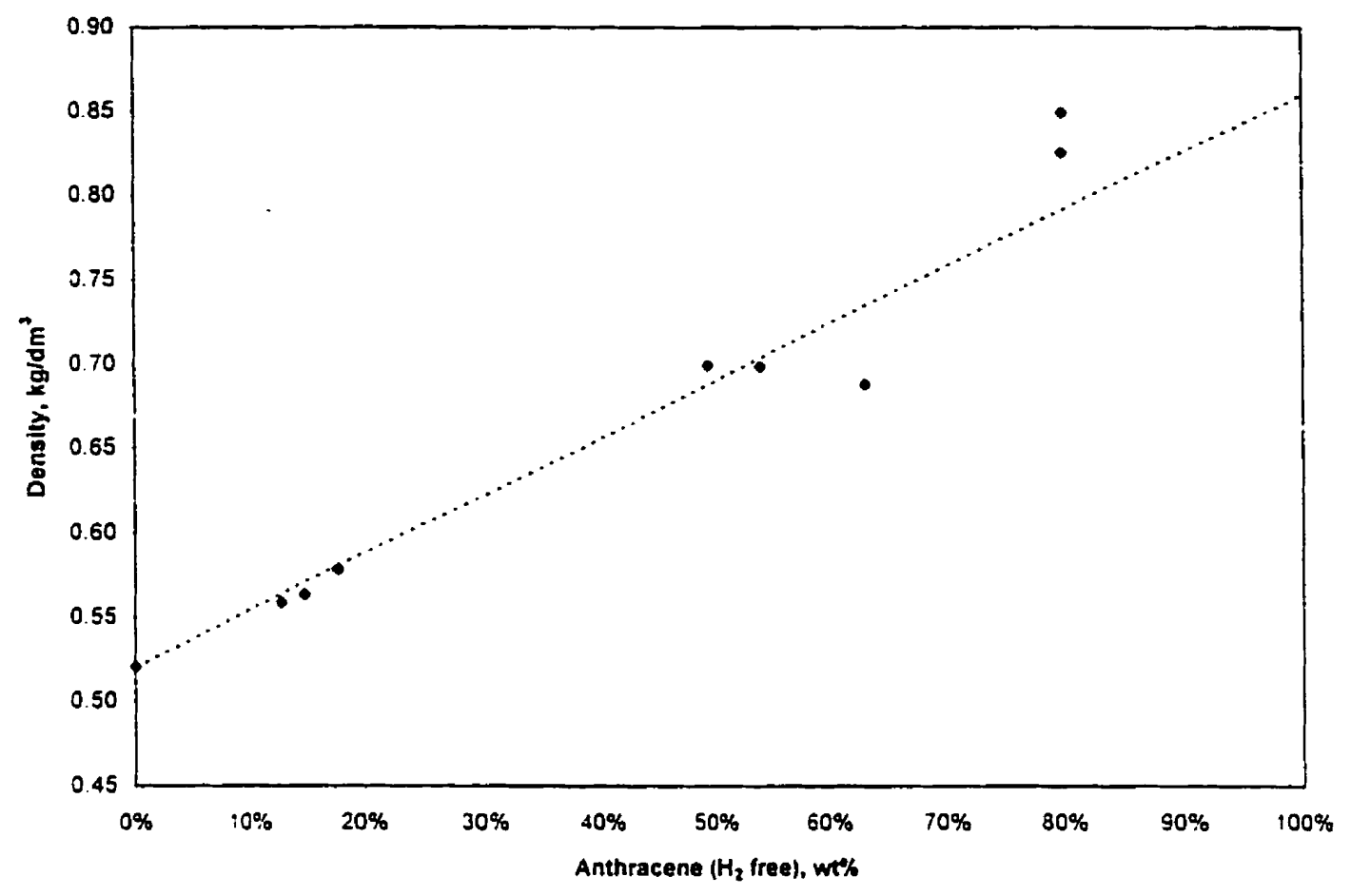

Figure B9 - Estimated liquid density at $13 \mathrm{MPa}$ and $646 \mathrm{~K}$ 


\section{Appendix C - P-R EOS binary interaction parameters fit to solid-fluid solubility data.}

Fugacity models have been fit to solid-fluid equilibrium data for anthracene + (methane, ethane, propane. and pentane) binary mixtures. The only fitting parameter is the binary interaction parameter for the Peng-Robinson equation of state.

The solubility of solute $i$ in a solvent is calculated by

$y_{i}^{\text {solv }}=\frac{f_{i}^{\text {solv }}}{\phi_{i}^{\text {solv } P}}$

Since the solvent and the solid solute are in equilibrium, their fugacities are equal.

$f_{1}^{\text {solv }}=f_{1}^{\text {solid }}$

The solid is assumed to be pure: therefore. the fugacity of the solid is determined by

$f_{1}^{\text {solid }}=P_{1}^{\text {sat }} \phi_{1}^{\text {sat }} \exp \int_{P^{\text {ust }}}^{p} \frac{v_{1}^{\text {solth }}}{R T} d P$

Combining the three previous equations and integrating gives

$y_{1}^{\text {solv }}=\frac{P_{1}^{\text {sot }}}{P} \frac{\phi_{1}^{\text {sut }}}{\phi_{i}^{\text {sulv }}} \exp \left[\frac{v_{1}^{\text {solut }}}{R T}\left(P-P_{1}^{\text {sur }}\right)\right]$

The fugacity coefficient $\phi^{\text {stt }}$ is very close to unity since the saturation pressure is low.

The fugacity coefficient for component $i$ in the solvent is given by

$\ln \phi_{i}=\frac{b_{i}}{b}\left(\frac{P v}{R T}-1\right)-\ln \frac{P(v-b)}{R T}-\frac{a}{2 \sqrt{2} b R T}\left[\frac{2 \sum_{1} x_{,} a_{i j}}{a}-\frac{b_{i}}{b}\right] \ln \frac{v+(1+\sqrt{2}) b}{v+(1-\sqrt{2}) b}$

If the component 1 is the solute and the binary solvent mixture is very dilute in solute, $x_{1}=0, a=a_{22}$, and $b=b_{22}$. The above equation reduces to:

$\ln \phi_{1}=\frac{b_{1}}{b_{22}}\left(\frac{P v_{2}^{\text {pure }}}{R T}-1\right)-\ln \frac{P\left(v_{2}^{\text {pure }}-b_{22}\right)}{R T}-\frac{a_{22}}{2 \sqrt{2} b_{22} R T}\left[\frac{2 a_{12}}{a_{22}}-\frac{b_{1}}{b_{22}}\right] \ln \frac{v_{2}^{\text {pure }}+(1+\sqrt{2}) b_{22}}{v_{2}^{\text {pure }}+(1-\sqrt{2}) b_{22}}$ 
The only fitting parameter is the binary interaction parameter that arises in the expression

$$
a_{12}=\left(a_{11} a_{22}\right)^{1 / 2}\left(1-k_{12}\right)
$$

The binary interaction parameter has been fit in order to minimize the sum of the squares of the error. The performance index is given by.

$$
I=\sqrt{\sum_{i}\left|y_{1}^{\bmod }-y_{1}^{\exp }\right|^{2}}
$$

The saturation pressure. in bars. for anthracene (i.e. component 1 in the above equations) is determined by,

$$
P_{t}^{\text {vax }}=0.083144 T \cdot 10^{\left(+.065-\frac{-1839}{r}\right)}
$$

where $T$ is in Kelvin (Rößling and Franck. 1983).

The estimated models are presented as a series of graphs. 

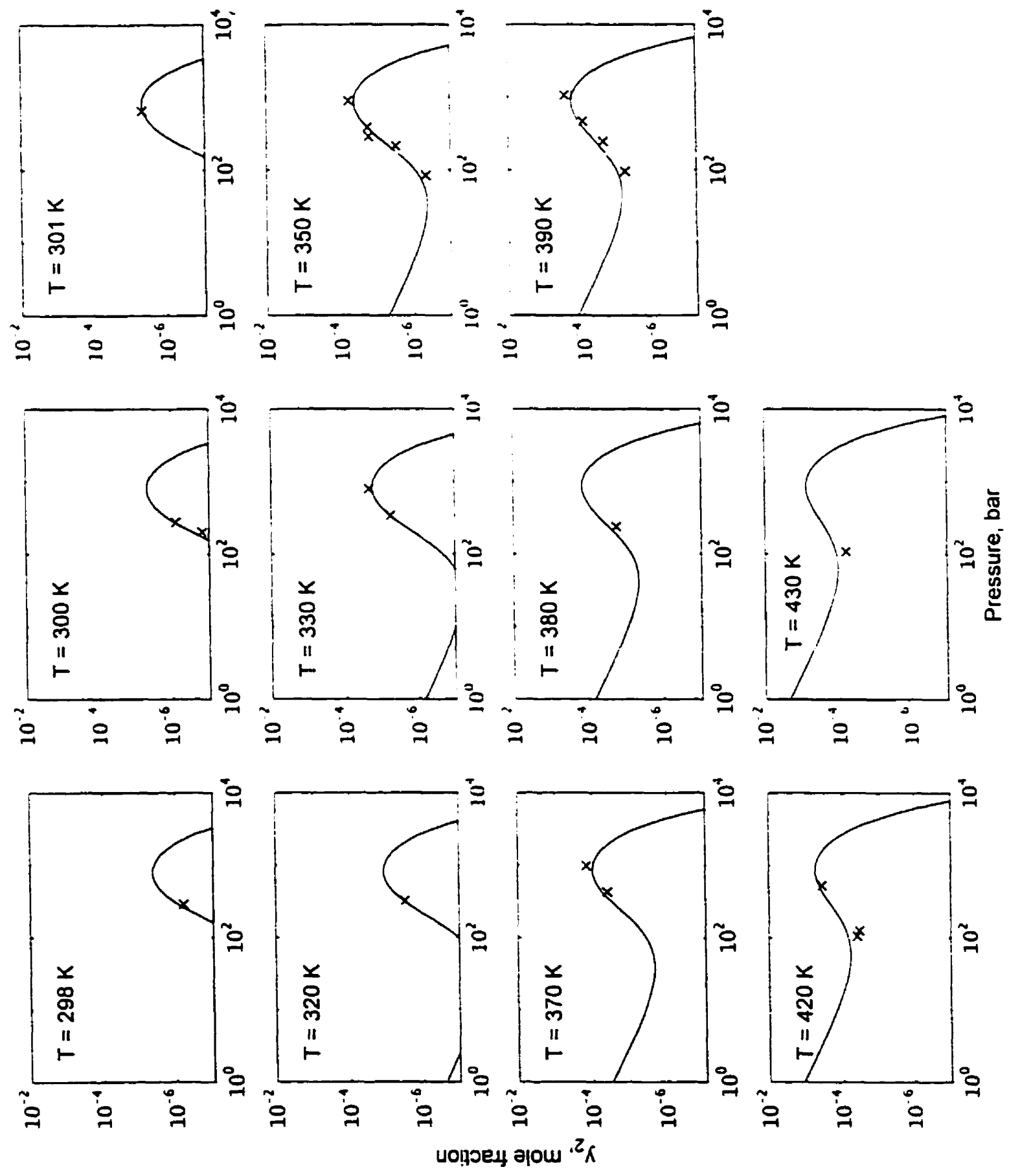

Figure C1 - Solid-fluid solubility models for anthracene with methane. 


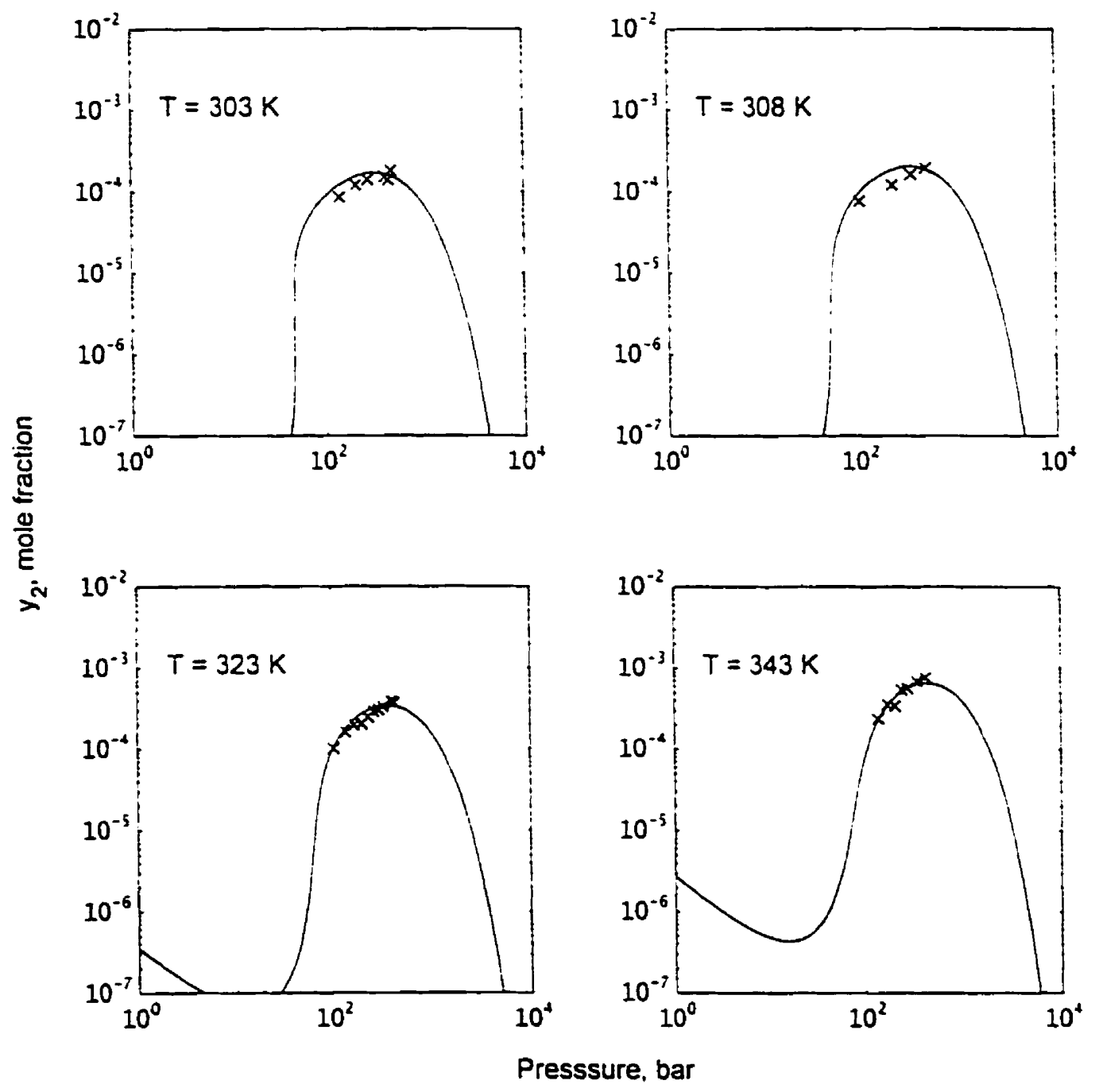

Figure C2 - Solid-fluid solubility models for anthracene with ethane. 

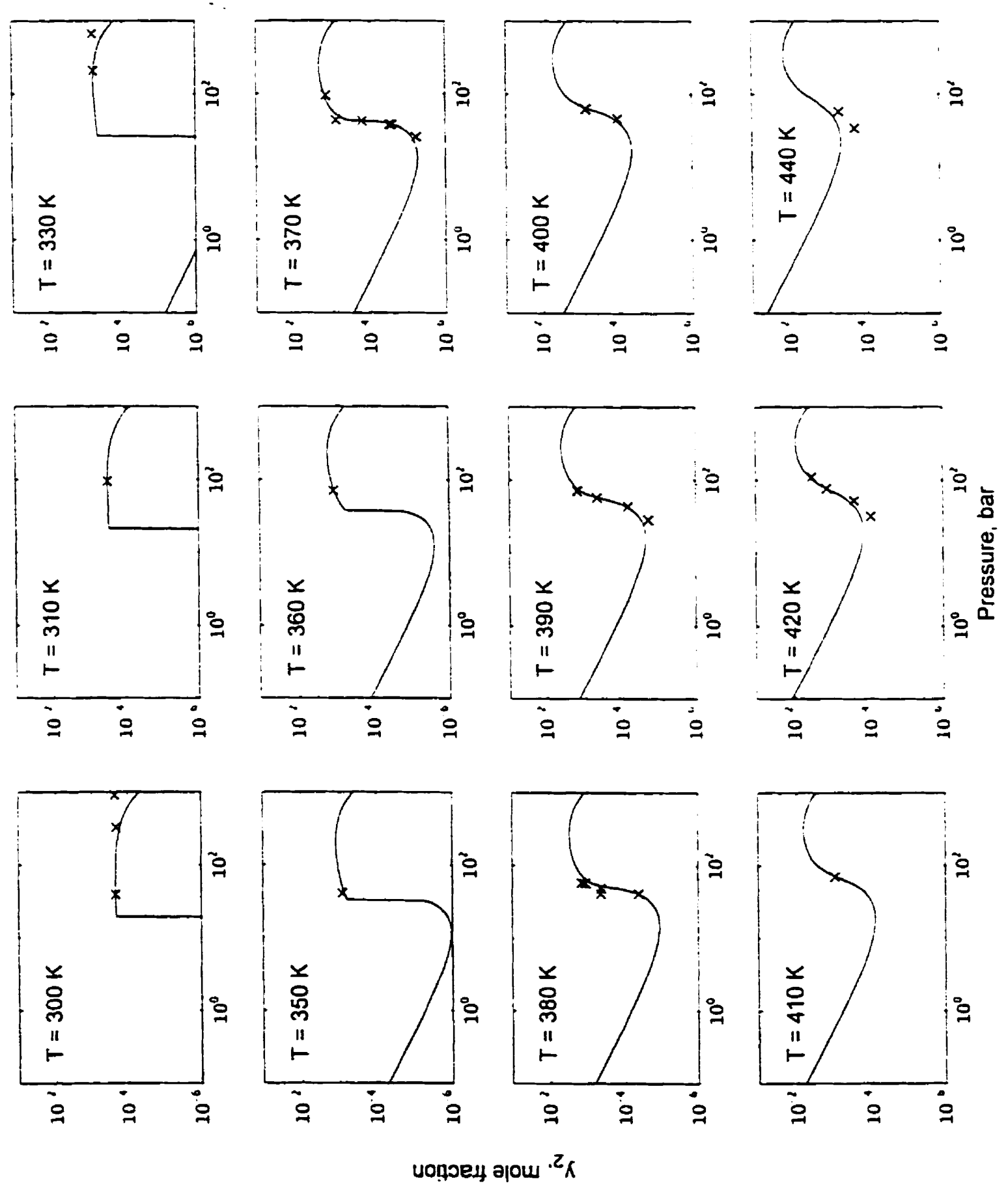

Figure C3 - Solid-fluid solubility models for anthracene with propane. 

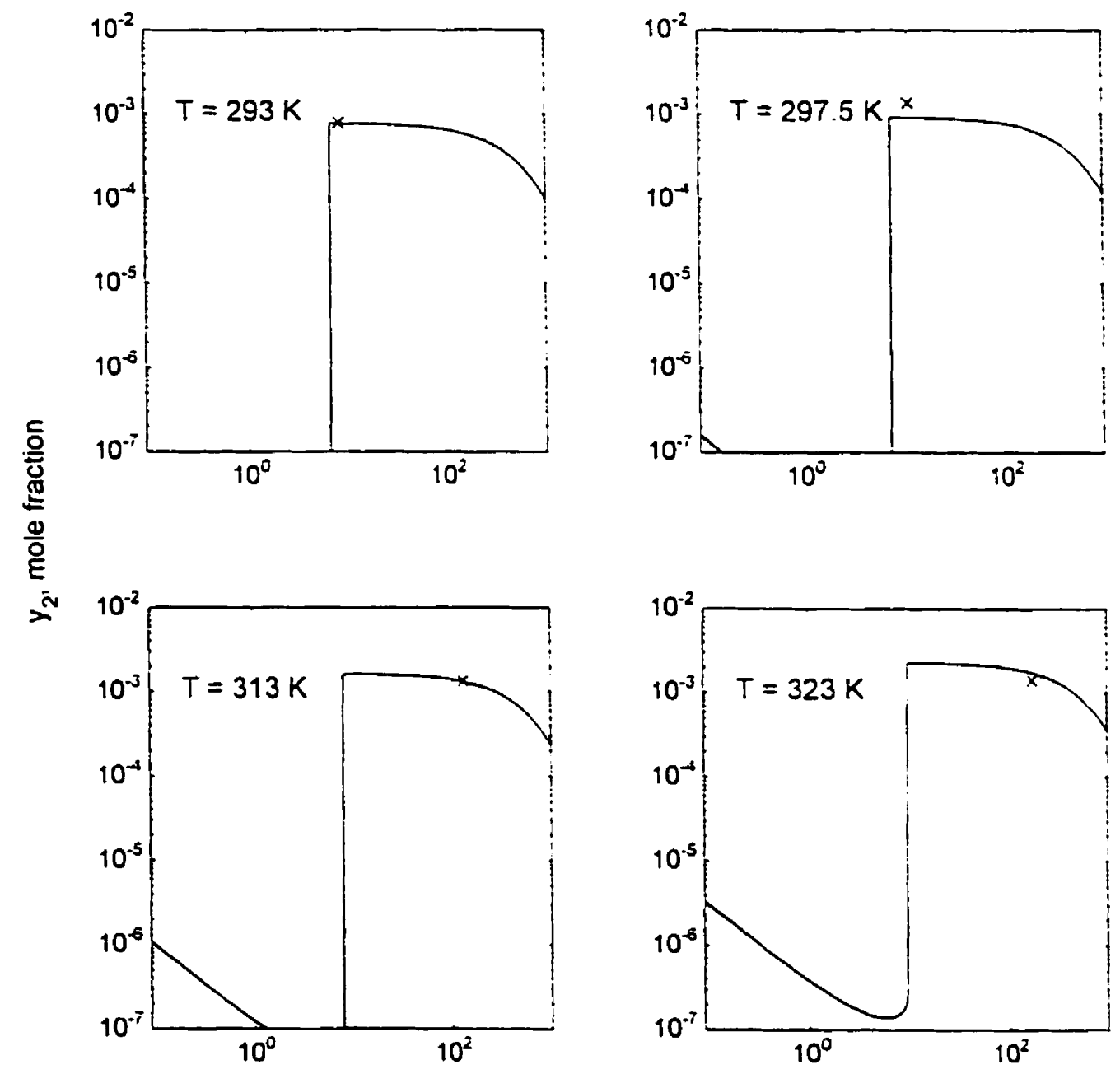

Pressure, bar

Figure C4 - Solid-fluid solubility models for anthracene with n-pentane. 